\title{
RECENT GEODYNAMICS OF FAULT ZONES: FAULTING IN REAL TIME SCALE
}

\author{
Yu. O. Kuzmin \\ The Schmidt Institute of Physics of the Earth RAS, Moscow, Russia
}

\begin{abstract}
Recent deformation processes taking place in real time are analyzed on the basis of data on fault zones which were collected by long-term detailed geodetic survey studies with application of field methods and satellite monitoring.

A new category of recent crustal movements is described and termed as parametrically induced tectonic strain in fault zones. It is shown that in the fault zones located in seismically active and aseismic regions, super intensive displacements of the crust (5 to $7 \mathrm{~cm}$ per year, i.e. (5 to 7$) \cdot 10^{-5}$ per year) occur due to very small external impacts of natural or technogenic / industrial origin.

The spatial discreteness of anomalous deformation processes is established along the strike of the regional Rechitsky fault in the Pripyat basin. It is concluded that recent anomalous activity of the fault zones needs to be taken into account in defining regional regularities of geodynamic processes on the basis of real-time measurements.

The paper presents results of analyses of data collected by long-term (20 to 50 years) geodetic surveys in highly seismically active regions of Kopetdag, Kamchatka and California. It is evidenced by instrumental geodetic measurements of recent vertical and horizontal displacements in fault zones that deformations are 'paradoxically' deviating from the inherited movements of the past geological periods.

In terms of the recent geodynamics, the 'paradoxes' of high and low strain velocities are related to a reliable empirical fact of the presence of extremely high local velocities of deformations in the fault zones (about $10^{-5}$ per year and above), which take place at the background of slow regional deformations which velocities are lower by the order of 2 to 3 . Very low average annual velocities of horizontal deformation are recorded in the seismic regions of Kopetdag and Kamchatka and in the San Andreas fault zone; they amount to only 3 to 5 amplitudes of the earth tidal deformations per year.

A 'fault-block' dilemma is stated for the recent geodynamics of faults in view of interpretations of monitoring results. The matter is that either a block is an active element generating anomalous recent deformation and a fault is a 'passive' element, or a fault zone itself is a source of anomalous displacements and blocks are passive elements, i.e. host medium. 'Paradoxes' of high and low strain velocities are explainable under the concept that the anomalous recent geodynamics is caused by parametric excitation of deformation processes in fault zones in conditions of a quasi-static regime of loading.

Based on empirical data, it is revealed that recent deformation processes migrate in fault zones both in space and time. Two types of waves, 'inter-fault' and 'intra-fault', are described. A phenomenological model of auto-wave deformation processes is proposed; the model is consistent with monitoring data. A definition of 'pseudo-wave' is introduced. Arrangements to establish a system for monitoring deformation auto-waves are described.

When applied to geological deformation monitoring, new measurement technologies are associated with result identification problems, including 'ratios of uncertainty' such as 'anomaly's dimensions - density of monitoring stations' and 'anomaly's duration - details of measurements in time'. It is shown that the RSA interferometry method does not provide for an unambiguous determination of ground surface displacement vectors.
\end{abstract}

Key words: faulting, deformation, seismically active zones, geodynamic processes, quazi-meridional faults, Pripyat basin, Kopetdag, Kamchatka, California, strain velocities, anomalous deformation, displacement, pseudo-waves, deformation auto-waves, geostrain monitoring.

Recommended by K.Zh. Seminsky

Citation: Kuzmin Yu.O., 2014. Recent geodynamics of fault zones: faulting in real time scale. Geodynamics \& Tectonophysics 5 (2), 401-443. doi:10.5800/GT-2014-5-2-0135. 


\title{
СОВРЕМЕННАЯ ГЕОДИНАМИКА РАЗЛОМНЫХ ЗОН: РАЗЛОМООБРАЗОВАНИЕ В РЕАЛЬНОМ МАСШТАБЕ ВРЕМЕНИ
}

\author{
Ю.О. Кузьмин
}

\author{
Институт физики Земли им. О.Ю. Шмидта РАН, Москва, Россия
}

Аннотация: Приведен анализ современных, протекающих в реальном масштабе времени, деформационных процессов в зонах разломов, выявленных по данным многолетних геодезических (наземных и спутниковых) наблюдений, выполненных с повышенной пространственно-временной детальностью.

Продемонстрирован новый класс современных движений земной поверхности - параметрически индуцированные тектонические деформации разломных зон. Показано, что возникновение суперинтенсивных (до 5-7 см в год, (5-7)· $10^{-5}$ в год) движений земной поверхности в разломных зонах сейсмоактивных и асейсмичных регионов происходит под влиянием крайне малых внешних воздействий природного или техногенного генезиса.

Установлена пространственная дискретность аномальных деформационных процессов вдоль простирания регионального Речицкого разлома (Припятская впадина). Сделан вывод о необходимости учета современной аномальной активности разломных зон при установлении региональных закономерностей геодинамических процессов на основе измерений, проводимых в реальном масштабе времени.

Представлены результаты анализа длительных (20-50 лет) геодезических наблюдений, проведенных в регионах с повышенной сейсмотектонической активностью (Копетдаг, Камчатка, Калифорния). Установлено, что результаты инструментальных геодезических наблюдений за современными вертикальными и горизонтальными смещениями в зонах разломов указывают на «парадоксальное» отклонение деформаций от унаследованных движений прошлых геологических эпох.

«Парадоксы» больших и малых скоростей деформаций в современной геодинамике сводятся к надежному эмпирическому факту - наличию исключительно высоких локальных скоростей деформаций в зонах разломов, порядка $10^{-5}$ в год и более, которые протекают в обстановке низких региональных деформаций, имеющих среднегодовые скорости на 2-3 порядка меньше. В Копетдагском и Камчатском сейсмоактивных регионах, а также в зоне разлома Сан Андреас (Северная Калифорния) выявлены очень низкие среднегодовые скорости относительных горизонтальных деформаций, которые составляют всего 3-5 амплитуд земноприливных деформаций в год.

Сформулирована «разломно-блоковая» дилемма, которая возникает при интерпретации результатов наблюдений в современной геодинамике разломов. Либо активным элементом, формирующим современные аномальные деформации, является блок, а разлом выступает в качестве «пассивного» элемента, либо зона разлома сама является источником аномальных движений, а блоки являются пассивными элементами - вмещающей средой. Показано, что «парадоксы» больших и малых скоростей деформаций снимаются, если считать, что современная аномальная геодинамика формируется за счет параметрического возбуждения деформационных процессов в зонах разломов, в обстановке квазистатического режима нагружения.

На основе эмпирических данных установлено наличие пространственно-временной миграции современных деформационных процессов в разломных зонах и существование двух типов волн: «межразломной» и «внутриразломной». Разработана феноменологическая модель формирования автоволновых деформационных процессов, и показано ее согласие с наблюдениями. Введено понятие «псевдоволны», и предложен подход к организации наблюдений за деформационными автоволнами.

Отмечены проблемы идентификации результатов геодеформационных наблюдений, обусловленные новыми технологиями измерений, которые приводят к «соотношениям неопределенности» типа «пространственный размер аномалии - густота наблюдательных пунктов» и «длительность аномалий - временная детальность измерений». Показана неоднозначность в определении векторов смещений земной поверхности методом РСА интерферометрии.

Ключевые слова: разломообразование, деформационные процессы, сейсмоактивные зоны, геодинамические процессы, квазимеридиональные разломы, Припятская впадина, Копетдаг, Камчатка, Калифорния, скорости деформаций, аномальные деформации, псевдоволны, деформационные автоволны, геодеформационные наблюдения.

«В настоящее время трудно решать многие геологические проблемы без осмысления физической природы процессов и углубленного численного анализа фактического материала» С.И. Шерман [Sherman, 1977]

\section{1. ВВЕДЕНИЕ}

Со слов, вынесенных в эпиграф, начинается монография выдающегося исследователя в области разлом- ной тектоники С.И. Шермана. Очевидно, что сказанное остается крайне актуальным и сегодня. Действительно, лавинообразное увеличение эмпирической информации, обусловленное широкомасштабным приме- 
нением новых методов исследований, технологий и измерительных средств, требует более тщательного и адекватного количественного анализа с позиций фундаментальных наук, и прежде всего физики. Собственно говоря, физика тектонических процессов и есть тектонофизика.

Методология количественного изучения процессов разломообразования определяется с этих позиций как физика разрушения, учитывающая специфику протекания тектонических процессов в качестве начальных и граничных условий. Эта специфика состоит в необходимости учета трансмаштабности пространственновременного спектра динамических процессов при формировании разломных структур.

В отмеченной монографии убедительно показано, что при деликатном использовании физико-математического формализма можно существенно продвинуться в понимании закономерностей разломообразования.

Автор этих строк приступил к изучению современной геодинамики разломов именно в год выхода этой книги. Будучи по образованию рафинированным физиком и не имея базовых знаний в области геологии и геофизики, он испытывал острую необходимость в эвристических идеях, облегчающих вхождение в проблему. Для адаптации необходимы были побудительные и ободряющие мотивы. Необходимо было войти в проблему диалектически, рационально используя имевшийся багаж знаний применительно к новому объекту исследований.

Именно таким мотивом стала книга С.И. Шермана. В этой книге стрела геологического времени была унаследованно направлена в будущее. Современные движения земной поверхности, которые измеряются геодезическими методами, автор в те годы считал «фотографическим снимком», отражающим некий временной момент в истории развития тектонических процессов.

Шли годы. Можно только восхищаться, как классический геолог не только воспринял идеи современной нелинейной физики, но и, как всегда, эффективно и изящно применил эти воззрения к своим исследованиям. Как следует из письма С.И. Шермана автору этих строк, датированного 2005 годом, «...я понял, что активизация разломов происходит чаще, чем тектонические режимы активизации».

В результате С.И. Шерману удалось найти свой путь и выявить новые закономерности при анализе пространственно-временной миграции сейсмической активности в разломных зонах. Произошла эволюция взглядов. Но не путем отказа от прежних научных идей, а путем углубленного расширения ранее развитых представлений.

В этом состоит «метод Шермана». Метод, благодаря которому эволюция взглядов приводит к революционным и подчас парадоксальным выводам.

Далее представлены результаты изучения современных геодинамических процессов в зонах разломов, которые отражают процесс разломообразования в реальном масштабе времени.

Помимо сейсмических процессов, отражающих наиболее «быструю» компоненту тектонических движений, в последние четверть века были получены принципиально новые результаты в области исследования «медленных» движений на основе многолетних геодезических и геофизических наблюдений. Эти исследования привели к становлению нового направления в геодинамике - современной геодинамике разлоMOB.

Ниже рассматриваются наиболее принципиальные результаты, полученные в рамках этого направления. Здесь рассмотрение проведено комплексно: от анализа базовой терминологии и эволюции научных представлений, через количественный анализ эмпирических данных и физическую интерпретацию, к оценке информативности и адекватности современных методов измерений.

\section{2. ЭВОЛЮЦИЯ ПРЕДСТАВЛЕНИЙ О ПРЕДМЕТЕ И МЕТОДАХ СОВРЕМЕННОЙ ГЕОДИНАМИКИ}

На протяжении полувековой истории развития исследований по проблеме «Современные движения земной коры» сформировались два подхода к определению современной геодинамики как научной дисциплины: кинематический и силовой [Kuzmin, 1999]. Сторонники первого подхода (астрономы и геодезисты) полагали, что центральным предметом исследований в современной геодинамике является изучение основных кинематических характеристик (смещений, скоростей, векторов направленности и т.д.) движений земной поверхности в различных пространственно-временных масштабах протекания процессов для последующего анализа их природы. Это во многом понятно, поскольку начало широкомасштабному развитию этих исследований было положено в 1963 г. на XIII Генеральной ассамблее Международного геодезического и геофизического союза в рамках проекта «Современные движения земной коры». Проект состоял из трех разделов: «Мировая карта движений земной коры», «Мировая сеть полигонов (стационаров) для наблюдений за современными движениями земной коры», «Изучение общих деформаций земного шара». При этом координация исследований была в основном сосредоточена в рамках деятельности Международной ассоциации геодезии (МАГ). Так, например, работы по второму разделу этого проекта возглавлял выдающийся отечественный ученый Ю.Д. Буланже, который являлся вице-президентом МАГ.

Исследования, проводимые в рамках первого и третьего разделов проблемы, потребовали активного привлечения геологов, геоморфологов и геофизиков, что повлекло за собой трансформацию в определении базовых понятий, поскольку был существенно расши- 
рен арсенал применяемых методов изучения современных движений. Естественно, что геологи и геофизики, основываясь на втором (силовом) подходе, считали, что основной проблемой современной геодинамики является установление механизмов формирования движений в различных геосферах с последующей оценкой кинематических характеристик движений, и предполагали полную унаследованность современных движений от процессов прошлых геологических эпох. Понятно, что результаты измерений в реальном масштабе времени в этом случае не являются основным предметом исследований, а служат элементом доказательности принятой схемы приложения тектонических сил (напряжений).

Дальнейшее развитие исследований и, особенно, работы по тектонике плит (геодинамике) привели к тому, что термин «современные движения земной коры» постепенно был трансформирован в термин «современная геодинамика».

Наиболее гармоничное, с учетом двух подходов, определение основной задачи геодинамики дано в работе [Turcotte, Schubert, 1979], где утверждается, что геодинамика изучает движения и деформации, происходящие в земной коре, мантии и ядре, и причины таких движений и деформаций. Однако здесь имеет место двойственность определения - обособление движений и деформаций. Оно возникает из-за того, что исследователям зачастую приходится изучать раздельно (особенно на модельном уровне) движения литосферных плит и/или блоков земной коры как жестких тел и деформации, которым подвержены эти тела в результате взаимодействия.

Вместе с тем, представляется возможным снять обособления и противоречия при формулировании этих базовых понятий геодинамики. Как известно, в рамках механики деформируемого твердого тела возникновение деформаций (движений) обычно трактуется как результат действия на тело приложенных напряжений (сил). Однако, если обратиться к опыту, то справедливым оказывается и обратное утверждение.

Известно, что при деформации твердых тел возникают силы (напряжения), действующие как внутри тел со стороны одних частей на другие, так и между соприкасающимися телами. В случае объемных деформаций это справедливо также для жидкостей и газов в полном соответствии с основной аксиомой реологии. Это противоречие исчезает, если вспомнить, что деформация - это изменение формы и размеров тела, изменение взаимного расположения отдельных частей тела друг относительно друга, т.е. результат различных перемещений (движений) отдельных частей тела. Следовательно, объяснить происхождение деформаций значит объяснить происхождение тех движений, которые привели к изменению взаимного расположения отдельных частей тела. Таким образом, деформации, в самом общем виде, есть результат определенного движения, и поэтому непосредственной причи- ной деформаций являются движения, а не силы.

Для подтверждения этого тезиса достаточно, например, рассмотреть механизм формирования термических, пьезоэлектрических и магнитострикционных деформаций, где изменение температуры, электрического и магнитного полей возбуждает движения элементов, составляющих тело, что приводит к его деформации. Безусловно, силы играют существенную роль в возникновении движений, а значит, и в появлении деформаций. Однако только в случаях, когда эти силы таковы, что разные части тела будут двигаться по-разному, а взаимное расположение различных частей тела изменится, возникнут деформации. И напряжения (силы), и деформации есть отражение различных форм (силовой и кинематической) единого процесса - движения, и поэтому никакого обособления или противопоставления этих понятий при правильной трактовке не возникает.

На практике, оперируя терминами «напряжение» и «деформация», исследователи часто упускают из вида, что наблюдаемыми (измеряемыми) величинами в современной геодинамике являются именно движения (горизонтальные, вертикальные или сдвиговые перемещения), а напряжения и деформации (как отношение перемещений к базе измерений) определяются по результатам вычислений.

В современной геодинамике движения являются и объектом наблюдений, и объектом интерпретации одновременно. Кроме того, из основ классической механики (теорема Коши-Гельмгольца) следует, что любое движение можно представить как параллельный перенос и вращение участков среды как абсолютно твердых (жестких) тел и их деформаций (объемных и сдвиговых). Исходя из этого, геодинамику следует определить как науку, изучающую движения, происходящие в земной коре, мантии и ядре, и причины этих движений [Kuzmin, 1999].

Для формулировки определения «современная геодинамика» необходимо иметь в виду ряд принципиальных обстоятельств. Как известно из физики, динамику можно определить в противопоставлении либо кинематике, либо статике. В первом случае динамика ответственна за изучение причин, вызывающих движения, во втором - она понимается в более обобщенном смысле: и как описывающая сами движения и как изучающая причины, их вызывающие. В этом, обобщенном, смысле традиционный термин «современные движения земной коры» адекватно заменяется термином «современная геодинамика».

Особо следует остановиться на трактовке термина «современный». Его, как правило, определяют двояким образом: либо подчеркивая инструментальный характер изучения (фиксации) движений, либо отмечая длительность протекания процессов в сравнении с геологическими масштабами времени. В данном случае вновь возникает двойственность толкований основного предмета исследований в современной геодинамике. Так, в случае полной унаследованности дви- 
жений от прошлых геологических эпох можно инструментально зарегистрировать движения, которые по длительности протекания формирующих их процессов не относятся к разряду современных.

В то же время существует определенная относительность средств наблюдений к свойствам исследуемых объектов. Если измерять с помощью повторных нивелирований такой типичный для современной геодинамики процесс, как земноприливные деформации, то существует ограничение по чувствительности и временной детальности наблюдений. В случае, когда предпринимается попытка измерения движений плит или блоков земной коры наклономерами и деформографами, существует ограничение по пространственному масштабу наблюдений.

Основным методом интерпретации геодинамических наблюдений является решение обратных задач установление глубинного источника аномальных движений по данным измерений на земной поверхности. Однако и в данном случае вновь возникает относительность средств наблюдений к свойствам объекта.

Так, например, если имеет место фиксация унаследованного движения, например, вызванного конвекцией в мантии, методами современной геодинамики, то вследствие ограниченности (кратковременности) периода наблюдений возникает принципиальная невозможность решения обратных задач (как кинематики, так и динамики). Для однозначной интерпретации необходимо, чтобы «начало» и «завершение» наблюдаемого процесса целиком укладывались в интервал между повторными циклами наблюдений.

Ситуация усугубляется еще и тем, что имеет место острый дефицит достоверных сведений о базовых характеристиках среды в условиях их естественного залегания в земных недрах. Хорошо известно, что даже анализ керновой информации страдает определенной степенью необъективности.

В связи с этим, одним из главных условий реальной трактовки наблюдаемых процессов является соизмеримость длительности протекания последних с длительностью самого измерения. В этом случае совершенно необходимо четко следовать принципу наблюдаемости Нильса Бора: существующим считается лишь то, что наблюдаемо или может быть сделано таковым, который был разработан именно в тех областях естествознания, в которых базовые свойства объекта не всегда доступны прямому наблюдению.

Таким образом, можно определить, что современная геодинамика - это часть общей геодинамики, изучающая движения земных недр и причины, их вызывающие, когда время действий последних соизмеримо с длительностью самого процесса наблюдений [Kuzmin, 1999]. При этом под длительностью наблюдений понимается либо интервал между повторными (геодезическими, геофизическими) измерениями, либо период непрерывной регистрации параметров геофизическими (аппаратурными) методами.
С позиций сформулированного определения объектом изучения в современной геодинамике могут быть наиболее мобильные и активные структуры литосферы и, в первую очередь, зоны тектонических нарушений (разломов). Учитывая некоторую степень дискуссионности в определении понятия «разлом», необходимо сформулировать авторскую позицию в этом вопросе.

Как правило, термин «разлом» или «разломная зона» используется как некая граница раздела между блоками, которые отличаются различной мобильностью или иными характеристиками. По мнению автора, разломы следует рассматривать как специфические геологические тела, некий объем земной коры, имеющий аномальное строение и повышенную трещиноватость, возникший в результате линейной деструкции среды. Эти представления в существенной мере корреспондируются с представлениями С.И. Шермана и возглавляемой им тектонофизической школы [Sherman, 1977, 2012; Sherman et al., 1983; Seminsky, 2003]. В данной работе такие понятия, как «разлом», «разломная зона», «зона разрывных нарушений», «зона повышенной трещиноватости», рассматриваются в качестве синонимов. Главным здесь является то, что зона разлома есть область, вмещающая породы с аномальными физико-механическими, геолого-геофизическими, флюидо-геохимическими и другими характеристиками.

В этом случае зоны разломов естественным образом являются концентраторами современного аномального напряженно-деформированного состояния, а следовательно, и базовым объектом изучения современных геодинамических процессов. Кроме того, при исследованиях в рамках геодинамического мониторинга особо ответственных и экологически опасных объектов зачастую употребляется термин «геодеформационные» процессы, которые отличаются от собственно деформационных процессов самих материалов конструкций изучаемых объектов. Автор считает, что при правильном и профессиональном использовании понятий «деформационные», «геодеформационные» и «сейсмические процессы» по отношению к соответствующим объектам исследования, путаницы в употреблении этих понятий не происходит.

Необходимо также определиться в использовании терминов «недра» и «верхние слои земной коры», когда речь идет о характеристике тех объемов среды, в которых протекают современные геодинамические процессы.

Согласно определению, данному в законе РФ «О недрах», недра - это верхняя часть земной коры, расположенная ниже почвенного слоя, при его отсутствии - ниже земной поверхности и дна водоемов и водотоков, простирающаяся до глубин, доступных для геологического изучения и освоения. Авторская позиция заключается в том, что недра - это тот слой земной коры, в котором имеют место современные аномальные геодинамические процессы, обусловленные совокупностью природных и техногенных воздействий. 
Таким образом, становится очевидным, что современная аномальная геодинамика недр - это современная геодинамика разломных зон. Принципиально важно то, что в отличие от геодинамики, изучающей только природные процессы, в современной геодинамике исследуются процессы как природного, так и техногенного происхождения. Основные явления, изучаемые в современной геодинамике, это деформационные и сейсмические процессы, а также взаимосвязанные с ними вариации геофизических и флюидо-геохимических полей.

Очень часто сейсмичность относят к современной геодинамике. Это так, поскольку сейсмичность - это «быстрая» составляющая геодинамического процесса. Современные движения (деформации), естественно, относятся к «медленной» части спектра геодинамических явлений. В последние годы среди специалистов утвердилась тенденция медленные движения именовать современной геодинамикой (или деформационными процессами), а все связанное с землетрясениями определять как сейсмические процессы.

\section{3. ПРОСТРАНСТВЕННО-ВРЕМЕННАЯ СТРУКТУРА СОВРЕМЕННЫХ ГЕОДИНАМИЧЕСКИХ ПРОЦЕССОВ В ЗОНАХ РАЗЛОМОВ}

Согласно традиционной точке зрения, современные движения земной поверхности платформенных, асейсмичных, областей характеризуются относительно слабыми скоростями - до 5-10 мм/год, в отличие от орогенных и сейсмоактивных регионов, где скорости могут достигать величин, значительно больших, чем 50 мм/год. Этот вывод следует из анализа карт современных вертикальных движений земной коры, построенных по данным повторных нивелирований больших территорий с интервалами между наблюдениями в десятки лет [Sidorov, Kuzmin, 1989].

Как известно, одной из основных особенностей пространственного распределения современных вертикальных движений земной поверхности больших территорий (порядка сотен километров и более) являются протяженные аномальные зоны, представленные градиентным характером аномальных изменений, которые контролируются зонами глубинных разломов. Ширина этих зон достигает 10-15 км и более. При этом величины горизонтальных градиентов движений составляют первые мм/км в год. На графиках, отражающих линейную (профильную) составляющую движений, эти градиентные участки имеют форму ступенеобразных изменений в полном соответствии с общепринятыми представлениями о медленных, дифференцированных вертикальных перемещениях смежных объемов среды (блоков земной коры) вдоль зон разломов под воздействием изменений регионального поля напряжений.

На рис. 1 представлена кривая современных вер- тикальных движений земной поверхности, построенная по результатам сравнения повторных нивелирований, выполненных с интервалом в 35 лет. Профиль расположен по простиранию Рионо-Куринского межгорного прогиба. Особенности кривой современных вертикальных движений земной поверхности являются типичными для всех крупных территорий, включая сейсмоактивные и слабосейсмические. Так, среднегодовые скорости движений достигают 3-4 мм/год, ширина участков с однородным характером движений (блоковый характер) достигает 80-100 км, ширина пограничных зон с высокими градиентами движений 20-25 км.

Таким образом, главной характерной особенностью движений является совпадение зон с повышенными градиентами смещений, которые сосредоточены на границах между региональными поднятиями и опусканиями, с зонами глубинных разломов. Поднятия блоков фундамента устойчиво коррелировали с поднятиями земной поверхности и, наоборот, в полном соответствии с унаследованным характером развития процессов. Это есть основная закономерность современных вертикальных движений земной коры, полученных в региональном пространственно-временном масштабе описания процесса [Sidorov, Kuzmin, 1989].

Подобная система взглядов господствовала в исследованиях по современной геодинамике до того момента, когда в середине шестидесятых годов XX века под эгидой Междуведомственного геофизического комитета при Президиуме АН СССР была развернута обширная программа изучения современных движений земной коры на геодинамических полигонах различного целевого назначения. Результаты повторных наблюдений на этих полигонах с интервалами времени между повторениями в месяцы и годы выявили наличие интенсивных (10-20 мм/год и более) локальных движений, которые имели пульсационный и короткопериодический характер. Это не явилось большой неожиданностью для специалистов, поскольку первые геодинамические полигоны закладывались в орогенных, сейсмоактивных регионах.

Знаковым событием, изменившим привычную парадигму унаследованного характера развития современных геодинамических процессов, явилась организация Министерством нефтяной промышленности СССР в начале семидесятых годов прошлого века долгосрочной программы изучения современных движений земной коры в нефтегазоносных осадочных бассейнах.

В качестве таких объектов были использованы территории крупных нефтегазоносных бассейнов древней докембрийской Русской платформы (Припятский прогиб, западное и северо-западное обрамления Прикаспийской впадины, Башкирский свод и Соликамская впадина), Западно-Сибирской плиты (Вартовский свод), предгорных и межгорных прогибов складчатых областей (Терско-Каспийский, Предгиссарский, Рио- 


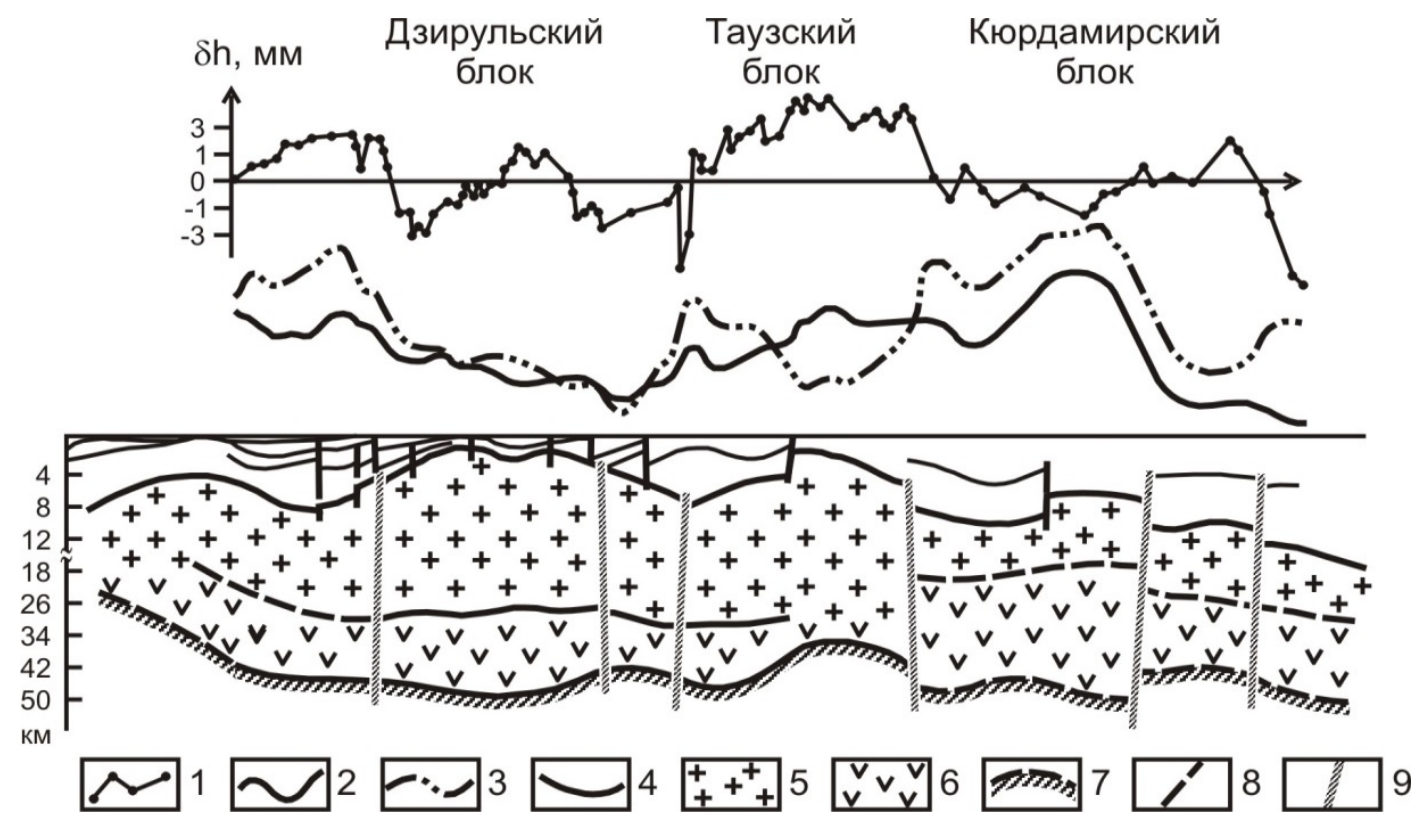

Рис. 1. Современные вертикальные движения земной поверхности по простиранию Рионо-Куринского прогиба.

1 - кривая скоростей современных вертикальных движений земной поверхности (мм/год); 2 - кривая аномалий силы тяжести в редукции Буге; 3 - кривая остаточных аномалий силы тяжести $\left(\Delta g_{O C T}=\Delta g_{H}-\Delta g_{3 . K}\right) ; 4$ - граница между комплексами осадочного чехла; 5 - «гранитный» слой; 6 - «базальтовый» слой; 7 - поверхность Мохоровичича; 8 - разломы в осадочной толще; 9 - разломы в земной коре.

Fig. 1. Recent vertical displacements of the ground surface along the strike of the Riono-Kura trough.

1 - curve of recent vertical velocities of ground surface displacements, mm per year; 2 - curve of gravity anomalies in the Bouguer reduction; 3 - curve of residual gravity anomalies $\left(\Delta g_{O C T}=\Delta g_{H}-\Delta g_{3 . K}\right.$.); 4 - boundary between suites of the sedimentary cover; 5 - 'granite' bed; 6 - 'basalt' bed; 7 - Moho surface; 8 - faults in the sediment bed; 9 - crustal faults.

но-Куринский) [Sidorov, Kuzmin, 1989]. Крайне важно то, что параметры измерительных систем (густота пунктов, частота опроса и точность наблюдений) на геодинамических полигонах, расположенных в платформенных, асейсмичных районах, были идентичными системам измерений, расположенным в сейсмоактивных областях.

На рис. 2 представлены результаты повторных нивелирных и гравиметрических наблюдений вдоль регионального профиля ГСЗ МОГТ VIII-VIII, проходящего через Припятский прогиб. Этот профиль имеет протяженность 140 км, нивелирные и гравиметрические пункты наблюдений заложены через 250-300 м. В нижней части рисунка представлены геолого-геофизические разрезы осадочного чехла и земной коры в целом. Там же показано распределение глубинных температур вдоль этого профиля.

Как следует из рис. 2, в этом регионе также существуют аномальные деформационные процессы, которые пространственно приурочены к разломным зонам. Аномальные изменения представлены двумя характерными морфологическими типами: протяженными изгибами вверх и локальными просадками земной поверхности, которые также аналогичны предыдущим результатам.

В результате комплексного сопоставительного ана- лиза данных, полученных идентичными системами измерений (плотность пунктов наблюдений, точность и частота опроса), расположенными в сейсмоактивных и асейсмичных регионах, были сформулированы следующие эмпирические обобщения [Kuzmin, 1989, 1996, 1999; Sidorov, Kuzmin, 1989].

- Выявлены интенсивные локальные аномалии вертикальных и горизонтальных движений земной поверхности, которые приурочены к зонам разломов различного типа и порядка. Эти аномальные движения высокоамплитудны (50-70 мм/год), короткопериодичны (0.1-1.0 года), пространственно локализованы (0.1-1.0 км), обладают пульсационной и знакопеременной направленностью. Среднегодовые скорости для них чрезвычайно высоки и составляют величины порядка 2-7·10 /год. Поэтому их следует определить как суперинтенсивные деформации (СД) земной поверхности в зонах разломов [Kuzmin, 1996, 1999].

- Существуют устойчивые типы локальных аномалий в вертикальных движениях земной поверхности в зонах разломов (рис. 3). При этом горизонтальные размеры $(L) \gamma$-аномалий составляют 0.1-2.0 км, $S$-аномалий - 5-10 км, а $\beta-10-30$ км. Там же приведены соотношения между амплитудой $(\Delta h)$ и протяженностью $(L)$ для каждого типа аномалий, связанные через масштабный коэффициент $m=10^{-6}$ (если амплитуда выра- 


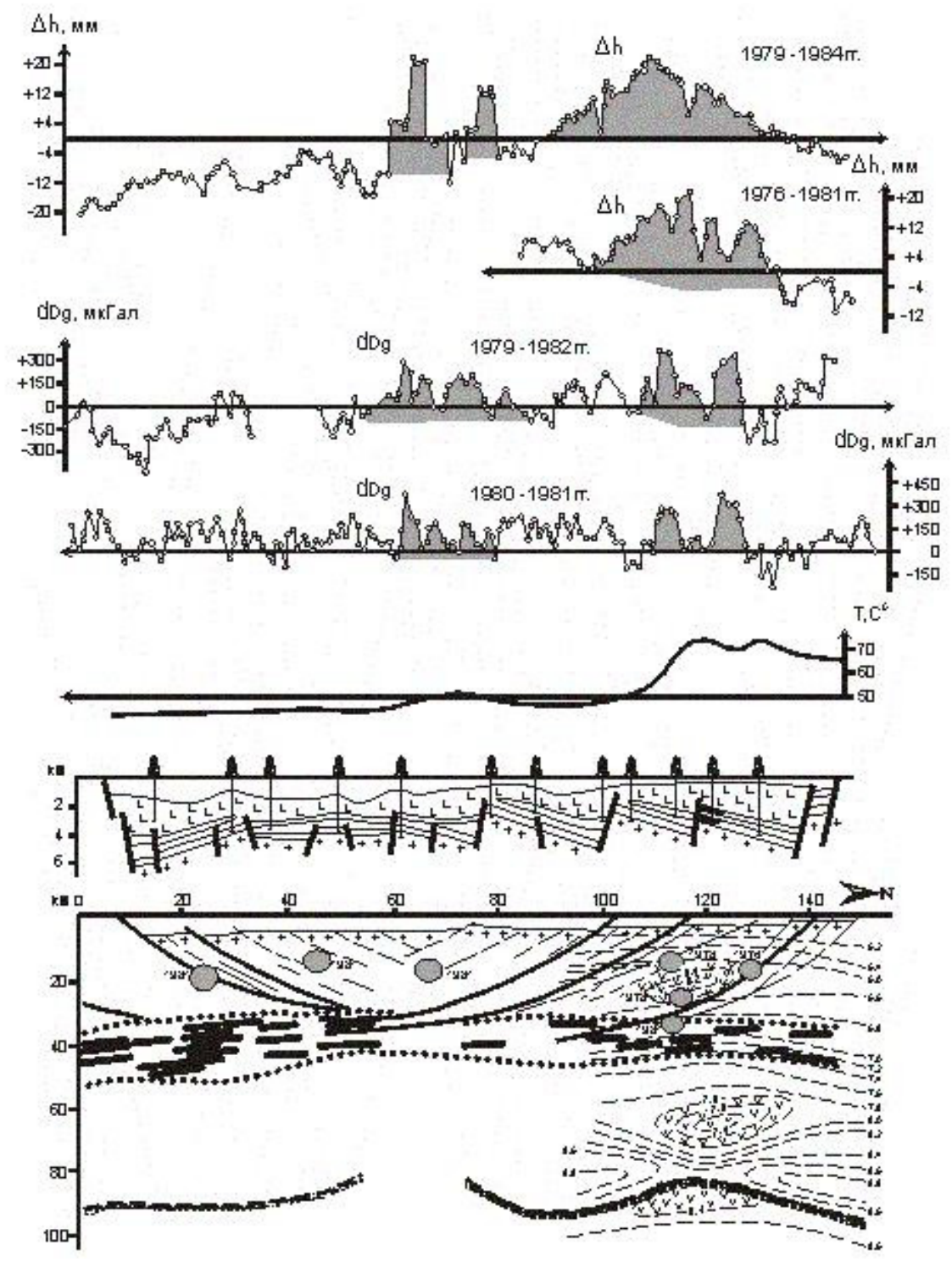

Рис. 2. Современные вертикальные движения земной поверхности и изменения силы тяжести во времени по региональному сейсмическому профилю ГСЗ МОBЗ VIII - VIII через Припятский прогиб.

Fig. 2. Recent vertical displacements of the ground surface and gravity changes in real time along the regional seismic profile (constructed by deep seismic sounding and earthquake converted-wave methods) VIII - VIII across the Pripyat trough.

жена в миллиметрах, то ширина аномалии в километpax).

- Основные пространственно-временные характеристики аномальных движений идентичны как для сейсмоактивных, так и для асейсмичных разломных зон. При этом интенсивность деформационного процесса в разломах асейсмичных регионов выше, чем в сейсмоактивных.

- Установленные типы аномальных движений находятся в определенном соответствии с региональными типами напряженного состояния земной коры. В районах предгорных и межгорных прогибов (области сжимающих напряжений) доминируют $\beta$-аномалии, а в рифтовых областях (зоны растяжений) преобладают $\gamma$-аномалии. Аномалии типа $\mathrm{S}$ оказались крайне редким явлением для всех изученных регионов.

На рис. 4 представлены примеры СД для различных регионов. Хорошо видно, что кривые совершенно идентичны по морфологии, т.е. у них совпадают ширина (горизонтальный масштаб всех графиков одинаков) и амплитуда.

Необходимо отметить, что на данном графике приведены амплитуды, а не скорости деформаций. Если же принять во внимание длительность между повторными наблюдениями, то окажется, что среднегодовая скорость СД-процессов для асейсмичных разломов будет выше, чем для сейсмоактивных.

Важной особенностью СД-процессов является 


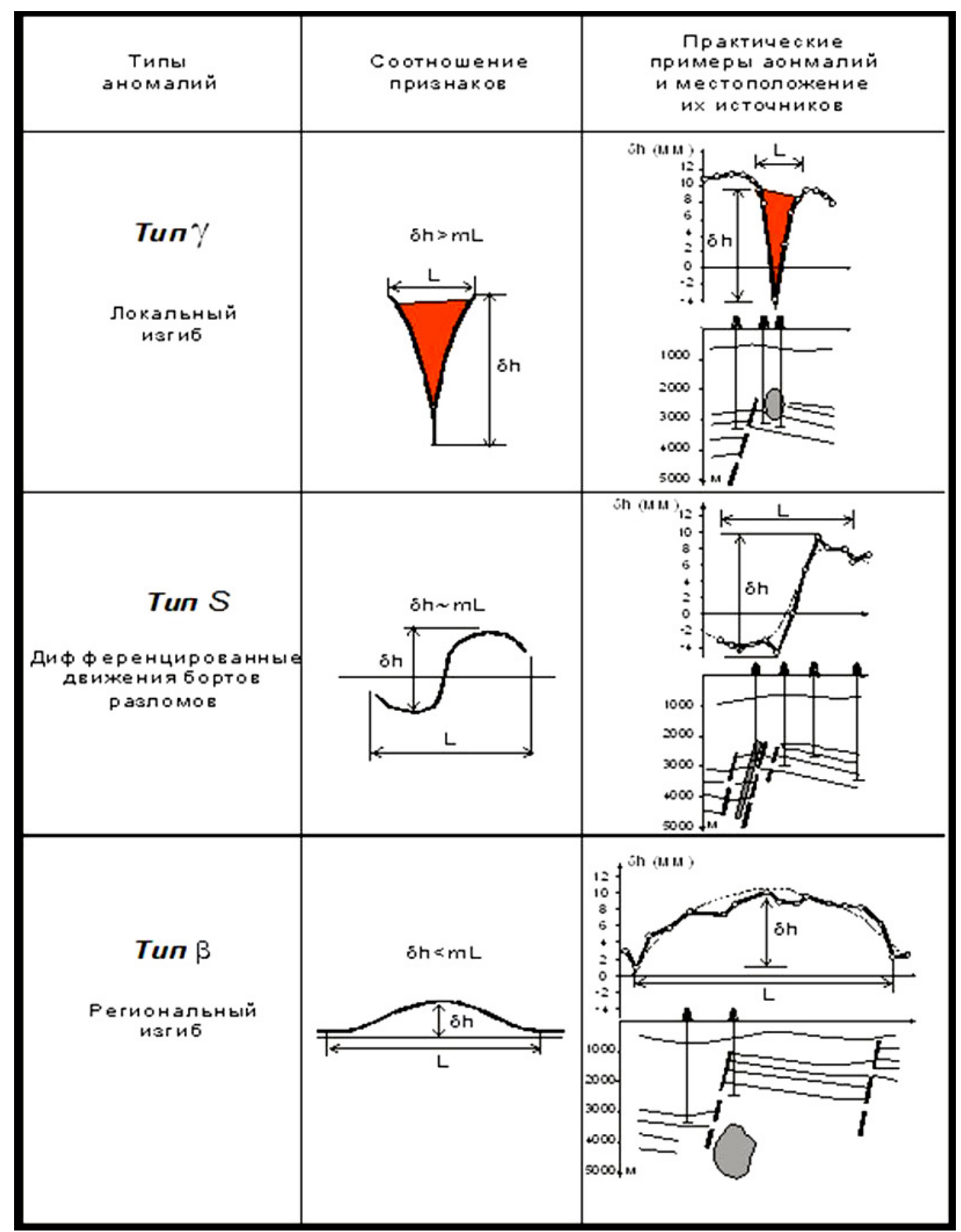

Рис. 3. Таблица основных типов аномального изменения современных движений земной поверхности в пределах зон разломов.

Fig. 3. Table of main types of anomalous changes of recent ground surface displacements within fault zones.

пульсационный характер их проявлений во времени.

Имеются многочисленные примеры, когда происходит перемежаемость периодов активизации и покоя [Kuzmin, 1999]. Так, на рисунке 5 представлены результаты повторных нивелирных наблюдений вдоль нескольких локальных профилей (длиной порядка 5 км), расположенных в пределах северной части Припятской впадины. Как видно из графика, происходит периодическая активизация СД-процессов ( $\gamma$-аномалии) и перемежаемость периодов активности и покоя с преимущественной активизацией одних и тех же разломных зон.
Таким образом, локальные просадки земной поверхности ( $\gamma$-аномалии) в зонах разломов - довольно распространенное явление, но только в том случае, когда измерения проводятся высокоточными геодезическими методами с повышенной пространственновременной детальностью.

Естественно, что подобный, «высокочастотный» спектр движений оказался труднообъяснимым в рамках динамики астеносферных процессов. В конечном итоге главный вопрос разрешения «парадокса» больших скоростей сводится к анализу соотношения региональных и локальных процессов. Действительно, 

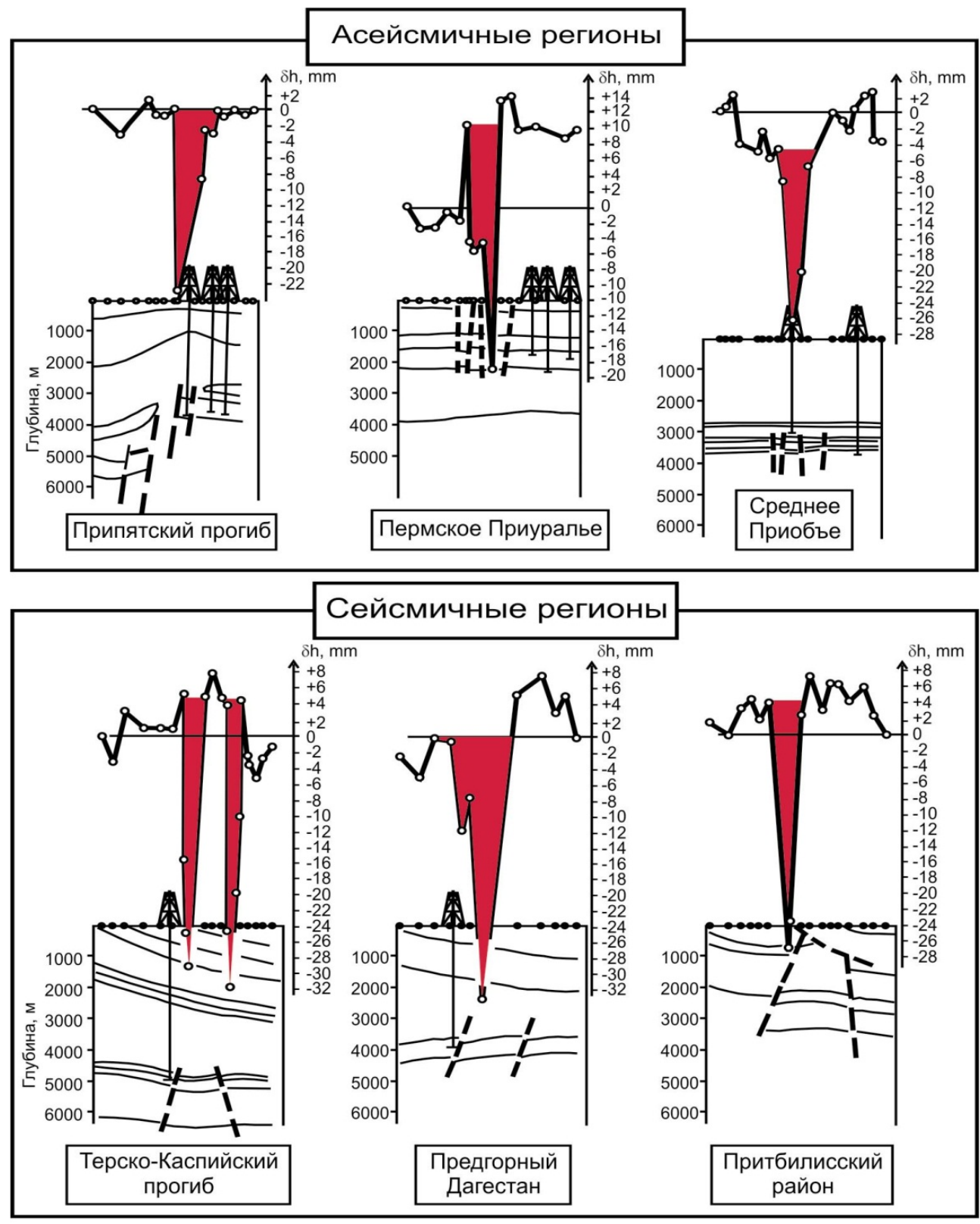

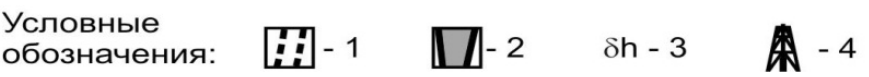

Рис. 4. Примеры локальных аномалий современных вертикальных движений земной поверхности типа для различных регионов.

1 - зоны разрывных нарушений; 2 - зоны аномальных вертикальных движений; 3 - амплитуды современных вертикальных движений; 4 - скважины.

Fig. 4. Examples of local anomalies of recent vertical displacements of the ground surface in different regions.

1 - fault zones; 2 - zones of anomalous vertical displacements; 3 - amplitudes of recent vertical displacements; 4 - wells.

если имеет место унаследованная схема деформирования, то локальные деформации в зонах разломов должны иметь монотонный, однонаправленный характер развития во времени в полном соответствии с морфолого-генетическими характеристиками разрывных структур и региональной схемой тектонических напряжений. Однако оказалось, что локальная дина- мика разломных зон демонстрирует явно выраженный автономный характер.

Так, в целях выявления тонкой структуры деформационных процессов на локальном уровне был проведен уникальный эксперимент. Вдоль простирания регионального Речицкого разлома (Припятская впадина, Белоруссия) было исследовано пространственное 


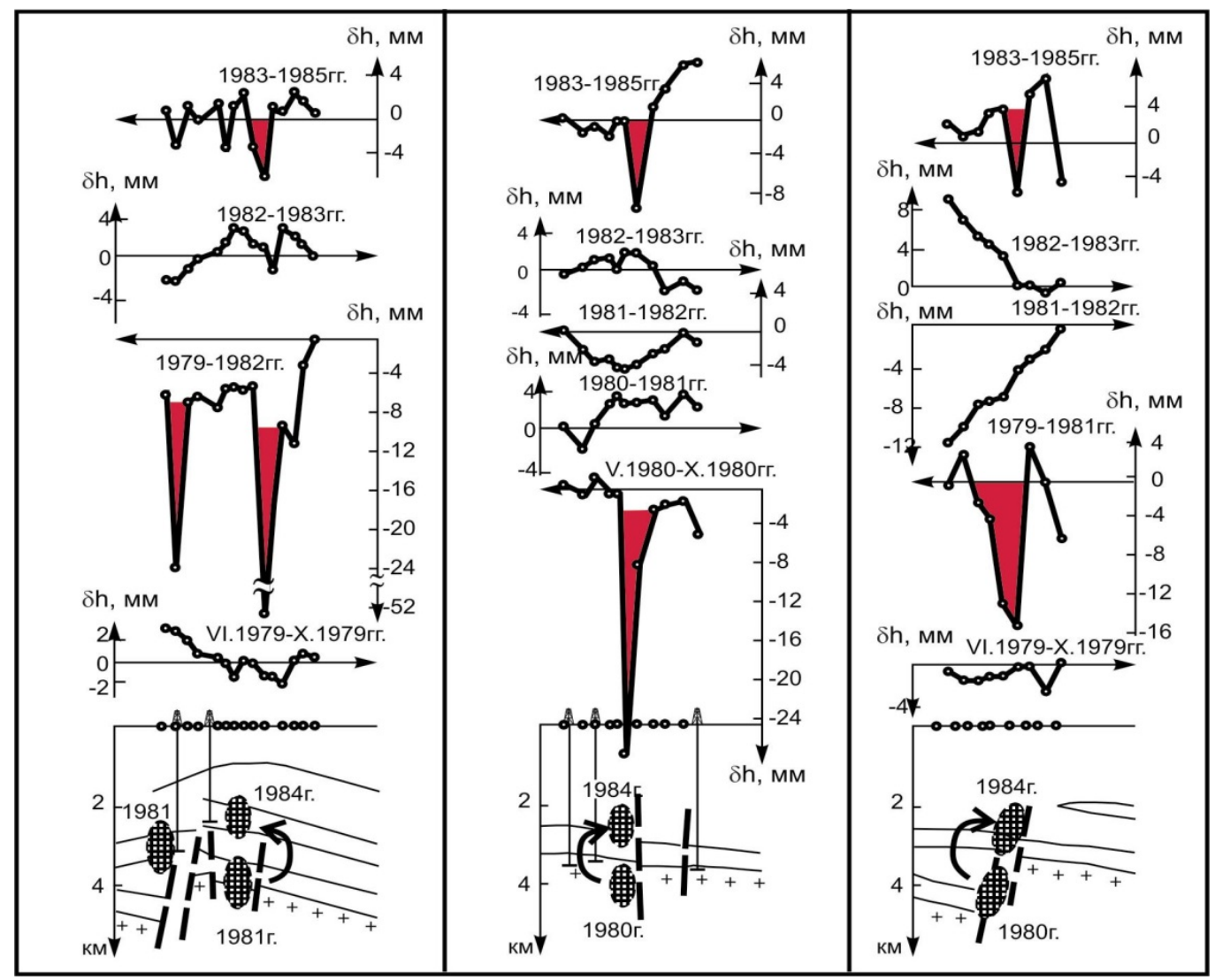

Рис. 5. Пульсирующий характер СД-процессов в зонах разломов.

Fig. 5. Pulsating recent deformation processes in fault zones.

распределение вертикальных смещений на основе 26 квазиортогональных пересечений зоны разлома нивелирными профилями. Уникальность заключалась в том, что практически одновременно проводились повторные высокоточные (с погрешностью 1.5-2.0 мм) наблюдения с интервалом порядка 1 года [Kuzmin, 2009].

На рис. $6(a$, б) представлены итоговые результаты. Оказалось, что из 26 пересечений только на девяти участках были выявлены аномальные деформации. Примечательно то, что амплитуда и морфология аномальных смещений во многом идентичны. Из рис. $6, a$, следует, что величины среднегодовых скоростей варьируются в пределах от 10 до 20 мм/год. Морфологически смещения представляют собой узкие пикообразные просадки земной поверхности, имеющие ширину 0.5-1.0 км. Местоположение Речицкого разлома в пределах Припятской впадины и номера профилей, на которых были выявлены аномальные смещения, показаны на рис. 6,6 .

В центральной части выделяется зона Речицкого разлома, в пределах которой идентифицировано наибольшее количество активизированных фрагментов. Необходимо отметить, что аномалии выявляются только в разломных зонах широтной и квазиширотной ориентации. В зонах разломов квазимеридиональной ориентировки аномальные деформации земной поверхности не обнаружены. И это несмотря на то, что конфигурация нивелирной сети обеспечивала пересечение квазимеридиональных разломов. Очевидно, что данная картина площадного распределения локальных аномалий отражает характер регионального напряженного состояния, а именно горизонтальное квазимеридиональное растяжение Припятского палеорифта.

На рис. 7 представлено площадное распределение деформационных аномалий на территории Припятской впадины. Общая площадь покрытия нивелирной сетью

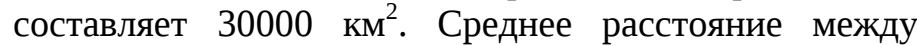
нивелирными пунктами (показаны точками) - 250 $300 \mathrm{M}$.

Из рисунка видно, что зоны аномальных деформаций представлены дискретными полосами широтного простирания, приуроченными к разломным зонам, каждая из которых состоит из набора активизированных фрагментов.

Отсюда следует три важных вывода. Во-первых, показано, что даже в пределах одной разломной зоны картина пространственного распределения деформаций носит контрастно-неоднородный, дискретный характер. Во-вторых, полученные результаты указывают 

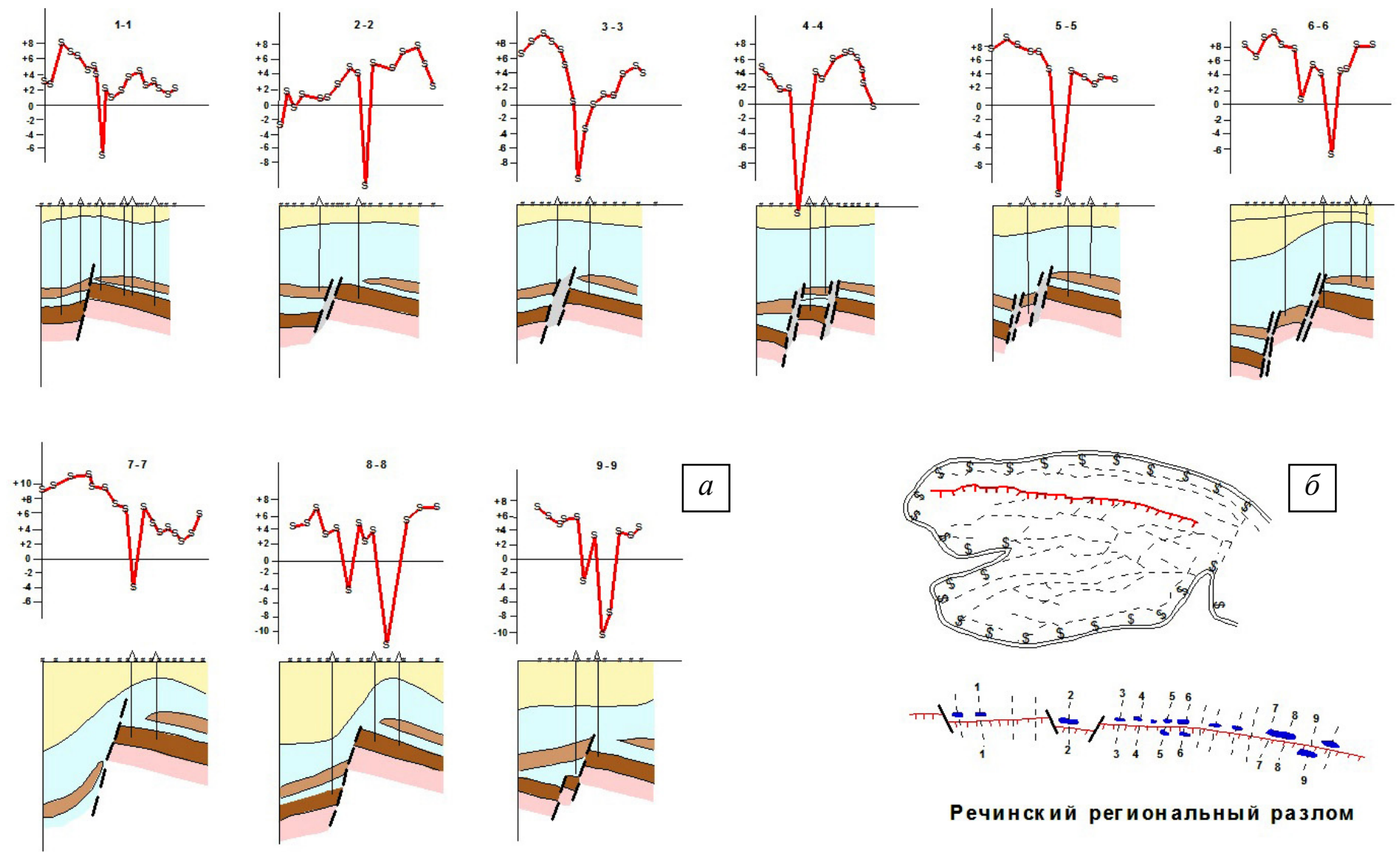

Речинский региональный разлом

Рис. 6. Распределение современных вертикальных смещений земной поверхности по профилям, организованным вдоль простирания Речицкого разлома (a) и местоположение нивелирных профилей (б).

Fig. 6. Distribution of recent vertical displacements of the ground surface by profiles along the strike of the Rechitsky fault (a), and locations of level-measurement profiles (б).

на отсутствие ступенеобразных вертикальных смещений в пределах столь ярко выраженных разломных зон сбросового типа. В-третьих, морфологический тип (локальные, симметричные просадки) выявленных аномалий современных вертикальных движений соответствует характеру регионального поля напряжений. Подробный анализ других разломных зон, расположенных в других регионах мира [Kuzmin, 1999, 2002, 2004], также выявил повсеместное проявление аномалий $\mathrm{\gamma}$-типа и отсутствие значимых ступенеобразных смещений, т.е. отсутствие унаследованности современных движений.

\section{4. ПАРАДОКСЫ СКОРОСТЕЙ ДЕФОРМАЦИЙ И МЕХАНИЗМ ФОРМИРОВАНИЯ СОВРЕМЕННОЙ ГЕОДИНАМИЧЕСКОЙ АКТИВНОСТИ РАЗЛОМОВ}

Проблема парадокса скоростей деформаций в современной геодинамике возникла сразу после того, как были проведены первые сравнения скоростей современных движений земной коры, измеренных геодезическими методами, со скоростями, определенными по геолого-геоморфологическим данным.

Впервые наиболее полно эта проблема была рассмотрена в работе [Bulanzhe, Magnitsky, 1974] на примере «парадокса больших скоростей» современных вертикальных движений земной коры. Было показано, что если предположить, что современные движения являются, как правило, продолжением движений ближайшего геологического прошлого, то при скоростях нескольких мм/год в течение одного четвертичного периода, т.е. за $10^{6}$ лет, на платформах возникли бы горы и впадины в несколько км высотой (глубиной), чего фактически нет. По существу, «парадокс больших скоростей» представляет собой инструментально установленный факт отклонения унаследованного характера современных движений коры от движений прошлых геологических эпох.

Для объяснения этого парадокса были привлечены 


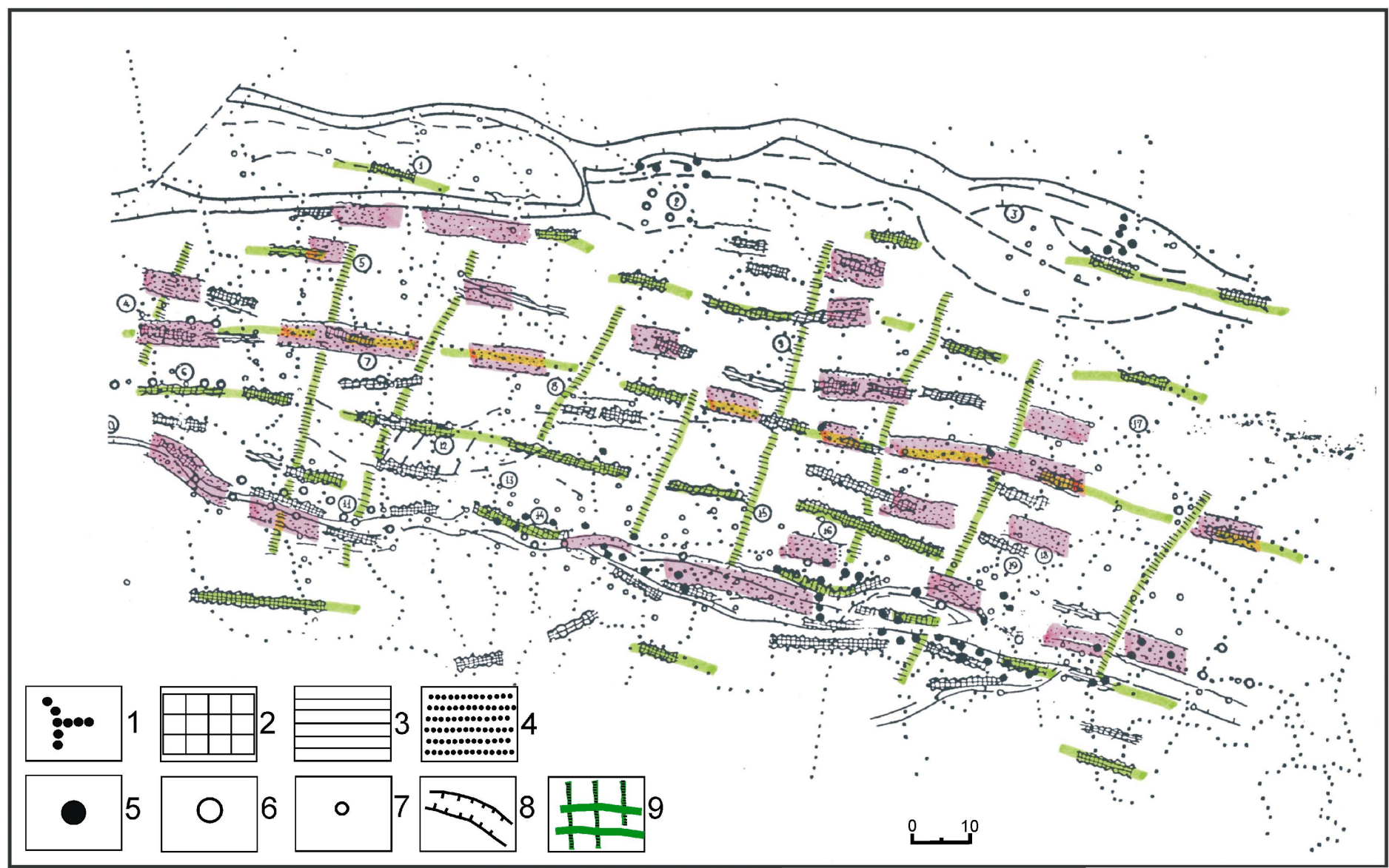

Рис. 7. Площадное распределение аномалий современных вертикальных движений земной поверхности в пределах Припятской впадины.

1 - пункты повторного нивелирования; 2-4 - зоны повышенной трещиноватости пород: 2 - в межсолевых и подсолевых отложениях (аномалии типа ү), 3 - в подсолевых отложениях и фундаменте (аномалии типа S), 4 - в фундаменте (аномалии типа $\beta$ ); 5-6 - эксплуатационные скважины, добывающие нефть: 5 - из межсолевых отложений, 6 - из подсолевых отложений; 7 - глубокие скважины; 8-9 разломы: 8 - глубинные первого порядка, 9 - третьего и четвертого порядка.

Fig. 7. The spatial pattern of anomalous recent vertical displacements of the ground surface within the limits of the Pripyat basin.

1 - repeated level measurement sites; $2-4$ - zones of high fracturing of rocks: 2 - in inter-salt and subsalt deposits ( $\gamma$-anomalies), 3 -in sub-salt deposits and base rocks (S-anomalies), 4 - in base rocks ( $\beta$-anomalies); 5-6 - wells producing oil: 5 - from inter-salt deposits, 6 - from subsalt deposits; 7 - deep wells; $8-9$ - deep faults of the $1^{\text {st }}$ order; 9 - faults of the $3^{\text {rd }}$ and $4^{\text {th }}$ orders.

представления [Magnitsky et al., 1974; Magnitsky, Kalashnikova, 1978] о знакопеременном и/или прерывистом (пульсационном) характере движения астеносферного слоя, который приводит к знакопеременным движениям земной поверхности, что при больших временах осреднения приводит к компенсации движений различных знаков (поднятий и опусканий).

Предложенные механизмы достаточно хорошо объясняли формирование основных пространственно-временных характеристик современных геодинамических процессов, полученных по результатам повторных нивелирных наблюдений вдоль линий Государственной нивелирной сети с большими интервалами между повторениями (десятки лет) и расстояниями между измерительными пунктами (десятки километров).
Однако выше было показано, что даже на платформах имеют место интенсивные, короткопериодичные (0.1-1.0 года) и локальные (0.1-1.0 км) аномалии современных движений земной поверхности, приуроченные к зонам разломов различного типа и порядка. Естественно, что подобный, «высокочастотный» спектр современных вертикальных движений оказался труднообъяснимым в рамках динамики астеносферных процессов. В этой связи, основной вопрос разрешения «парадокса» больших скоростей сводится к анализу соотношения региональных и локальных процессов.

Действительно, если имеет место унаследованная схема деформирования, то локальные деформации в зонах разломов должны иметь монотонный, однонаправленный характер развития во времени в полном 
соответствии с морфолого-генетическими характеристиками разрывных структур и региональной схемой тектонических напряжений. Однако оказалось, что локальные деформационные процессы в разломных зонах имеют явно выраженный автономный характер, развиваются в обстановке квазистатического нагружения и распространяются в форме автоволн [Kuzmin, 2004, 2009; Kuz'min, 2012].

Важно отметить, что основные результаты в изучении современных геодинамических процессов (современных движений земной коры) в XX веке были получены в основном по вертикальной компоненте движений (нивелирные наблюдения). На рубеже веков, в связи с активным внедрением методов спутниковой геодезии (ГНСС наблюдений), основной информацией, напротив, стали данные по современным горизонтальным движениям.

При анализе результатов измерений в современной геодинамике одним из наиболее важных вопросов является вопрос временной стабильности регионального напряженно-деформированного состояния. Зачастую исследователям приходится постулировать неизменность и/или монотонность во времени уровня и направленности регионального поля напряжений. Это естественным образом связано с информативностью натурных данных. Нередко при использовании результатов геодезических наблюдений (наземных и/или спутниковых) возникает необходимость тривиального осреднения и экстраполяции измеряемых кинематических величин (скорость и направленность смещений) в условиях редких и нерегулярных циклов повторных наблюдений, проводимых на больших базах измерений.

Естественно, что при сопоставлении GPS-наблюдений, имеющих 2-3 повторных цикла измерений в интервале нескольких лет на расстояниях десятков или сотен километров, с высокоточными наземными многолетними наблюдениями возникают принципиальные противоречия. Так, по результатам исследований, скорости относительных горизонтальных деформаций земной поверхности, полученные по данным GPS-измерений, достигают величин $10^{-8}-10^{-9}$ в год. Подобные низкие скорости относительных горизонтальных деформаций противоречит скоростям монотонного, однонаправленного движения литосферных плит. Все это позволяет трактовать выявленные несоответствия как «парадокс малых скоростей горизонтальных деформаций» земной поверхности [Kuzmin, 2009].

При этом, если «парадокс больших скоростей современных вертикальных движений» можно было объяснять суперпозицией вертикальных движений различных знаков, то с «парадоксом малых скоростей горизонтальных деформаций» все обстоит намного сложнее. Простое объяснение этого парадокса состоит в том, что расстояния между пунктами ГНСС измерений слишком велики, что естественно приводит к существенному занижению величины относительной де- формации. Однако привлечение к анализу данных по длительным рядам наземных наблюдений за горизонтальными смещениями на расстояниях 1-10 км показывает, что этот парадокс остается в силе.

В этой связи представляется актуальным детальное рассмотрение длительных (20-50 лет) рядов наземных наблюдений за вертикальными и горизонтальными движениями земной поверхности в зонах разломов различных регионов, которое позволяет существенно продвинуться в разрешении «парадоксов больших и малых скоростей» [Kuzmin, 2013].

\section{1. КОПЕТДАГСКАЯ СЕЙСМОАКТИВНАЯ ЗОНА}

Как известно, геодинамика Копетдагского сейсмоактивного региона обусловлена динамическим взаимодействием Иранской и Туранской плит. Основной зоной коллизии этих плит является Передовой разлом Копетдага (Главный Копетдагский надвиг). Естественно, что подобная кинематика плит должна приводить к систематическому (с юга на север) надвигу Копетдага на Туранскую плиту вдоль зоны Передового разлома Копетдага, а также к постоянному правостороннему сдвиговому перемещению вдоль этого разлома. При этом среднегодовые скорости подобных смещений должны иметь порядок первых сантиметров в год. На это указывают результаты спутниковых измерений, проведенных на разнесенных друг от друга (более 500 км) пунктах GPS-наблюдений, которые выявили скорость коллизии Иранской и Туранской плит порядка 30 мм/год [Kuzmin, 2009; Izyumov, Kuzmin, 2010].

Если следовать этой схеме и предполагать полную унаследованность современных движений земной коры от прошлых геологических эпох, то существующая система геодеформационных наблюдений, развернутая в центральной части Копетдагского региона и имеющая многолетнюю (около 50 лет) историю наблюдений, должна уверенно фиксировать систематический наклон предгорных участков земной поверхности на север - северо-восток по нивелирным данным, монотонное во времени сокращение длин светодальномерных линий от Копетдага к платформе и постоянное увеличение длины линий, пересекающих Передовой разлом Копетдага под углом $45^{\circ}$ и менее.

Однако оказалось, что многолетние наземные геодезические наблюдения локального масштаба за горизонтальными и вертикальными движениями земной поверхности в Копетдагском регионе полностью противоречат результатам спутниковых наблюдений за скоростями сближения Туранской и Иранской плит, а также наличию систематического правостороннего сдвига вдоль Передового разлома Копетдага.

Исследования проводились в пределах активных разломов и, в первую очередь, в зоне Передового разлома Копетдага. Нивелирные и светодальномерные наблюдения проводились на специально организованных тестовых деформационных площадках. Длины ниве- 


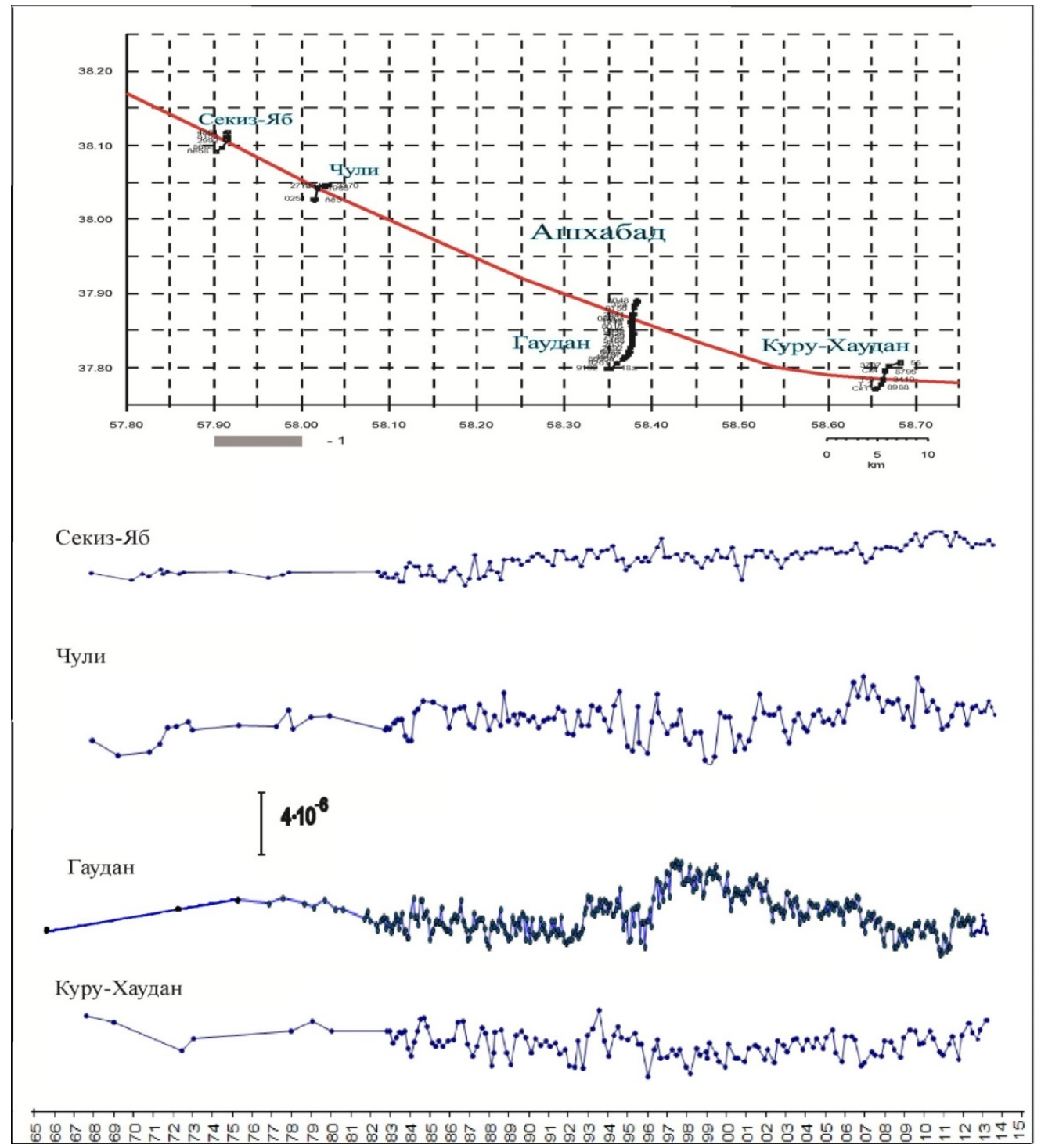

Рис. 8. Результаты многолетних нивелирных наблюдений вдоль локальных профилей, пересекающих Передовой разлом Копетдага. Красная линия - Передовой разлом Копетдага.

Fig. 8. Results of long-term level-measurement surveys along local profiles across the Frontal fault, Kopetdag (the fault is shown by the red line).

лирных профилей и светодальномерных линий на этих площадках варьировались в пределах 1-10 км. Частота опроса, в среднем, составляет от 1 раза в месяц до 4 раз в год для нивелирных наблюдений и порядка 1-2 раза в неделю для светодальномерных измерений. Общая длительность наблюдений на отдельных приразломных участках достигает 40-45 лет. Точность всех нивелирных наблюдений в Копетдагском регионе составляет $0.5 \mathrm{~mm} / \mathrm{кM}$.

На рис. 8 представлены результаты многолетних (почти 50 лет) высокоточных нивелирных наблюдений, проводимых по локальным профилям, пересекающим Передовой разлом Копетдага. При этом измерительной сетью контролируется полоса Передового разлома протяженностью порядка 100 км.
Для удобства сопоставительного анализа результаты вертикальных превышений переведены в угловую меру путем деления их значений на расстояние между реперами. Иными словами, система наблюдений представляет собой четыре «длиннобазисных наклономера», которые пересекают разломную зону и ориентированы в субмеридиональном направлении.

Как следует из графика, имеют место локальные вариации скоростей наклонов земной поверхности, составляющие (0.12-4.00) $10^{-6} /$ год. При этом трендовые среднегодовые скорости наклонов имеют порядок от $2 \cdot 10^{-8}$ до $1.3 \cdot 10^{-7}$. Таким образом, разница между локальными и трендовыми изменениями составляет 1.5-2.0 порядка.

Очевидно, что отсутствие систематических измене- 

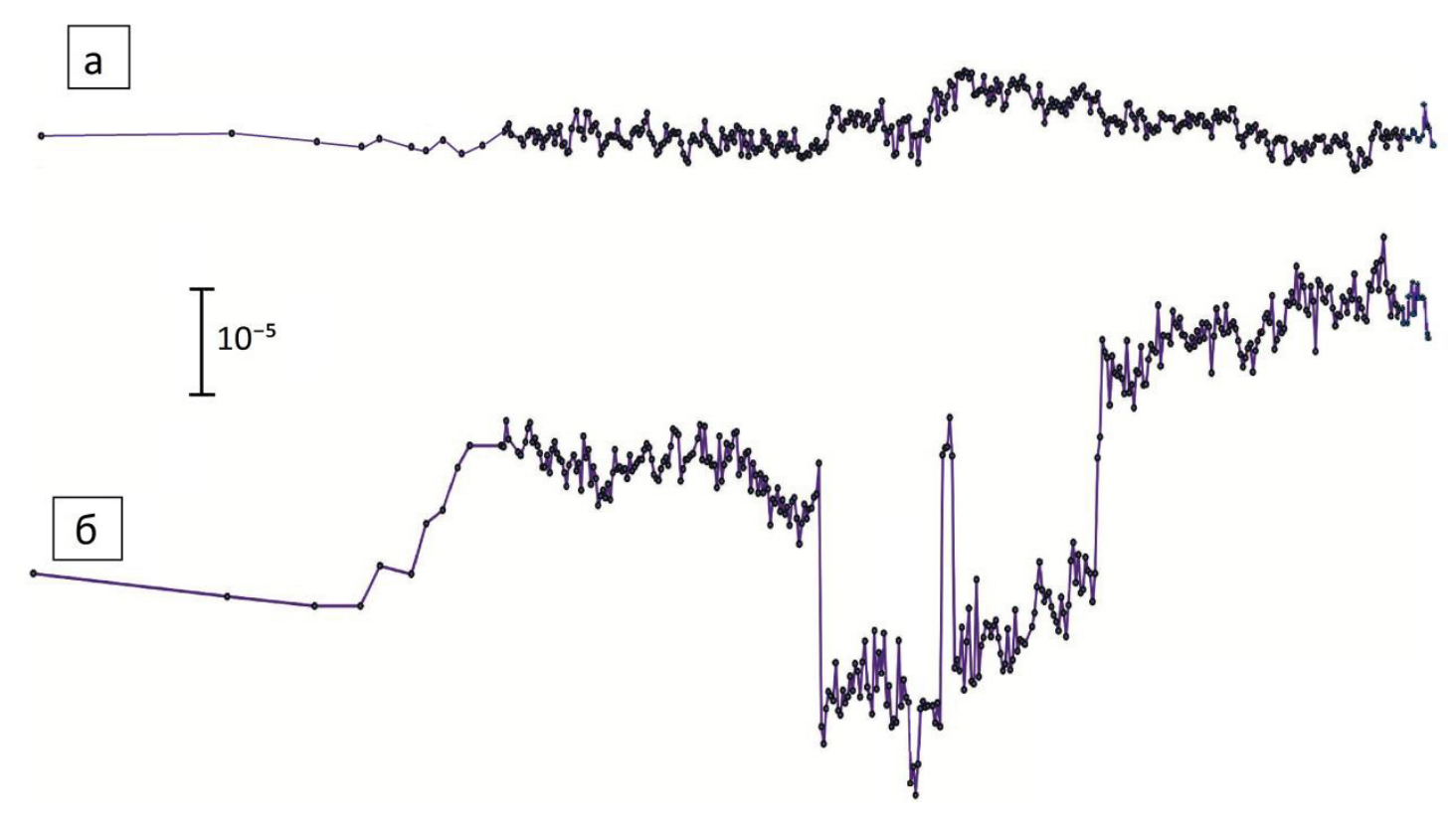

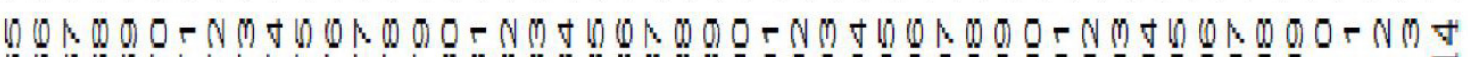

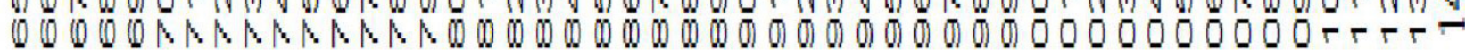

Рис. 9. Временной ход вертикальных смещений земной поверхности (Копетдагский регион): $a$ - «бортовая» секция (l=4 км); б - «приразломная» секция (l=0.6 км).

Fig. 9. The timeline of vertical displacements of the ground surface in the Kopetdag region: $a$ - 'side' segment (l=4 km); 6 - 'nearfault' segment $(\mathrm{l}=0.6 \mathrm{~km})$.

ний в ходе вертикальных смещений означает, что в рассматриваемый промежуток времени (около 50 лет) региональное напряженно-деформированное состояние имеет квазистатический характер.

Для более детального анализа соотношения региональных и локальных процессов в зонах разломов на рис. 9 представлены результаты многолетних высокоточных нивелирных наблюдений по профилю, пересекающему Передовой разлом Копетдага в районе г. Ашхабада. Профиль специально разбит на две секции: «блоковую», расположенную вне зоны разлома, и «разломную», организованную непосредственно в разломной зоне. Частота опроса составляла 1 раз в месяц. Для удобства сопоставительного анализа результаты вертикальных превышений также переведены в угловую меру. Система измерений представляет собой два расположенных друг за другом длиннобазисных наклономера.

Из графика следует практически полное отсутствие трендовых изменений в бортовой части, тогда как в зоне разлома имеют место интенсивные знакопеременные процессы со своей временной структурой. При этом видно, что на фоне практического отсутствия тренда имеют место знакопеременные вариации движений, которые достигают скоростей порядка $6 \cdot 10^{-8}$ в год для бортовой части и $10^{-5}$ в год для зоны разлома.

Для того чтобы исследовать пространственное распределение вертикальных смещений земной поверхности, на рис. 10 представлены результаты нивелирных наблюдений в зоне Передового разлома Копетдага, организованных в режиме повышенной пространственно-временной детальности. Расстояние между реперами здесь достигло первых сотен метров, частота измерений - 1 раз в месяц. Здесь отчетливо проявляются аномальные смещения (просадки) земной поверхности $ү$-типа с амплитудой порядка 5 мм и шириной 0.5-1.0 км.

Это типичная морфология современной геодинамики разломов, выявленная по многочисленным геодезическим измерениям во многих регионах мира [Kuzmin, 1989, 1999, 2004]. Данный тип аномалий современных вертикальных движений земной поверхности получил название «аномалия типа ү», так как по морфологии кривой это похоже на соответствующую букву греческого алфавита. Кривые смещений построены по принципу «от цикла к циклу», где каждый график представляет собой разность результатов смежных нивелирований: 2-1; 3-2; 4-3 и т.д., где цифры означают номера циклов повторных наблюдений. Это позволяет сделать вывод о том, что амплитуды ано- 


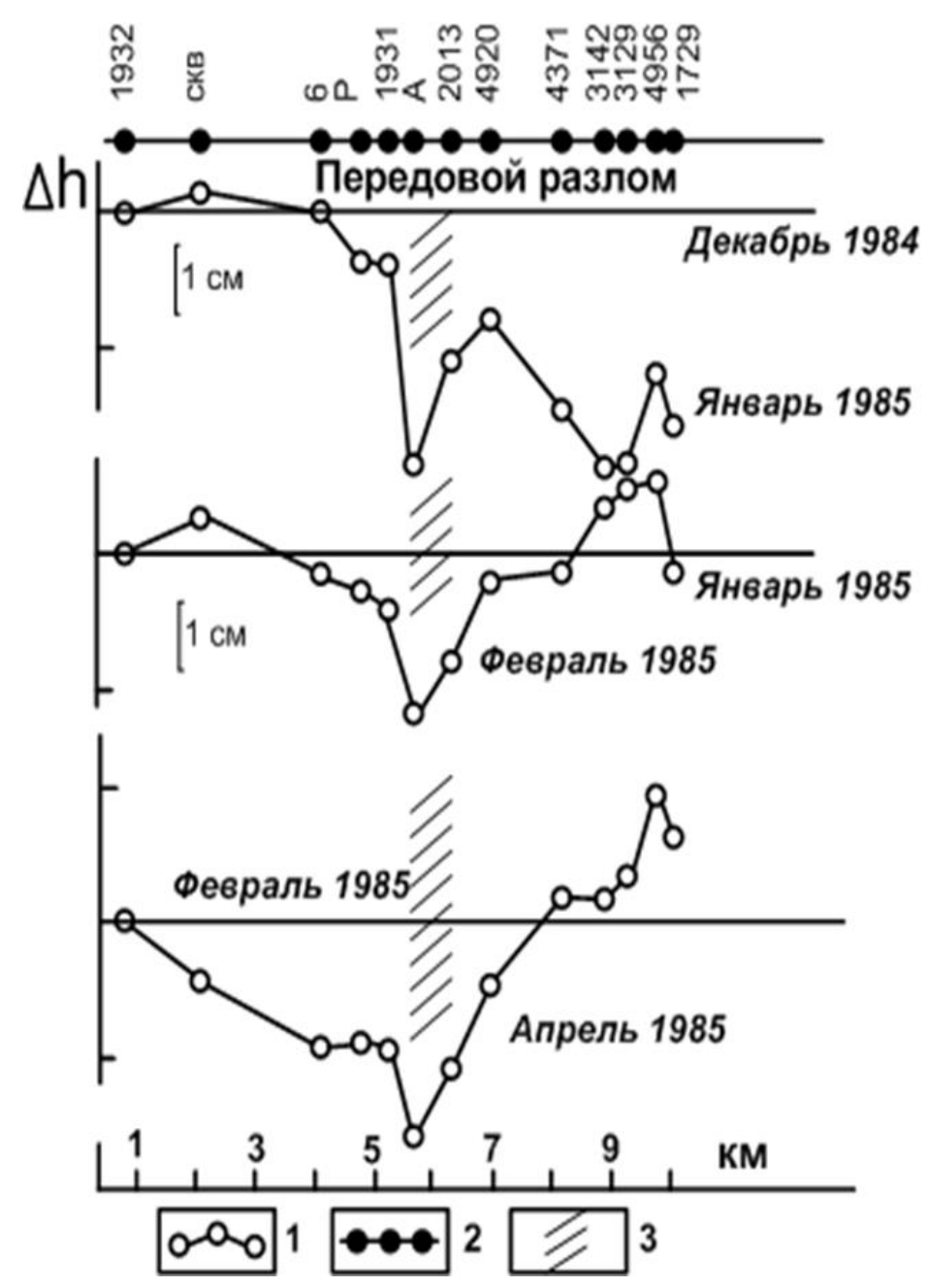

Рис. 10. Пространственное распределение современных вертикальных движений земной поверхности в зоне Передового разлома Копетдага.

1 - значения вертикальных смещений вдоль профиля; 2 - пункты наблюдений; 3 - местоположение разломной зоны.

Fig. 10. The spatial pattern of recent vertical displacements of the ground surface in the Frontal fault zone, Kopetdag.

1 - vertical displacements along the profile; 2 - monitoring sites; 3 - location of the fault zone.

мальных вертикальных смещений земной поверхности накапливаются от цикла к циклу. Если просуммировать накопившиеся вертикальные смещения и оценить скорость относительных деформаций, то она будет иметь величину $6 \cdot 10^{-5}$ в год.

Аналогичная картина складывается и при анализе результатов режимных светодальномерных наблюдений за горизонтальными движениями земной поверхности. И в данном случае система наблюдений организована таким образом, что одна линия (3330 м) пересекает зону разлома, а другая (1532 м) расположена в пределах блока.

На рис. 11 представлен временной ход среднемесячных значений горизонтальных смещений земной поверхности за период с 1977 по 2007 г. Вновь имеет место полное отсутствие систематического тренда. Особенно интересны результаты измерений по линии
L 3330. Согласно изложенной выше региональной геодинамической схеме, данная линия должна испытывать систематическое удлинение со среднегодовой скоростью порядка первые сантиметры в год, в соответствии с правосторонним сдвигом в зоне Передового разлома Копетдага. Так как этого не происходит, то очевидно, что региональные характеристики напряженно-деформированного состояния остаются практически неизменными во времени [Kuzmin, 2009].

Среднегодовая трендовая скорость относительных деформаций, определенная по измерениям горизонтальной компоненты движений, оказывается равной $3.2 \cdot 10^{-8}$ в год. Отмечается, что величины вариаций во времени горизонтальных смещений земной поверхности имеют примерно одинаковую амплитуду как вдоль линии, пересекающей разлом, так и вдоль линии, расположенной в блоковой части. 


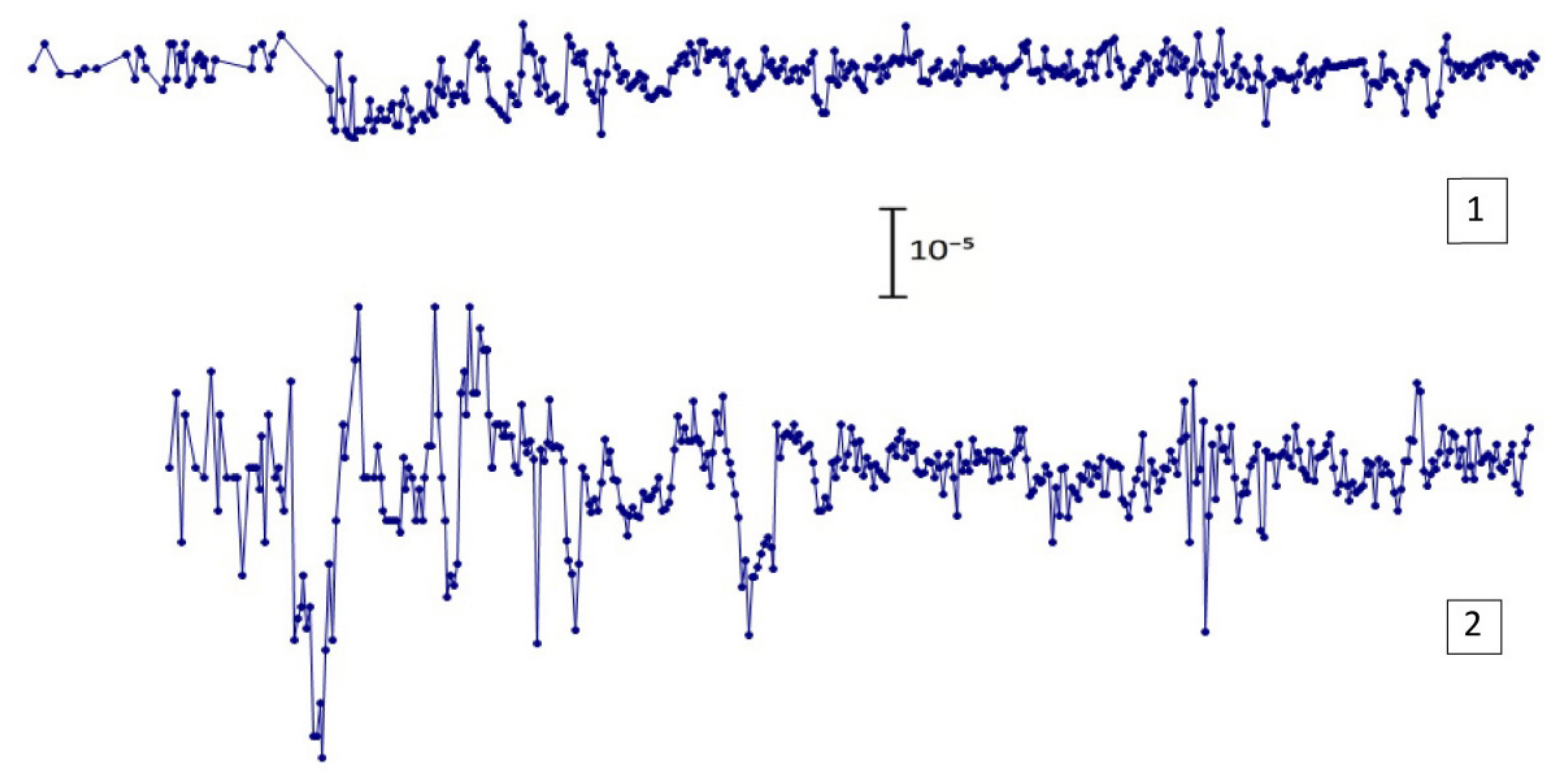

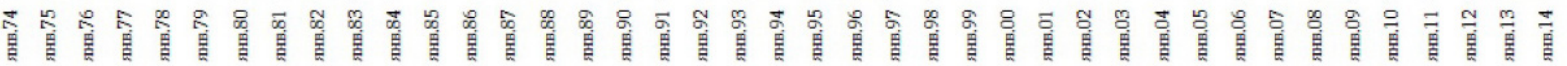

Рис. 11. Временной ход горизонтальных движений земной поверхности (Копетдагский регион): 1 - светодальномерная линия L 3330; 2 - светодальномерная линия L1532.

Fig. 11. The timeline of horizontal displacements of the ground surface in the Kopetdag region. Optical distance measurement lines: 1 - L 3330; 2 - L1532.

Это означает, что деформационные процессы в зоне разлома носят крайне локальный характер, что и подтверждается результатами измерения вертикальных смещений земной поверхности. Действительно, если оценивать размер зоны проявления аномальных деформаций по данным о вертикальных движениях, то оказывается, что она имеет порядок 1 км. Естественно, что вдоль светодальномерной линии длиной 3330 м не выявляются локальные знакопеременные флуктуации, приуроченные непосредственно к разлому, в силу их резкого затухания с расстоянием от разлома.

Кроме наблюдений на локальных тестовых площадках, исследование горизонтальной компоненты современных движений проводилось вдоль «светодальномерного профиля», имеющего общую протяженность порядка 40 км. Профильные наблюдения организованы в зоне перехода от Копетдага к Туранской платформе, ориентированы по направлению юг-север и состоят из четырех светодальномерных линий. Последовательный анализ временной структуры горизонтальных смещений показал, что имеет место ситуация, аналогичная характеру изменений вертикальных движений. При локальных вариациях горизонтальных деформаций на уровне $2 \cdot 10^{-7}-3 \cdot 10^{-7} /$ год трендовые среднегодовые скорости деформаций по отдельным линиям составляют диапазон изменений от $-4 \cdot 10^{-8} /$ год (сокращение длин линий) до $+3 \cdot 10^{-8} /$ год (увеличение длин линий). Таким образом, данные по горизонтальным движениям также демонстрируют чрезвычайно низкую скорость трендовой составляющей движений [Izyumov, Kuzmin, 2010].

Таким образом, становится очевидным, что на протяжении последних 45-50 лет региональное поле напряжений во фронтальной части Главного Копетдагского надвига и зоне коллизии Туранской и Иранской плит находится в квазистатическом состоянии. Среднегодовая трендовая скорость деформаций, измеренная по комплексу геодезических данных, имеет величину (3-5) $10^{-8}$ в год, что составляет всего 1-2 амплитуды земноприливных деформаций. При этом локальные деформации в разломной зоне достигают величин скоростей на 1.5-2.0 порядка выше. Это парадоксальная ситуация, если учесть, что речь идет о регионе с высоким уровнем сейсмического потенциала, в пределах которого за указанный интервал времени происходили существенные сейсмические события.

\section{2. КАМЧАТСКИЙ СЕЙСМОАКТИВНЫЙ РЕГИОН}

Работы по исследованию современных движений земной коры (СДЗК) на Камчатском полуострове были начаты научными учреждениями Академии наук СССР (Институт физики Земли, Институт вулканологии) и Предприятием № 2 Главного управления геодезии и картографии при Совете Министров СССР в 70-е годы XX века. Для выполнения этих работ создавались локальные геодинамические полигоны, приуроченные к районам активных вулканов (Авачинский, Карым- 

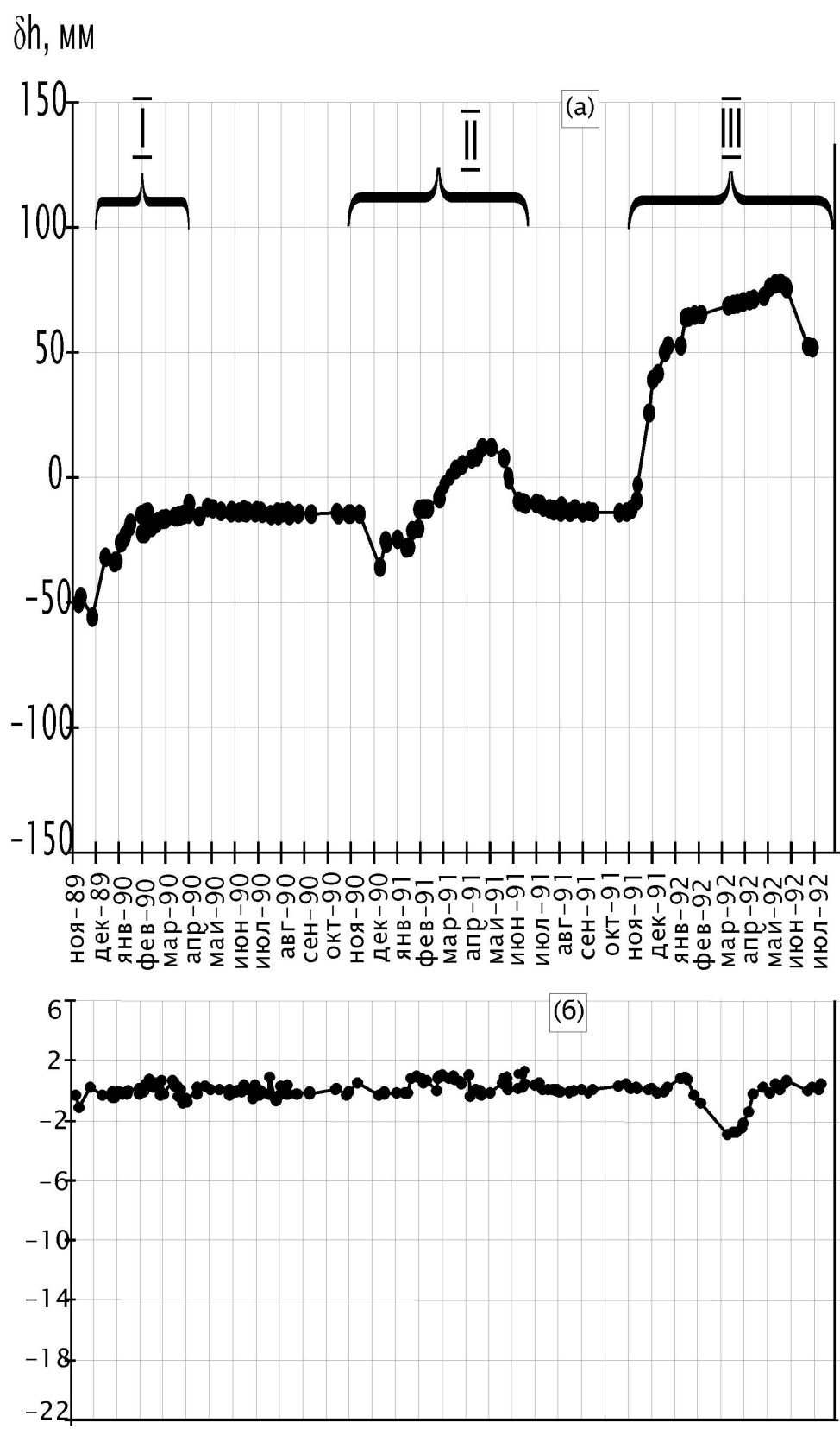

Рис. 12. Временной ход вертикальных смещений земной поверхности (Камчатка): $a$ - «приразломная» секция; б - «бортовая» секция.

Fig. 12. The timeline of vertical displacements of the ground surface in Kamchatka: $a$ - 'near-fault' segment; $\sigma$ - 'side’ segment.

ский, Толбачинский, Ключевской, Горелый, Ксудач) и эпицентральным зонам возможных мест сильных землетрясений (Авачинский залив, Кроноцкий залив, Камчатский залив). Создавались также протяженные профили высокоточного нивелирования вдоль восточного побережья Камчатки, по центральной Камчатской депрессии и перпендикулярно к Курило-Камчатской сейсмофокальной зоне. В 1979 г. был организован светодальномерный мониторинг современных движений земной коры в районе Авачинского залива из обсерватории «Мишенная» [Levin et al., 2006].

В целях исследования тонкой структуры современ- ной геодинамики разломных зон в районе г. Петропавловск-Камчатский были организованы нивелирные наблюдения с повышенной пространственно-временной детальностью. На локальном нивелирном профиле длиной 2.6 км были проведены прецизионные (с точностью до 0.3 мм/км) многократные (1-2 повторения в неделю в течение трех лет) и детальные (расстояние между пунктами наблюдений 80-100 м) наблюдения [Churikov, Kuzmin, 1998; Kuzmin, Churikov, 1999].

На рис. 12 показаны временные изменения вертикальных движений земной поверхности по различным секциям нивелирного профиля. Из графика следует, 


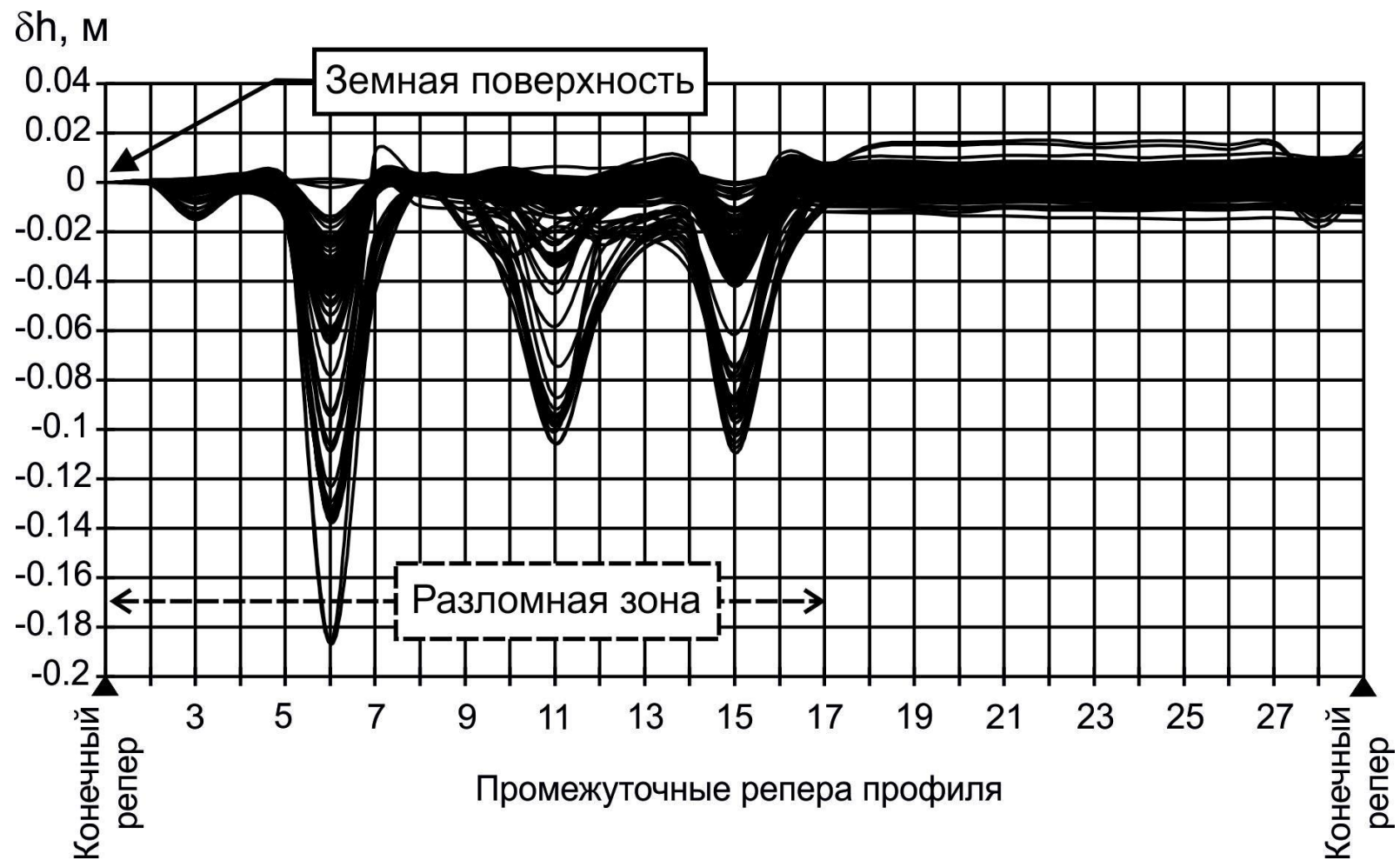

Рис. 13. Распределение вертикальных смещений земной поверхности на нивелирном профиле относительно первого репера (Камчатка).

Fig. 13. Recent vertical displacements of the ground surface at the level-measurement profile against the first reference point (Kamchatka).

что имеет место резкое различие между характером временного хода и амплитудами аномальных деформаций для «приразломной» секции (рис. 12, a) и «бортовой» секции (рис. 12, б). Фигурными скобками и римскими цифрами на графике обозначены аномальные периоды деформационной активности. Отсюда следует, что в пределах секции, расположенной в зоне разлома, отмечены аномальные смещения порядка 10 см, а на секциях, которые находятся в бортовой части (вне разломной зоны), смещения достигают величин на 1.5- 2.0 порядка меньше. Особенно характерен аномальный период III, который предварял Камчатское землетрясение 2 марта 1992 г. Принципиально важно то, что процесс его подготовки произошедший на расстоянии 100 км от нивелирного профиля, проявился в разломной зоне с амплитудой на 1.5-2.0 порядка интенсивнее, чем в бортовой части. Примечательно то, что воздействие от процесса подготовки землетрясения, которое, затухая, достигает в окрестности нивелирного профиля уровня деформации порядка $10^{-6}$, в зоне разлома отмечается деформацией порядка $10^{-4}$ [Kuzmin, 2004]. При этом видно, что так же, как и в Копетдагской сейсмоактивной зоне, временной ход «бортовой» секции не имеет ярко выраженного тренда.

На рис. 13 показано пространственное распределение вертикальных смещений земной поверхности вдоль этого профиля за весь период наблюдений. Очевидно, что разломная зона представлена тремя аномальными просадками типа $ү$. Характерным для всех трех аномалий является ярко выраженный пульсационный и симметричный характер просадок. Периоды интенсивного опускания перемежаются с периодами относительного покоя, затем процесс проседания возобновляется.

В отдельные промежутки времени наблюдаются периоды незначительных (меньших на порядок) инверсионных движений. Амплитуды локальных максимумов в эти периоды незначительно уменьшаются. Однако, в целом, имеет место устойчивая тенденция к пульсационному, последовательному проседанию локальных участков земной поверхности. Ширина аномалий колеблется от 200 до 500 м, а их амплитуда достигает 10-12 см, длительность пульсационных процессов заключена в интервале от нескольких недель до нескольких месяцев. Среднегодовая скорость относительных деформаций достигает величин $10^{-4}$ в год. Иными словами, выявленные аномальные деформации земной поверхности полностью соответствуют аналогичным процессам, зарегистрированным в Копетдагской сейсмоактивной зоне.

Хорошо известно, что Курило-Камчатская зона субдукции является наиболее подвижным и сейсмоак- 


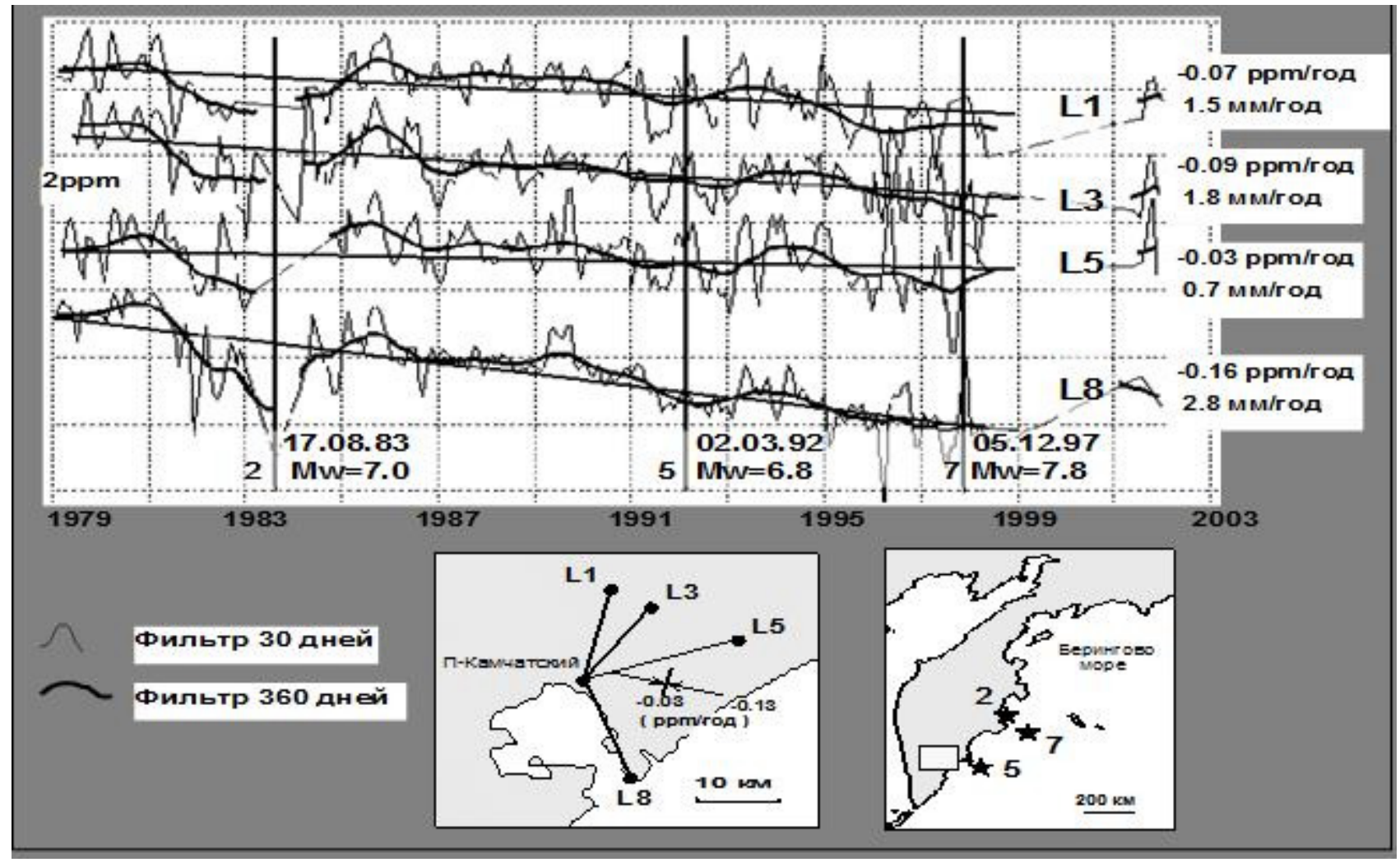

Рис. 14. Временной ход горизонтальных движений земной поверхности (Камчатка) [Levin et al., 2006].

Fig. 14. The timeline of horizontal displacements of the ground surface in Kamchatka [Levin et al., 2006].

тивным регионом в северо-восточной части Евразии. Скорость пододвигания океанической литосферной плиты под континентальную составляет 8 см/год [Titkov et al., 2010]. Более детальное рассмотрение показывает, что происходит сжатие восточного побережья Камчатки под воздействием субдукции Тихоокеанской плиты под Охотскую.

По результатам светодальномерного мониторинга (рис. 14) в районе Авачинского залива из обсерватории «Мишенная» был выявлен тренд (укорочение длин линий), который, казалось бы, соответствует отмеченным выше представлениям о региональной геодинамической обстановке [Levin et al., 2006].

Однако, как следует из рис. 14, среднегодовые скорости относительных горизонтальных деформаций испытывают укорочение по всем направлениям и варьируются от $3 \cdot 10^{-8}$ в год до $1.6 \cdot 10^{-7}$ в год в зависимости от ориентации измерительной линии. Средняя длина светодальномерных линий составляет 15-20 км. За период наблюдений (23 года) в окрестности радиусом 300 км происходили сильные землетрясения с магнитудами от 6.8 до 7.8. В целом же кривые деформаций носят квазипериодический, упругий характер. Об этом, в частности, свидетельствует отношение скоростей деформаций по взаимно ортогональным линиям $\mathrm{L}_{5}$ и $\mathrm{L}_{8}$. Если полагать, что деформации, измеренные по направлению C-Ю $\left(\mathrm{L}_{5}\right)$ являются поперечными, а по направлению B-3 $\left(\mathrm{L}_{8}\right)$ продольными, то их отношение равно классическому значению коэффициента Пуассона $v=0.25$. Эта ситуация кинематически реализуема, если полагать, что систематическое сжатие со стороны субдуцирующей плиты приводит к естественному укорочению в широтном направлении (линия $\mathrm{L}_{8}$ ) и «удлинению» в меридиональном. В этом случае в условиях бокового стеснения «Пуассоновское» поперечное удлинение вызывает сокращение длины линии $\mathrm{L}_{5}$.

Важно подчеркнуть, что среднегодовые скорости горизонтальных смещений, полученные по спутниковым наблюдениям Камчатской сети KAMNET, имеют величины первых сантиметров в год, что на порядок больше, чем по данным наземных измерений.

Эти результаты аналогичны тем, что получены для Копетдагского сейсмоактивного региона, поскольку и в данном случае имеет место «парадокс малых скоростей» относительных горизонтальных деформаций, что подчеркивает квазистатический характер регионального нагружения. При этом локальные вертикальные смещения в зонах разломов имеют скорости относительных деформаций на два порядка больше, что указывает на наличие «парадокса больших скоростей» современных вертикальных движений. И вновь приходится отмечать, что большая длина светодальномер- 
ных линий не позволяет выявлять интенсивные локальные горизонтальные деформации в зонах разломов.

Вместе с тем, наличие монотонно развивающихся локальных просадок поверхности, которое происходит в условиях систематического регионального сжатия, является ярким примером отклонения наблюдаемых процессов от унаследованной схемы регионального нагружения. Кроме того, изменение регионального напряженно-деформированного состояния со среднегодовой скоростью, равной по уровню нескольким амплитудам приливных воздействий в зоне с аномально высокой сейсмотектонической активностью, является действительно парадоксальной ситуацией!

\section{3. КАЛИФОРНИЯ, РАЗЛОМ SAN ANDREAS}

Исследования проводились с целью изучения приразломных деформаций в зоне разлома San Andreas, в районе залива San Francisco (Северная Калифорния). Электронные дальномерные наблюдения (EDM), дополненные GPS-наблюдениями (в 1996-1997 гг.), проводились с 1975 по 1997 г. со средней частотой опроса 1 раз в 2-3 года на пунктах пяти малоапертурных геодезических сетей, расположенных вдоль разлома. Типичные расстояния между пунктами наблюдений составляли величины 2-3 км, редко 4-5 км. Точность измерений длин линий для типичных длин в 2 км составляла 3.0-4.5 мм в зависимости от типа геодезического инструмента. Столь высокая точность достигалась путем тщательного учета метеорологических возмущений и анализа устойчивости наблюдательных пунктов в различных системах отсчета. Для того чтобы анализировать деформационные процессы, обусловленные асейсмичным скольжением, из результатов исключались косейсмические смещения, вызванные землетрясением в Loma Prieta в 1989 г. [Chen, Freymueller, 2002].

На рис. 15 представлены наиболее типичные результаты, полученные по измерениям в геодезической сети Black Mountain-Radio Facility и конфигурация измерительной системы, где номерами отмечены линии, которые были представлены временными рядами. Как и ранее, сначала анализировались линии, которые не пересекают разлом или пересекают его ортогонально простиранию; затем изучались линии, пересекающие зону разлома. Длина линии $\mathrm{rf}_{1}-\mathrm{rf}_{2}$, которая расположена вне зоны разлома и отстоит от него на расстоянии около 3 км, изменяется со скоростью -0.4 мм/год (укорочение), но с ошибкой в \pm 0.3 мм/год. Среднегодовая скорость относительной деформации будет составлять примерно 9.1·10

Линия pawt - $\mathrm{rf}_{1}$, пересекающая разлом, однозначно отмечает трендовую составляющую движения (удлинение), что характерно для правостороннего сдвига по разлому. Среднегодовая скорость смещений достигает $1.3 \pm 0.2$ мм/год, а деформаций $-0.31 \cdot 10^{-7}$ в год.
Вдоль линии bmt $_{8}-$ bmt $_{9}$, которая ориентирована параллельно разлому и отстоит от него почти на 2 км, систематических движений не происходит. Среднегодовая скорость равна -0.1 мм/год \pm 0.1 мм/год. Скорость относительных деформаций составляет величину $6 \cdot 10^{-8}$ в год, что соизмеримо с величинами, полученными вдоль линии $\mathrm{rf}_{1}-\mathrm{rf}_{2}$, которая также расположена вне разлома, но на противоположном (западном) борту.

Интересно рассмотреть поведение горизонтальных смещений вдоль линии $\mathrm{bmt}_{10}-\mathrm{bmt}_{9}$, которая пересекает разломную зону почти ортогонально. Ориентация линии по отношению к разломной зоне такова, что при реализации правостороннего сдвигового смещения длина этой линии должна укорачиваться. Вместе с тем, как следует из рис. 15, происходит слабое, на уровне ошибок, удлинение линии со скоростью $0.2-0.3$ мм/год. Скорость относительных деформаций составляет $8 \cdot 10^{-8}$ в год.

И, наконец, линия $\mathrm{bmt}_{11}$ - pawt , которая пересекает разломную зону, показывает устойчивый тренд (укорочение), которое соответствует правостороннему сдвигу по разлому, со среднегодовой скоростью 1.0

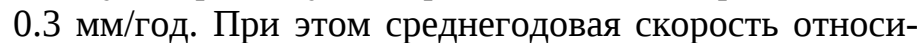
тельных деформаций равна $3 \cdot 10^{-7}$ в год.

Таким образом, становится очевидным, что и в Калифорнии отмечается резкая локализация деформаций в зоне разлома. При этом деформации в бортовых частях разломной зоны имеют скорости относительных горизонтальных деформаций на 1.0-1.5 порядка меньше, что аналогично данным, полученным в Копетдагском и Камчатском регионах.

Согласно модели NUVEL-1A [De Mets et al., 1994], Тихоокеанская плита движется со скоростью 45 мм/год по отношению к Североамериканской в районе Северной Калифорнии. Большая часть этого движения сосредоточена вдоль разлома San Andreas. Скорости скольжения разлома San Andreas хорошо известны также и из палеосейсмологических исследований. Рабочая группа Working Group on California Earthquake Probabilities (WGCEP99) приняла скорости скольжения в горах Santa Cruz и участке полуострова равными $17 \pm 2$ мм/год и $24 \pm 1.5$ мм/год на южном участке North Coast.

Авторы работы [Chen, Freymueller, 2002] определили скорости деформаций сдвига $\varepsilon_{12}-$ правостороннего сдвига поперек линии с севера на юг. Для этого использовались три линии различной ориентации. Была проведена трансформация тензора деформаций в локальную систему координат с осями параллельно и перпендикулярно разлому, поэтому скорость относительных деформаций сдвига непосредственно соответствует сдвигу параллельно разлому. В этой системе координат обосновано эмпирически, что $\varepsilon_{11}=\varepsilon_{22}=0$, то есть деформации «удлинения-укорочения», ориентированные вкрест и вдоль простирания разлома, равны нулю. 


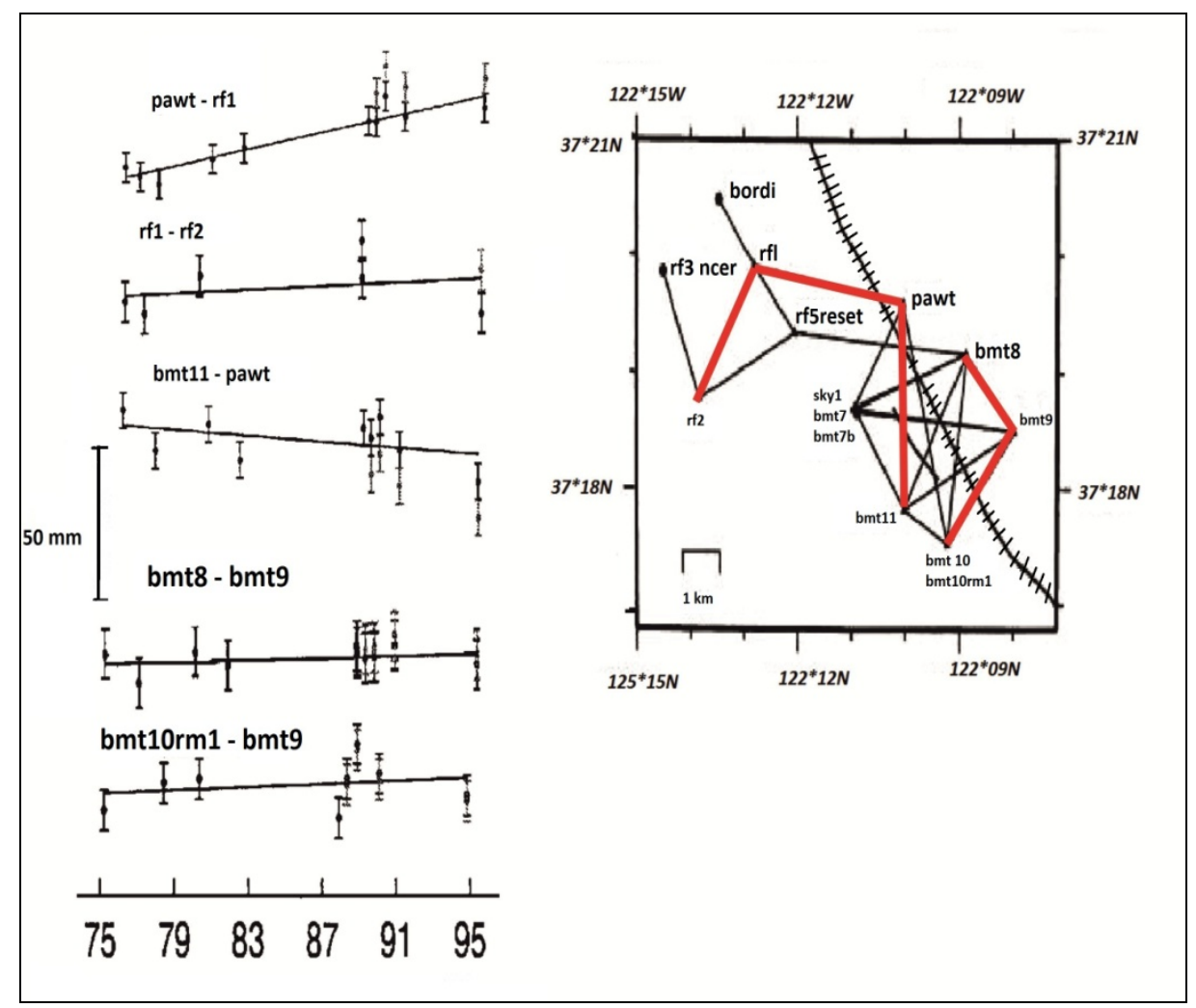

Рис. 15. Результаты длительных наблюдений за горизонтальными движениями в геодезической сети Black Mountain-Radio Facility (Северная Калифорния) [Chen, Freymueller, 2002].

Fig. 15. Results of long-term monitoring of horizontal displacements (Black Mountain-Radio Facility, Northern California) [Chen, Freymueller, 2002].

Однако оказалось, что практически вдоль всего разлома San Andreas в районе залива San Francisco скорость приразломных деформаций значительно выше, чем можно было бы ожидать на основе моделей однородного полупространства. Таким образом, представления о недеформируемых (жестких) бортах разлома оказались некорректными.

Вычисленный по результатам наблюдений тензор скорости относительных деформаций сдвига $\varepsilon_{12}=$ $=0.316 \pm 0.06 \cdot 10^{-6} /$ год в сети Black Mountain-Radio Facility оказался значительно выше, чем тот, который ожидали, используя однородную модель $\left(0.18 \cdot 10^{-6} /\right.$ год).

Наблюдаемые скорости деформаций в сетях Black Mountain-Radio Facility и Lake San Andreas могут быть, по мнению авторов, объяснимы только введением неоднородной модели с аномально деформируемой зоной (включением) с пониженной жесткостью материала разлома, если жесткость зоны разлома составляет 50-60 \% от окружающих пород. При этом наиболее реалистична ширина зоны разлома величиной 1 км и менее.

Обобщая приведенные результаты по исследованию длительных (20-50 лет) рядов геодезических наблюдений по трем различным сейсмоактивным регионам, можно отметить следующие общие свойства, ко- торые характеризуют «парадоксы больших и малых скоростей деформаций».

I. Аномальные деформационные процессы локализуются в узких зонах (1 км и менее) и протекают в обстановке квазистатического регионального напряженно-деформированного состояния, когда среднегодовая скорость относительных деформаций в зоне разлома превышает на 1-2 порядка деформации в блоке.

II. Среднегодовые региональные скорости относительных деформаций по данным многолетних геодезических (спутниковых и наземных) измерений составляют величины порядка 2-5 амплитуд земноприливных деформаций в год.

III. Пространственно-временные характеристики современных вертикальных и горизонтальных движений земной поверхности в зонах разломов, получаемые по данным длительных наблюдений, затруднительно объяснять с позиции только сдвиговых перемещений жестких блоков по разломам. Необходимо вводить представления о разломных зонах как о локальных областях (включениях) с пониженной жесткостью.

Для детального анализа и установления природы резкого усиления деформационных процессов в зонах разломов предпочтительнее использовать феномено- 
логический подход, т.е. оперировать наблюдаемыми величинами, поскольку именно этот подход используется в тех областях естествознания, в которых объект наблюдения (в данном случае зона разлома) не доступен прямому измерению в полном объеме.

C точки зрения феноменологического подхода, необходимо выделить объект наблюдения как некоторую систему, которая выходит из состояния равновесия под влиянием различного вида воздействий. Здесь используется именно термин «воздействие», как это принято в теории динамических систем.

Современное геодинамическое состояние недр многофакторное явление, обусловленное совокупностью природных и техногенных, эндогенных (глубинных) и экзогенных (поверхностных) воздействий, изменяющихся в пространстве и во времени.

Приведенные выше результаты высокоточных наблюдений были получены в регионах с повышенной сейсмотектонической активностью и, следовательно, с высоким уровнем эндогенных воздействий. Кроме того, прецизионные геодезические наблюдения сопровождались тщательной селекцией помех экзогенного и техногенного генезиса. Это позволяет рассматривать характеристики современных вертикальных и горизонтальных движений в зонах разломов как проявление тектонических процессов.

Эндогенные природные воздействия подразделяются по механизмам формирования на эволюционные, пульсационные и знакопеременные [Kuzmin, 1999]. Эволюционные эндогенные воздействия - это процессы, протекающие с постоянной скоростью и направленностью. В общем случае это эволюция всей Земли, как планеты. Пульсационные эндогенные воздействия - это процессы, которые протекают с переменной скоростью и постоянной направленностью. Это, например, горизонтальное перетекание вещества верхней мантии под корой с прерывистой скоростью, поднятие подошвы астеносферы с переменной скоростью и т.п. Знакопеременные эндогенные воздействия - это процессы, характеризующиеся как переменной скоростью, так и переменной направленностью. Среди них - химико-плотностная конвекция, тепловая конвекция в мантии с частичным плавлением астеносферного слоя, волны напряжений в верхних слоях астеносферы и т.п.

Длительность протекания этих процессов составляет интервал от $10^{9}$ до $10^{3}$ лет. Установлена четкая закономерность - уменьшение пространственно-временного масштаба процессов ведет к уменьшению глубины, размеров и длительности действия источника аномальных движений и наоборот [Kuzmin, 1999].

Отдельно следует упомянуть земноприливные лунно-солнечные деформации, которые имеют длительность от нескольких часов до нескольких недель, и весьма малые амплитуды относительных деформаций $-10^{-8}-10^{-9}$. Эти воздействия можно в равной степени отнести, как к экзогенным, так и к эндогенным воздействиям. Они являются экзогенными по местоположе- нию источника воздействия (Луна и Солнце) и эндогенными по механизму проявления.

Согласно традиционным представлениям, динамика разломов обусловлена силовым воздействием меняющегося во времени регионального поля тектонических напряжений (эндогенное воздействие), которое приводит к сдвиговым перемещениям смежных объемов (плит, блоков) среды, локализованных в пределах собственно разломных зон. В этом случае уровень и длительность приложенной нагрузки должны соответствовать уровню и длительности деформационной реакции среды. Естественно, что в случае упругой среды подобное соответствие полностью выполнимо. Однако считать среду только упругой справедливо не во всех случаях, тем более что исследуется степень унаследованности процессов от прошлых геологических периодов.

В этой связи представляется актуальным рассмотреть вопрос о соответствии амплитуды и длительности простейшего синусоидального воздействия на среду с типичной реологией тела Максвелла.

Пусть в упруговязкой среде Максвелла в момент времени $t_{0}=0$ начинает действовать источник периодических возмущений (напряжений):

$$
\sigma=\sigma_{0} \cdot \sin \omega t
$$

где $\sigma_{0}$ - амплитуда напряжений; $\omega$ - частота.

Среда Максвелла описывается уравнением:

$$
\dot{\varepsilon}=\frac{\dot{\sigma}}{\mathrm{E}}+\frac{\sigma}{\eta}
$$

где $\dot{\varepsilon}, \dot{\sigma}$ - скорость деформации и напряжений, соответственно.

Скорость изменения напряжений будет равна:

$$
\dot{\sigma}=\sigma_{0} \cdot \omega \cdot \cos \omega t
$$

Подставляя (3) и (1) в (2), получаем выражение:

$$
\dot{\varepsilon}=\frac{\sigma_{0}}{\mathrm{E}} \omega \cdot \cos \omega t+\frac{\sigma_{0}}{\eta} \cdot \sin \omega t
$$

Деформация $\varepsilon$ определяется интегрированием (4):

$$
\varepsilon=\int \dot{\varepsilon} d t=\frac{\sigma_{0}}{\mathrm{E}} \cdot \sin \omega t-\frac{\sigma_{0}}{\eta \cdot \omega} \cos \omega t+C
$$

Для определения $C$ используется естественное условие, что при $t=0 \quad \varepsilon=0$.

$$
\text { Тогда } C=\frac{\sigma_{0}}{\eta \omega} \text {. }
$$

В итоге, подставляя (6) в (5), проведя преобразова- 
ния и замечая, что $\tau=\frac{\eta}{\mathrm{E}}-$ время релаксации, а $\omega=\frac{2 \pi}{\mathrm{T}}$, (5) приводим к окончательному виду:

$$
\varepsilon=\frac{\sigma_{0}}{\mathrm{E}}\left(\sin \frac{2 \pi t}{\mathrm{~T}}-\frac{\mathrm{T}}{2 \pi \tau} \cdot \cos \frac{2 \pi}{\mathrm{T}}+\frac{\mathrm{T}}{2 \pi \tau}\right) .
$$

Анализ уравнения (7) показывает, что характер деформационного процесса существенным образом зависит от соотношения между периодом возмущений Т и временем релаксации $\tau$. Так, становится очевидным, что минимальное искажение синусоиды напряжений происходит тогда, когда время релаксации соизмеримо с периодом возмущений или превосходит его (в идеале на порядок и более).

Если использовать типичные реологические параметры земной коры и верхней мантии [Birger, 2012; Trubitsyn, 2012; Burov, 2007; Karato, 2008], то время релаксации определяется на уровне $10^{3}$ лет. Естественно, что в этом случае весь наблюдаемый спектр современных движений в зонах разломов, который заключен в интервале времени $10^{-1}-5 \cdot 10^{1}$ лет, невозможно описать с позиций прямого силового воздействия на вязкоупругую среду. Эти воздействия являются квазистатическими нагрузками по отношению к временным флуктуациям современных деформаций в разломах.

Таким образом, многочисленные эмпирические данные, включая приведенные выше, входят в «парадоксальное» противоречие с представлениями о степени соответствия приложенных воздействий и деформационных реакций среды в зонах разломов.

Для разрешения этих «парадоксов» и установления взаимосвязи региональных и локальных процессов в современной геодинамике были использованы методы наследственной механики деформируемых сред [Rabotnov, 1977]. Рассматривая, для феноменологической иллюстрации, одномерное уравнение развития деформации во времени, можно записать:

$$
\varepsilon(t)=\frac{\sigma(t)}{\mathrm{E}(t)}+\int_{0}^{t} \mathrm{~K}(t-\Theta) \cdot \sigma(\Theta) d \Theta
$$

где $\sigma(t)$ и $E(t)$ - приложенное напряжение и модуль Юнга соответственно, $(t-\Theta)$ - история нагружения, $\mathrm{K}$ - интегральное ядро Вольтерра, характеризующее функцию памяти (унаследованности) процесса. В уравнении (8) полагается, что рассматриваемая среда обладает зависящими от времени жесткостными характеристиками. Справедливо полагая, что установившееся вязкое течение (установившаяся ползучесть) является полностью унаследованным процессом, можно уравнение (8) переписать в следующем виде:

$$
\varepsilon(t)=\frac{\sigma(t)}{\mathrm{E}(t)}+\int_{0}^{t} \mathrm{~K}(\sigma) \cdot \sigma(\Theta) d \Theta
$$

Дифференцируя (9) по времени, получаем:

$$
\dot{\varepsilon}=\frac{\dot{\sigma}}{\mathrm{E}}-\frac{\sigma}{\mathrm{E}^{2}} \cdot \dot{\mathrm{E}}+\mathrm{K}(\sigma) \cdot \sigma
$$

Так как в случае установившегося течения: $K(\sigma)=\frac{1}{\eta}$, то (10) будет иметь вид:

$$
\dot{\varepsilon}=\frac{\dot{\sigma}}{\mathrm{E}}-\frac{\sigma}{\mathrm{E}^{2}} \cdot \dot{\mathrm{E}}+\frac{\sigma}{\eta}
$$

Уравнение (11) является аналогом уравнения Максвелла для вязкоупругой среды, но с нестабильными во времени жесткостными характеристиками, так как модуль упругости (модуль Юнга) в физическом смысле является коэффициентом «сопротивляемости» (жесткости) среды приложенным нагрузкам. В случае неизменности во времени жесткостных свойств второе слагаемое стремится к нулю и (11) переходит в уравнение Максвелла (2).

Следует отметить, что структура многих базовых законов физики (закон Гука, Закон Ома, Закон Ньютона для скорости деформации вязкой среды и др.) представлена дробью, где в числителе обозначено воздействие на объект, а параметр сопротивления (в обобщенном смысле) расположен всегда в знаменателе. Как правило, варьирование во времени происходит в числителе, а знаменатель предполагается пассивным элементом. Однако можно показать, что в случае «переменных знаменателей» необходимо проведение сравнительного анализа вклада каждой из составляющих дроби [Kuzmin, 2013].

Пульсационный и знакопеременный характер выявленных движений, «парадоксальное» отклонение от унаследованной схемы развития позволяют пренебречь третьим слагаемым в (11), поскольку именно это слагаемое описывает состояние унаследованного движения от прошлых геологических эпох. В этом случае уравнение (11) трансформируется в

$$
\dot{\varepsilon}=\frac{\dot{\sigma}}{\mathrm{E}}-\frac{\sigma}{\mathrm{E}^{2}} \cdot \dot{\mathrm{E}}
$$

Если первое слагаемое очевидно и означает прямое силовое воздействие на разломную зону, то второе слагаемое, обеспечивающее возникновение аномальных деформаций за счет переменной во времени жесткости среды, менее очевидно и требует разъяснений.

Из теории колебаний хорошо известно, что любую систему можно вывести из состояния равновесия (возбудить систему) двояким образом: либо посредством внешнего силового воздействия на систему в целом, либо путем возмущений внутренних параметров системы, предварительно нагруженной извне. Такой тип вывода системы из состояния равновесия назван в 
физике параметрическим возбуждением.

Наиболее часто приводимый пример параметрического возбуждения процессов - это человек, который, приседая и вставая на качелях, может раскачать сам себя, без вмешательства внешней, вынуждающей силы. В этом случае предварительно нагруженная система-маятник «человек-качели» изменяет свой параметр (длину маятника как расстояние от точки подвеса до центра тяжести), что приводит к выводу ее из состояния равновесия. Принципиально важно, что возбуждающие силы действуют не в направлении совершающихся колебаний, а в перпендикулярном направлении. Очевидно, что эти силы не могут непосредственно совершать работу над колебательной системой. Работа совершается силой веса человека и вкладывается в систему посредством изменения ее параметра.

Возвращаясь к проблемам современной геодинамики разломов, можно утверждать, что аномальные деформационные процессы в зонах разломов, которые происходят в обстановке региональных квазистатических полей напряжений, обусловлены флуктуациями внутренних параметров среды внутри самих разломных зон, что является примером параметрического возбуждения.

Энергетика возникновения этих процессов представляется следующим образом. Существующие в геологической среде длительное время региональные, квазистатические силы (напряжения) тектонического и гравитационного генезиса производят работу на локальных перемещениях (деформациях), которые вызваны изменениями во времени жесткостных характеристик в локализованных фрагментах разломов, обусловленными малыми, индуцированными воздействиями на внутренние параметры среды разломных зон. Именно поэтому эти деформации были названы параметрическими [Kuzтin, 1989].

В этом смысле современные суперинтенсивные деформации разломных зон - это параметрически индуцированные тектонические деформации геологической среды [Kuzmin, 1996, 1999, 2004].

Из вышеизложенного следует, что существуют два варианта формирования локальных деформационных аномалий в зонах разломов (рис. 16):

- вариант I - зона разлома представляет собой ослабленный участок среды, вдоль которого происходят движения блоков, напрямую обусловленные вариациями во времени поля напряжений;

- вариант II - реализуется механизм параметрического возбуждения аномальных деформаций в зоне разлома. В этом случае региональное поле напряжений квазистационарно, а разломная зона представляет собой параметрически возбудимую (малыми воздействиями) активную среду.

Оценить вклад каждого из вариантов в процессе современной геодинамической активизации разломов можно на примере формирования $\gamma$-аномалии (ло- кальной просадки земной поверхности в зоне разлома). Согласно первому варианту $\gamma$-аномалия возникает за счет приращения во времени регионального поля напряжений (например, раздвиг блоков фундамента и проседание весомой толщи вышележащих пород) [Grigoriev et al., 1987]. Во втором варианте региональное напряжение (внешнее по отношению к разлому) остается неизменным во времени и проседание весомой толщи происходит за счет уменьшения жесткостных характеристик внутри разломной зоны [Kuzmin, 1989].

На рис. 17 показана схема формализации граничных условий при формировании локальных просадок в зонах разломов (аномалий $\mathrm{\gamma}$-типа). Как видно из приведенной схемы, $S_{1}=S_{1}^{\prime}+S_{0} ; S_{2}=S_{2}^{\prime}+S_{0}$. Так как поверхность $S_{0}$, на которой выявлена аномалия, входит и в $S_{1}$ и в $S_{2}$, это означает, что кинематически равновероятны оба варианта схемы деформирования.

Для оценки вклада каждого из механизмов в образование наблюденных аномалий необходимо определить среднегодовую скорость деформирования в (13) на временном интервале, типичном для повторных нивелирований (порядка одного года). Если положить, что скорости вариации параметров меняются по гармоническому закону, то:

$$
\begin{aligned}
& \dot{\sigma}=\dot{\sigma}_{0} \cdot \cos 2 \pi t / \mathrm{T}_{1}, \\
& \dot{\mathrm{E}}=\dot{\mathrm{E}}_{0} \cdot \cos 2 \pi t / \mathrm{T}_{2},
\end{aligned}
$$

где $\mathrm{T}_{1}$ и $\mathrm{T}_{2}$ - периоды изменения внешних (региональное поле напряжений) и внутренних параметров (жесткость разломной зоны) среды соответственно.

Известно, что региональные поля напряжений меняются весьма медленно $\left(\mathrm{T}_{1} \geq 10^{3}-10^{5}\right.$ лет), а жесткостные параметры разломных зон меняются гораздо быстрее. Судя по временным вариациям параметров земноприливных деформаций, сейсмоскоростным аномалиям в процессе подготовки землетрясений и т.д., $\mathrm{T}_{2}$ находится в интервале $10^{-1}-10^{1}$ лет. Тогда, подставляя (13) и (14) в (12) и находя среднегодовую скорость в интервале $0-\mathrm{T}_{2} / 4\left(\mathrm{~T}_{2}=4\right.$ годa $)$, получаем

$$
\overline{\dot{\varepsilon}}=\frac{4 \dot{\sigma}_{0}}{\mathrm{~T}_{2} \mathrm{E}} \int_{0}^{\mathrm{T}_{2} / 4} \cos 2 \pi t / \mathrm{T}_{1} d t-\frac{4 \sigma \dot{\mathrm{E}}_{0}}{\mathrm{~T}_{2} \mathrm{E}^{2}} \int_{0}^{\mathrm{T}_{2} / 4} \cos 2 \pi t / \mathrm{T}_{2} d t .
$$

Подставляя типичные значения $\dot{\sigma}=10^{-2} \mathrm{M} а$ a $/$ год; $\dot{\mathrm{E}} / \mathrm{E}=0.01 /$ год $; \quad \sigma=\sigma_{0}=100 \mathrm{M} \Pi a ; \quad \mathrm{E}_{0}=10^{4} \mathrm{M} \Pi a ;$ $\mathrm{T}_{1} / \mathrm{T}_{2}=10^{4}$ и проведя интегрирование, видим, что наблюдаемую скорость аномальных деформаций $10^{-5}$ в год обеспечивает второе слагаемое в (12), в то время как первое слагаемое оказывается на два порядка меньшим. Если же процедуру осреднения проводить 


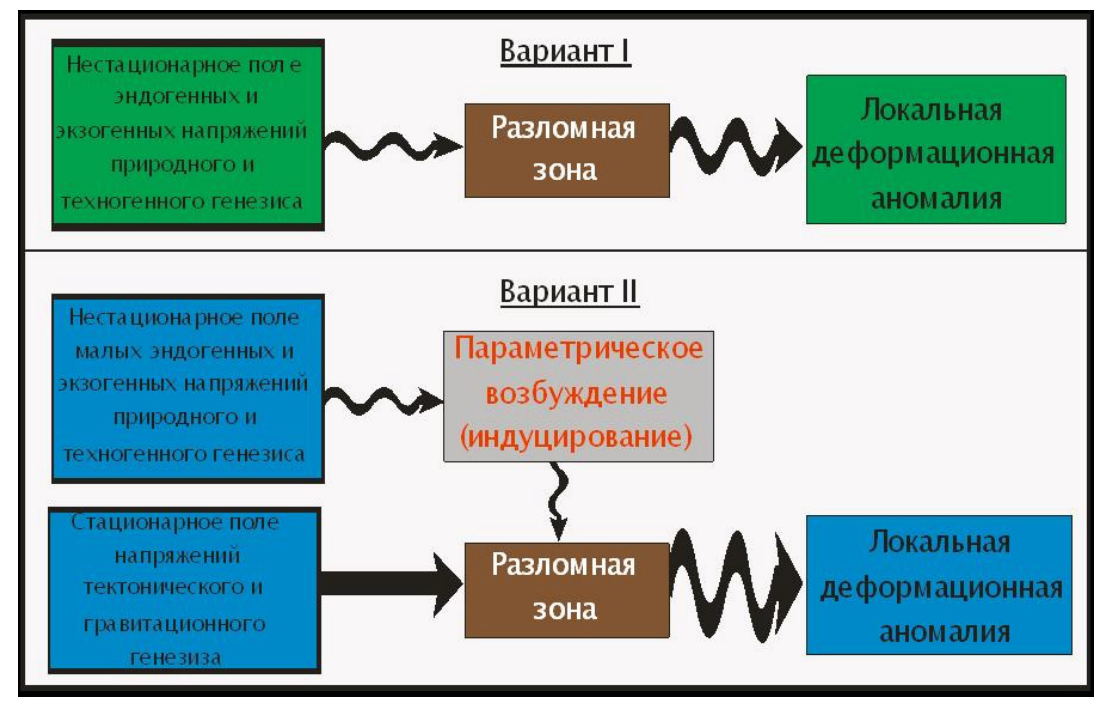

Рис. 16. Схема формирования аномальных деформационных процессов в зонах разломов.

Fig. 16. A scheme of anomalous deformation processes in fault zones.

на интервале времени $0-\mathrm{T}_{1} / 4 \quad\left(\mathrm{~T}_{1}=4 \cdot 10^{3}\right.$ лет $)$, что соответствует геолого-геоморфологическим методам определения скоростей движений земной коры, то в этом случае вклад первого слагаемого в (12) окажется на два порядка большим, чем второго.

Таким образом, формирование СД-процессов в зонах разломов обеспечивает вариант II формирования локальных деформационных аномалий (см. рис. 16). Механизм прямого формирования локальных смещений поверхности осадочного чехла раздвигом блоков фундамента, описанный в [Grigoriev et al., 1987], не применим для трактовки современных геодинамических процессов.

Вариант I представляет собой типичный линейный усилитель деформаций, когда внешние воздействия усиливаются за счет пониженной жесткости разломной зоны, как это следует из первого слагаемого уравнения (13). Это должно означать, что жесткостные характеристики разломной зоны должны быть на 2-3 порядка меньше, чем в бортовой зоне. Но тогда, например, приливные деформации в зонах разломов должны достигать величин $10^{-5}-10^{6}$. Подобные величины никогда не выявлялись по многочисленным и многолетним инструментальным наблюдениям земноприливных наклонов и деформаций.

Вариант II характеризует ситуацию, когда разломная зона представляет собой нелинейный параметрический усилитель деформаций.

В этой связи можно полагать, что локальные деформационные процессы, регистрируемые многократными детальными геодезическими наблюдениями в зонах разломов, обусловлены в основном «внутренними» источниками (параметрическими деформациями), а региональные процессы обеспечивают квазистатический фон приложенных напряжений, характер которых определяет конкрет- ную морфологию аномалий.

Кроме того, очень важно отметить, что для возникновения наблюдаемых величин аномальных деформаций $\left(5 \cdot 10^{-5} /\right.$ год $-5 \cdot 10^{-6} /$ год) достаточно создать условия для изменения во времени всего на несколько первых процентов жесткостных характеристик в локальных фрагментах изначально напряженных разломных зон.

Изложенные выше представления о параметрической природе аномально высокой активности разломных зон позволяют предложить решение «парадоксов» больших и малых скоростей современных движений земной поверхности. Если вновь рассмотреть уравнение Максвелла, обобщенное на случай нестабильности во времени жесткостных параметров среды (формула 11), то оказывается, что использование первого слагаемого позволяет разрешить «парадокс» больших скоростей в рамках схемы внешнего силового воздействия астеносферного слоя, предложенного В.А. Магницким [Magnitsky, Kalashnikova, 1978].

Однако в рамках этого подхода не удается разрешить «парадокс» малых скоростей, так как малым внешним силовым воздействиям соответствуют и малые деформационные реакции среды. В то же время выше было показано, что имеют место деформационные аномалии с высокой скоростью деформирования в зонах разломов при низких скоростях внешнего, по отношению к разломной зоне, нагружения.

Использование второго слагаемого, которое характеризует так называемое «параметрическое» возбуждение процессов, позволяет достаточно адекватно разрешать оба «парадокса» скоростей в современной геодинамике. Действительно, вариации во времени внутренних параметров среды в обстановке внешнего квазистатического нагружения обеспечивают наличие 


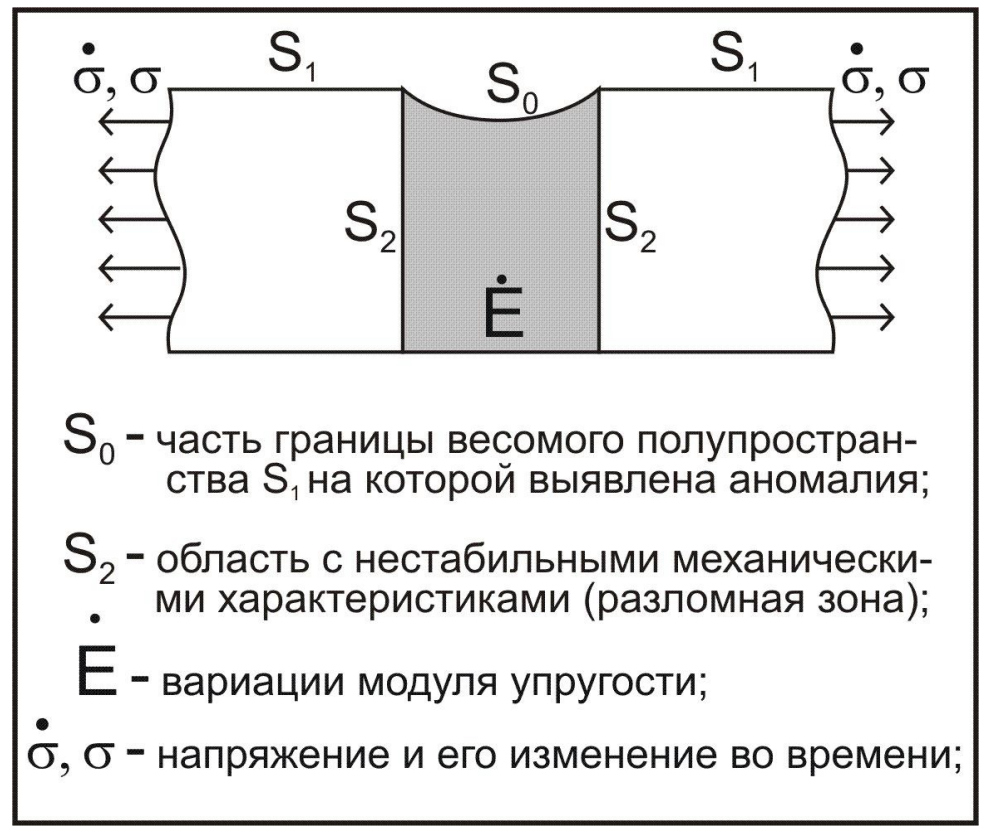

Рис. 17. Граничные условия при возникновении ү-аномалии.

Fig. 17. Boundary conditions in case of a $\gamma$-anomaly.

высокоинтенсивных деформаций в зонах разломов («парадокс» больших скоростей) и малую интенсивность региональных деформаций («парадокс» малых скоростей).

Исключительно важным аргументом в пользу использования «параметрической» идеологии при разрешении обоих «парадоксов» является анализ энергетики деформационных процессов. Как следует из основ физики деформируемых сред с дефектами, процесс нагружения деформируемой среды может быть осуществлен двумя путями: «мягким» и «жестким». В случае «мягкого» нагружения деформационные процессы развиваются в обстановке фиксированных квазистатических нагрузок. При реализации «жесткой» схемы фиксированными являются смещения (деформации). В опытах с образцами горных пород первая схема соответствует так называемым испытаниям на ползучесть. В рамках «жесткой» схемы реализуется заданная программа фиксированных (монотонных) смещений нагружающих элементов пресса.

Можно легко показать, что накопление энергии и концентрация напряженно-деформированного состояния в случае «мягкой» схемы нагружения происходит в пределах «мягких» включений - областей пониженных жесткостных параметров среды. В случае «жесткой» схемы накопление энергии происходит в пределах «жестких» включений - областей повышенной жесткости среды.

Зачастую многие исследователи используют термин «разуплотнение», характеризуя увеличение степени трещиноватости среды, так как во многих случаях бо- лее плотные породы имеют большую жесткость (прочность) и наоборот. Однако плотность гранита составляет величину $\rho=2.9 \cdot 10^{3} \mathrm{\kappa} / \mathrm{M}^{3}$, а, например, ртути $\rho=13.6 \cdot 10^{3}$ кг $/ \mathrm{M}^{3}$. Термины «плотность» и «жесткость» не являются идентичными понятиями. Более того, эти два понятия иногда выступают в качестве принципиальных антиподов.

Так, например, в формуле такого традиционного геодинамического параметра, как скорость сейсмических волн, жесткость среды (K) расположена в числителе, а плотность ( $\rho)$ в знаменателе $(\mathrm{V}=\sqrt{ } \mathrm{K} / \rho)$. Увеличение жесткости среды («ужесточение») приводит к увеличению скорости сейсмических волн, а уплотнение, соответственно, к уменьшению. Это находится в полном соответствии с принятой в акустике (сейсмические волны - это «земной звук») феноменологической моделью, согласно которой среда представлена набором материальных шаров плотностью $\rho$ и упругими пружинами жесткостью К. Естественно, что более жесткие пружины лучше передают колебания, а более тяжелые шары затрудняют эту передачу.

Может показаться, что подобная ситуация противоречит экспериментальным данным. Так, надежно установлено, что с глубиной увеличивается и скорость сейсмических волн, и плотность среды. Согласно же приведенной формуле, при увеличении плотности скорость должна падать. Но это справедливо, если считать, что жесткость среды не меняется с глубиной.

В действительности же, и жесткость среды, и ее плотность увеличиваются с глубиной, но увеличение жесткости с глубиной оказывается существенно боль- 
шим, чем плотности. Таким образом, жесткость среды является более тензочувствительным параметром, чем плотность, для величины скорости сейсмической волны. Именно поэтому для описания процессов трещинообразования более уместно использование термина «разупрочнение» («размягчение»). К сожалению, в сейсморазведке при построении сейсмических разрезов учитывается только плотность, точнее линейная корреляционная зависимость скорости от плотности, что существенно снижает возможности тектонофизической интерпретации сейсморазведочных данных.

Если в рамках феноменологического подхода в качестве базового энергетического параметра выбрать удельную объемную потенциальную энергию деформирования, то она может быть выражена в двух формах, учитывающих параметры жесткости, напряжений и деформаций. В первом случае используются параметры жесткости и напряжения:

$$
e=\frac{\sigma^{2}}{2 \cdot \mathrm{E}},
$$

во втором случае - жесткости и деформации:

$$
e=\frac{1}{2} \mathrm{E} \cdot \varepsilon^{2} .
$$

Если, как и прежде, считать, что $\sigma=\sigma(t), \varepsilon=\varepsilon(t)$, $E=E(t)$, то варьируя величину удельной энергии во времени, можно оценить знак ее изменения (накопление или уменьшение) в зависимости от знака изменений параметров жесткости («ужесточение» или «размягчение») для «мягкого» и «жесткого» способов нагружения, соответственно.

В случае «мягкого» нагружения - $\sigma=$ const,$\delta \sigma=0$ и изменение энергии будет

$$
\delta e=-\frac{\sigma^{2}}{2 \cdot \mathrm{E}} \cdot \alpha
$$

Для «жесткого» нагружения $-\varepsilon=$ const,$\delta \varepsilon=0$ и

$$
\delta e=\frac{1}{2} \mathrm{E} \cdot \varepsilon^{2} \cdot \alpha
$$

где $\alpha=\frac{\delta E}{E}-$ относительное изменение жесткости среды.

Отсюда следует, что в случае $\alpha<0$ (размягчение) энергия накапливается ( $\delta \mathrm{e}>0)$ при мягкой схеме нагружения, а в случае $\alpha>0$ (ужесточение) энергия накапливается $(\delta \mathrm{e}>0)$ при «жесткой» схеме нагружения. Таким образом, в случае малых скоростей регионального деформирования («мягкая» схема нагружения) аномальное напряженно-деформированное состояние будет фиксироваться в пределах «мягких» включений, т.е. в зонах разломов различного типа и порядка.

\section{5. АВТОВОЛНОВЫЕ ДЕФОРМАЦИОННЫЕ ПРОЦЕССЫ В ЗОНАХ РАЗЛОМОВ}

Исследование пространственно-временной миграции современных геодинамических процессов является, с одной стороны, одной из наиболее интересных проблем геодинамики, с другой - одной из наиболее дискуссионных проблем.

В фундаментальном обзоре В.Г. Быкова [Bykov, $2005 a, 2005 b]$ дана сводная информация о волновых процессах в земной коре и механизмах их формирования. В обзоре обобщена почти полувековая история исследований в этом направлении, начиная с классической работы Эльзассера [Elsasser, 1969].

Так, работами В.Н. Николаевского с соавторами [Nikolaevsky, 1983, 1995; Malamud, Nikolaevsky, 1989; Mitlin, Nikolaevsky, 1990] заложены теоретические основы объяснения тектонических волн на основе представлений о том, что система «литосферная плита + астеносферное течение» является автоволновой в широком смысле. Показано, что существуют уединенные тектонические волны, которые обеспечивают миграцию сейсмической активности вдоль зон разломов.

Также на представлениях об автоволнах основывается ряд работ В.Г. Быкова [Bykov, 2004, 2005a, 2005b, 2008]. В частности, обосновывается возможность рассматривать активные разломы как автоволновую систему, а автоволновой механизм, который может привести к циклическим повторениям сейсмических подвижек в разломе, предлагается рассматривать как один из возможных механизмов миграции тектонических напряжений в Земле.

Эти работы подчеркивают свойства нелинейности и неустойчивости в характере протекания современных геодинамических процессов. Это обстоятельство позволяет привлекать для их описания методы самоорганизации открытых физико-механических систем.

Однако в последнее время обострилась дискуссия [Antonov, Kondratiev, 2008; Nikolaevsky, 2008] по вопросу о существовании тектонических волн. Более того, в работе [Mukhamediev et al., 2008] поставлено под сомнение само существование термина «волна» применительно к пространственно-временной миграции процессов со скоростями в диапазоне 1-100 км/год.

Кроме того, все предложенные модели и эмпирические факты относятся в основном к сейсмическим процессам, мигрирующим исключительно вдоль зон разломов.

Учитывая, что существуют экспериментально выявленные деформационные волны [Kuzmin, 1989; Kuz'$\min , 2012]$, которые распространяются от разлома к разлому и которые с самого начала трактовались как отражение автоволновых процессов, автор счел необходимым еще раз изложить представления о существовании деформационных автоволн в разломных зонах и механизме их формирования. При этом особое внимание уделяется формулировке феноменологической 
модели процессов, базирующейся исключительно на наблюдаемых параметрах.

В упомянутых работах автора надежно установлено наличие пространственно-временной миграции деформационных процессов в зонах разломов. При этом создается впечатление, что по пространству распространяется волна возбуждения аномальных деформационных процессов, причем в качестве возбудимых элементов выступают зоны разломов. Скорости распространения деформационных волн заключены в диапазоне от первых километров до десятков километров в год в зависимости от характера распространения этих волн.

Основное различие в характере распространения этих зон заключается в том, что в случае передачи деформационного возбуждения от разлома к разлому («межразломная» волна) значение скорости заключено в интервале от 20 до 30 км/год и более. Если же возбуждение процессов протекает в пределах одной разломной зоны («внутриразломная» волна), то скорость меняется от 10 до 4 км/год и менее. Наблюдаемые процессы носят характер «эстафетной передачи» аномальной активности от одного геодинамически активизированного объекта к другому.

Резюмируя эти результаты, можно полагать, что пространственно-временная миграция аномалий современных движений земной поверхности в зонах разломов - следствие автоволновых деформационных процессов в геодинамически активной, возбудимой геологической среде, являющейся открытой системой.

Действительно, изолированные на первый взгляд разломные зоны имеют возможность обмениваться как энергией (за счет взаимодействия аномальных локальных полей напряжений и деформаций), так и веществом (за счет флюидодинамических процессов, присущих разломным зонам), что и формирует автоволны деформаций.

Иными словами, в условиях постоянной энергетической подпитки со стороны региональных и глобальных геодинамических процессов обеспечивается существование автоволновых пространственно-временных структур, выражающихся в эффектах триггерного взаимодействия и перезапуска активности смежных деформационно возбудимых зон разломов и их фрагментов.

Тот факт, что СД-аномалии являются результатом параметрического индуцирования, позволяет считать их существенно нелинейными процессами. Как известно, самое общее определение нелинейных систем - это отсутствие выполнения принципа линейной суперпозиции. Этот принцип заключается в том, что суммарный, результирующий эффект от нескольких независимых воздействий равен сумме эффектов, вызываемых каждым воздействием в отдельности. В случае возникновения СД процессов имеет место явная нелинейность, когда малые воздействия приводят к аномально большим откликам среды (до 2-3 порядков) на эти воздействия.

В нелинейных, неустойчивых системах принципиальным образом меняются представления о характере причинно-следственных связей. В устойчивых системах меры причин и следствий всегда одного порядка. В неустойчивых, существенно нелинейных системах малые, по уровню, причины могут привести к большим последствиям. В этих системах причиной явлений следует считать саму неустойчивость.

Для построения феноменологической модели формирования автоволновых деформационных процессов в зонах разломов следует представить среду в виде набора элементов - разломных зон, способных к параметрическому возбуждению малыми воздействиями.

Подобные процессы хорошо изучены в теории возбудимых сред. Отдельный элемент возбудимой среды может находиться в одном из трех принципиально различных состояний - покоя, возбуждения и рефрактерности. В отсутствие внешних воздействий сохраняется состояние покоя. Путем внешнего воздействия элемент переходит в возбужденное (аномальное) состояние. Достигнув максимума активности, элемент переходит в состояние рефрактерности, в котором он является невозбудимым. Затем процесс повторяется.

При параметрическом возбуждении разломной зоны в ее окрестности формируется зона аномального, локального напряженно-деформированного состояния, которое изменяется во времени по мере роста аномальных смещений на разломе.

В качестве базовой характеристики модели вводится радиус деформационной активности разлома $R$.

В данном случае этот радиус будет определяться размерами области, которая формируется при возбуждении, и «периодом жизни» аномального процесса, который зависит от интервала временем $t_{a}$ между началом возбуждения разломной зоны и моментом, когда процесс достигает максимального развития. Естественно, что величина $\mathrm{R}$ определяется исключительно наблюдаемыми параметрами $l$ и $t_{a}$ в полном соответствии с требованиями, предъявляемыми к феноменологическим моделям.

Пусть в промежутке между началом и завершением аномального протекания процесса на одном из разломов поле смещений может распространяться, захватывая все большую часть земной поверхности, на некоторое расстояние $l$.

Тогда, если $P(l) d l$ - вероятность перемещения на расстояние, лежащее между $l$ и $l+d l$ за единицу времени, измеряемого в периодах активизации разломной зоны $t_{a}$, то:

$$
R=\sqrt{\frac{l^{2}}{t_{a}}} \text {, где } l=\int_{0}^{\infty} l^{2} P(l) d l .
$$


То есть радиус индивидуальной деформационной активности разлома есть среднеквадратическое перемещение фронта смещений за период активизации $t_{a}$.

Пусть далее динамика роста аномального смещения в зоне разлома локально описывается уравнением:

$$
\frac{d U}{d t}=\widetilde{F}(u, x)
$$

По сути (22) есть локальный закон роста смещений в окрестности разломной зоны, характеризующий интенсивность деформационного процесса.

Тогда в одномерном случае приращение смещения за время $\delta t$ в некоторой точке $(x)$ за счет локального роста на разломе и миграции по пространству будет равно:

$$
\Delta U(x, t)=\left\{\int_{-\infty}^{+\infty} U\left(x^{\prime}, t\right) \cdot P(l) d x^{\prime}-U(x, t)+F(u, x)\right\} \delta t,
$$

где $l=\sqrt{\left(x^{\prime}-x\right)^{2}}$.

Разлагая $U\left(x^{\prime}, t\right)$ в ряд Тейлора в окрестности точки $(x)$ и предполагая, как это принято в статистической физике (см. например [Frenkel, 1948]), что кубическим слагаемым разложения можно пренебречь, в итоге получаем следующее уравнение:

$$
\frac{\partial U}{\partial t}=D \frac{\partial^{2} U}{\partial x^{2}}+F(U, x)
$$

Уравнение (24) легко обобщать на случай двух и более переменных.

Для решения уравнения (24) необходимо задать функцию локального роста аномальных смещений на разломе.

На рис. 12 показана эволюция вертикальных смещений земной поверхности во времени. Видно, что аномальные изменения современных вертикальных смещений земной поверхности в разломной зоне превосходят на 1.5-2.0 порядка изменения в блоковой части. При этом аномальный цикл активизации разломной зоны состоит из фазы возбуждения, фазы покоя и фазы рефрактерности. Всего выявлено три аномальных периода. У них различается амплитуда, а длительность у II и III аномалии практически совпадает. Примечательно, что у I аномалии и длительность, и амплитуда значительно меньше, чем у двух других. Эта аномалия характерна тем, что, завершив цикл активизации, амплитуда смещения практически вернулась на прежний уровень, а у II и III аномалии этого не происходит. Важно отметить, что в блоковой части нивелирного профиля никаких существенных аномалий в движениях не обнаруживается, что лишний раз подчеркивает автономный характер аномальной деформационной активности разломных зон.
Как показывает практика обработки большого массива нивелирных данных и анализа временной структуры аномальных деформационных процессов в разломных зонах, типовая кривая временного хода смещений аналогична закономерностям, отмеченным на рис. 6. Такой характер поведения кривых соответствует хорошо изученным процессам и средам с насыщением. Как правило, они описываются гиперболическими кривыми (например, гиперболическим тангенсом в теории намагничения ферромагнетиков) [Frenkel, 1948].

Так, например, кривая смещений земной поверхности в подавляющем большинстве случаев хорошо описывается широкоизвестной логистической функцией:

$$
U(U, t)=\frac{U_{\max } \cdot U_{0} e^{t / t_{a}}}{U_{\max }+U_{0}\left(e^{t / t_{0}}-1\right)},
$$

где $U_{\max }$ - максимальная амплитуда смещений земной поверхности в зоне разлома, достигнутая за период $t_{a}$ существования аномального процесса деформирования. $U_{0}$ - величина смещения в начальный период зарождения аномалии. В этом случае закон локального роста смещений поверхности в разломной зоне будет иметь вид:

$$
F(U)=\frac{d U}{d t}=\frac{U}{t_{a}}\left(1-\frac{U}{U_{\max }}\right) .
$$

Уравнение (24) относится к квазилинейным уравнениям параболического типа. Они впервые были получены в известной работе [Kolmogorov et al., 1937] и касались анализа распространения популяций в биологии.

Классический результат А.Н. Колмогорова, И.Г. Петровского и Н.С. Пискунова состоит в том, что решение уравнения (24) в случае, когда закон локального роста соответствует логистическому уравнению (25), указывает на существование бегущих волн $U(x+V t)$, причем для достаточно больших $t \quad V \rightarrow V_{0}=2 \sqrt{D F^{\prime}(0)}$ снизу.

Так как в уравнении (26) $F^{\prime}(0)=\frac{1}{t_{a}}$, для оценки скорости распространения деформационных автоволн получим:

$$
V_{0}=2 \sqrt{D / t_{a}}=2 \sqrt{R^{2} / 2 t_{a}} .
$$

С учетом (21) из (27) получается окончательная формула для оценки скорости, записанная в наблюдаемых величинах:

$$
V_{0}=2 \sqrt{\frac{l^{2}}{2 \cdot t^{2}{ }_{a}}}=\sqrt{2} \frac{l}{t_{a}} .
$$


В формуле (28) $l$ - это расстояние между разломными зонами, в которых наблюдаются аномальные деформации земной поверхности, или расстояние между активизированными фрагментами внутри разломных зон, а $t_{a}-$ длительность развития аномального процесса. Так как значение $l$ варьируется в пределах от 3-4 км до 20-30 км, длительность развития аномалий изменяется от 0.5 года до 2 лет, скорости автоволновых деформаций, рассчитанные по формуле (28), меняются в диапазоне от 4 до 60 км в год, что согласуется с фиксируемыми значениями.

Предложенная модель позволяет объяснить характерные различия в величинах скоростей «межразломных» и «приразломных волн». Анализ площадного распределения аномалий для Припятской впадины (см. рис. 7) показывает, что расстояния между разломными зонами и активизированными фрагментами внутри этих зон существенно отличаются. Если ввести в рассмотрение расстояние между активизированными разломами $l_{1}$ и расстояние между активизированными фрагментами в пределах одной разломной зоны $l_{2}$, то из рис. 1 видно, что отношение между ними будет приблизительно соответствовать $l_{1} / l_{2} \cong 2-3$.

С учетом, что $R=\frac{l}{\sqrt{t_{a}}}$, в этом случае за одно и то же время формирования аномалии $t_{0}$ скорость диффузии смещений между разломами будет в 2-3 раза больше, чем между фрагментами внутри разломной зоны. Результатом этого будет различие между скоростями «межразломной» и «внутриразломной» волн.

Кроме того, предложенная феноменологическая модель может быть использована и для анализа пространственно-временной миграции землетрясений. В этом случае $l$ будет представлять собой линейный размер области подготовки землетрясения, а $t_{a}$ - длительность процесса подготовки.

Так, например, в работах [Dobrovol'sky, 2009; Kuzmin, 1998] приведены количественные оценки этих параметров в зависимости от энергии готовящегося землетрясения. В этом случае можно выявленные пространственно-временные связи между землетрясениями дополнительно проверять на достоверность путем оценки размеров области и времени подготовки, а затем вводить в рассмотрение радиус сейсмической активности разломной зоны или ее активизированных фрагментов.

Детальный анализ уравнения (24) приводит к очень интересным следствиям, которые напрямую связаны с проблемой идентификации волновых процессов по результатам полевых наблюдений.

Пусть в уравнении (24) коэффициент диффузии $D=0$, т.е. имеются разломные зоны, которые имеют локальные аномалии смещений, но их радиусы деформационной активности столь незначительны, что эти зоны никак не связаны друг с другом. У них отсутствует взаимодействие. Тогда вместо (24) получаем уравнение:

$$
\partial U / \partial t=F(U)
$$

Или, переходя к волновой переменной $\xi=x+V t$,

$$
V d U / d \xi=F(U)
$$

Если повторить для наглядности логистическое уравнение (26):

$$
F(U)=\frac{d U}{d t}=\frac{U}{t_{a}}\left(1-\frac{U}{U_{\max }}\right)
$$

то, интегрируя (30) и полагая, например, что

$$
\begin{aligned}
& U(0)=U_{\max } / 2, \text { получаем: } \\
& U(x, t)=\frac{U_{\max }}{1+\exp \left\{-(x+V t) / V t_{0}\right\}} .
\end{aligned}
$$

Но такая «псевдоволна» возможна лишь тогда, когда задано соответствующее начальное распределение:

$$
U(x, 0)=\frac{1}{1+\exp \left\{-x / V t_{0}\right\}} .
$$

Например, уже для начального распределения типа ступеньки «псевдоволны» не будет, так как в тех точках, где начальное смещение было нулевым, оно нулевым и останется. Таким образом, несмотря на отсутствие взаимодействия между разломными зонами стороннему наблюдателю будет казаться, что по пространству распространяется волна. Уравнение (29), не являясь по сути волновым, допускает «волновое» решение только после перехода к волновым переменным.

Для примера можно рассмотреть случай, когда имеется две разломные зоны. Пусть в момент времени $\mathrm{t}_{1}$ в первой разломной зоне начинается процесс аномального роста смещений. В более поздний момент $\mathrm{t}_{2}$ во второй разломной зоне также начинается аномальный рост смещений, отражающий локальные процессы, присущие исключительно особенностям и свойствам режима деформирования только этой зоны.

Наблюдатель, который пытается связать два независимых процесса - аномальные деформации в первой и во второй разломной зонах, фактически осуществляет мысленный переход к волновым переменным. Разность между $t_{2}$ и $t_{1}$ представляется наблюдателю как время, которое нужно затратить волне, распространяющейся со скоростью $\mathrm{V}$, чтобы пройти расстояние $\mathrm{L}$ между двумя разломными зонами.

Записывая разность времен как $\Delta \mathrm{t}=\mathrm{t}_{2}-\mathrm{t}_{1}=\mathrm{t}_{2}-\mathrm{L} / \mathrm{V}$, можно легко убедиться, что $\mathrm{V}$ есть фазовая скорость. 


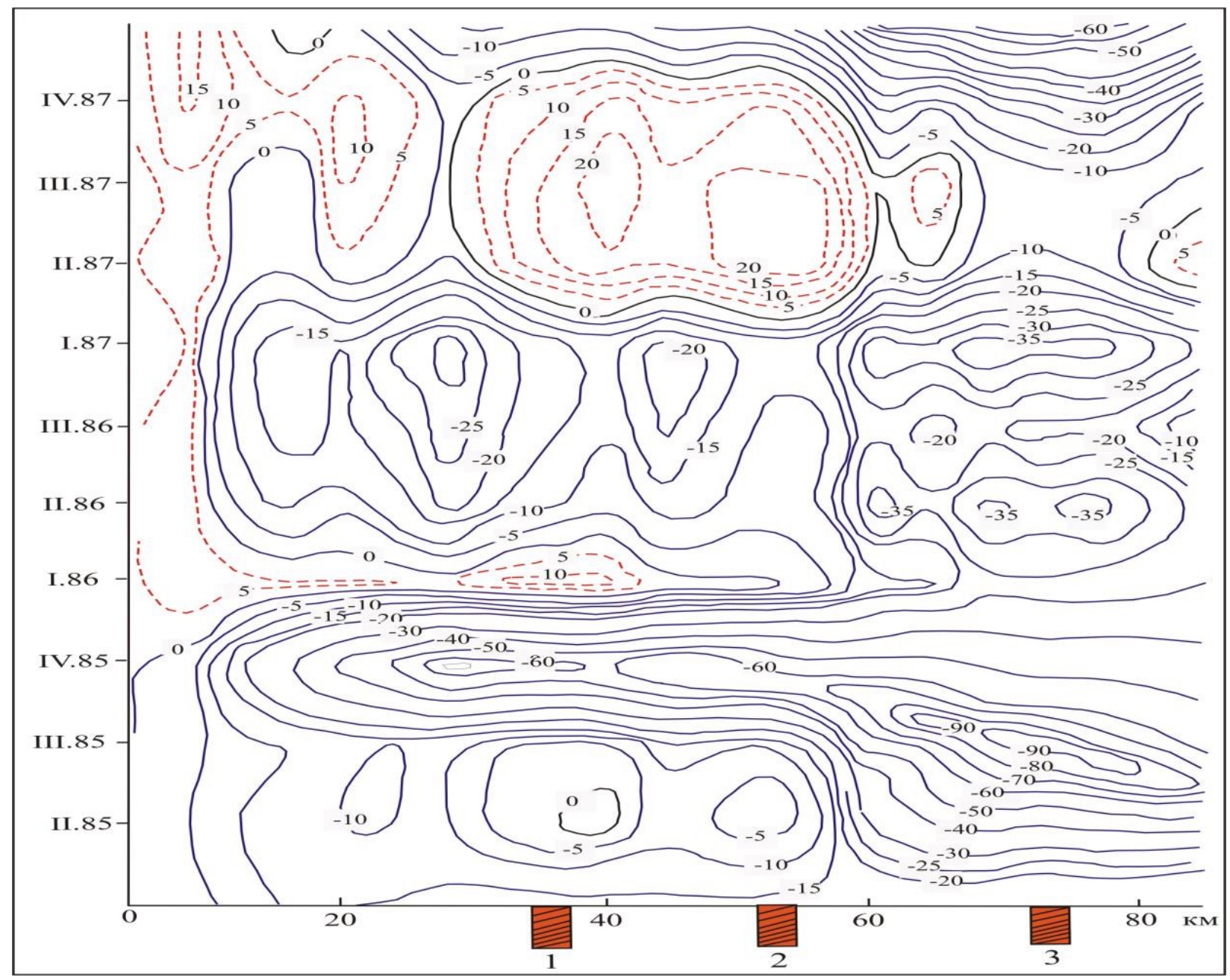

Рис. 18. Пространственно-временная диаграмма вертикальных смещений земной поверхности по профилю Ашхабад - Бахардок (Копетдагский сейсмоактивный регион).

1, 2, 3 - местоположение разломных зон на профиле.

Fig. 18. Vertical displacements of the ground surface in space and time along the Ashkhabad - Bakhardok profile in the Kopetdag seismically active region.

1, 2, 3 - locations of fault zones at the profile.

В реальности же между началом аномальных деформаций в первой и во второй разломных зонах отсутствует закономерная взаимосвязь, но желание связать два независимых явления, которые формально сдвинуты по фазе, приводит к стремлению оценить скорость $\mathrm{V}$ кажущейся или «псевдоволны».

Так, например, в работе [Kasahara, 1985] прямо сказано, что скорости миграции аномальных деформаций земной поверхности определены «... по фазовым сдвигам между станциями...». Поскольку станций было всего пять и они достаточно далеко отстояли друг от друга (десятки километров), ответить однозначно, реальная это волна или «псевдоволна», крайне затруднительно. Для объективной идентификации волновых процессов необходимы специальные требования - как к системе организации наблюдений, так и к методам обработки и анализа данных. Действительно, для слежения за развитием волновых деформаций необходимы специальные системы наблюдений с повышенной густотой и большим количеством пунктов измерений. Только в этом случае возможно отслеживание формирования и миграции деформационных фронтов.

На рис. 18 представлена пространственно-временная диаграмма вертикальных смещений земной поверхности, которая получена по результатам многократных повторных нивелирований вдоль профиля Ашхабад - Бахардок (Копетдагский сейсмоактивный регион). Повторные наблюдения проводились каждые три месяца по густой сети наблюдательных пунктов. Среднее расстояние между пунктами достигало порядка 1 км. Профиль пересекал несколько разломных зон, которые для удобства изложения отмечены цифрами. 
Из рисунка следует, что аномальное смещение формируется на 3-м разломе в период времени между II и III кварталом 1985 г. Отчетливо видимый деформационный фронт сначала мигрирует от третьего разлома ко второму, затем от второго разлома к первому. Спустя шесть месяцев аномальные деформации вновь начинают зарождаться на третьем разломе, но они не перемещаются, а локализуются. Аналогичные процессы происходят и в разломах 1 и 2.

Если теперь обратить внимание на аномальные деформации на 1-м разломе в период между III кварталом 1986 г. и I кварталом 1987 г. и сравнить их с аномальными деформациями в пределах третьего разлома за этот же интервал времени, то очевидно, что никакой волновой передачи активности между зафиксированными аномалиями не наблюдается. Аномальные смещения носят ярко выраженный локальный и автономный характер. Однако, если бы отмеченные разломные зоны не были бы охвачены единой сетью наблюдений, а представляли бы собой несколько измерительных станций, организованных локально в каждой разломной зоне, то из-за сдвига фаз аномальной активности во времени можно было бы «обнаружить» «псевдоволну», распространяющуюся со скоростью около 80 км в год.

Вполне может быть, что именно таким способом были вычислены скорости по результатам регистрации изменений уровня подземных вод [Kissin, 2009]. В этой работе приведены скорости деформационных волн, выявленные вдоль Передового разлома Копетдага, которые оказались равными в среднем 50 км в год, а в Припятской впадине - 60 км в год. Однако, по данным прямых геодезических измерений в Копетдагском регионе и Припятской впадине, скорости пространственно-временной миграции деформаций оказались там в несколько раз меньше. В этой связи есть серьезные основания полагать, что интерпретируемые волновые процессы по гидрогеологическим данным являются «псевдоволнами».

Еще более сложная ситуация складывается с идентификацией тектонических волн по данным о пространственно-временных характеристиках сейсмичности. Сейсмичность, в отличие от медленных деформационных процессов, обладает высокой дискретностью и спорадичностью, поэтому так трудно проследить истинную миграцию землетрясений. Для идентификации тектонических волн в данном случае необходимо привлекать априорную информацию о свойствах земной коры и разломных зон. А они обладают существенной изменчивостью даже в пределах одного сейсмоактивного региона.

Для учета этих обстоятельств С.И. Шерманом с соавторами [Sherman, Tsurkan, 2006; Sherman, Gorbuno$v a, 2008]$ разработан специальный показатель - количественный индекс сейсмической активности (КИСА), под которым понимается число сейсмических событий определенного энергетического класса, приходящихся на единицу длины разлома при принятой ширине области его динамического влияния за заданный промежуток времени. Применение этой методики позволило выявить волновые процессы со скоростями от 4 до 90 км в год. При этом даже столь тщательный подход показал заметный разброс величин определяемых скоростей миграции сейсмичности.

Следует подчеркнуть, что цикл работ по выявлению пространственно-временной миграции землетрясений и анализ, проведенный С.И. Шерманом для различных иерархических уровней литосферы, обобщенный в работе [Sherman, 2013], - блестящий пример того, как гармоничное сочетание геологического и физического описания процессов приводит к убедительным тектонофизическим обобщениям и заключениям эвристического характера.

Приведенный анализ показывает, что большинство эмпирически выявленных характеристик пространственно-временной миграции современных деформаций в разломных зонах наиболее естественным образом трактуются в рамках существующих представлений об автоволновых процессах.

Да, несомненно, выявленные автоволны не похожи на привычные нам сейсмические или температурные. Но это все-таки волны. Как известно, волна - это распространяющееся по пространству колебание. Автоволна - это распространяющееся по пространству автоколебание. В свое время физики непросто привыкали к понятию «автоколебание». Теперь эти представления вошли в школьные учебники. Так же будет и с автоволнами.

По мнению автора, представления о разломных зонах как объектах среды, способных к параметрическому возбуждению малыми воздействиями, являются весьма плодотворными. Их использование приводит к удовлетворительному согласию с наблюдениями с одной стороны, а с другой - позволяют обосновывать и проектировать эффективные системы геодинамического мониторинга.

\section{6. ПРОБЛЕМА ИДЕНТИФИКАЦИИ РЕЗУЛЬТАТОВ НАБЛЮДЕНИЙ В СОВРЕМЕННОЙ ГЕОДИНАМИКЕ}

Проблема идентификации измерений современных геодинамических (геодеформационных) процессов в последние годы существенно обострилась. Это обусловлено тем, что в арсенале исследователей, изучающих современные деформации (вертикальные и горизонтальные смещения, наклоны и т.п.) земной поверхности, появились спутниковые и скважинные методы измерений, которые внесли свою, подчас проблемную, специфику в традиционные методы наземных геодезических и обсерваторских геофизических (наклономерно-деформометрических) наблюдений.

Сюда относятся такие базовые понятия, как «чувствительность», «точность», «пространственно-времен- 
ное разрешение», «абсолютно и относительно измеренные величины», «адекватность идентификации измеренных данных», которые используются в теории измерения физических (механических) величин. Ситуация усугубляется тем, что некоторые исследователи полагают, что наблюдения не являются измерениями в строгом смысле этого понятия, так как «полевая» специфика налагает ограничения, которые не свойственны строгим лабораторным методам.

Кроме того, мониторинговые, повторные во времени измерения не воспроизводимы, так как повторить их в тех же условиях уже невозможно. Подчас это действительно так, но, по мнению автора, процедура наблюдения должна максимально приближаться к процедуре измерения. Для этого необходимо проводить тщательный метрологический анализ системы «измерительный датчик - вмещающая среда». И это касается не только тривиальных оценок статистической значимости получаемых результатов с позиции теории погрешности наблюдений. Наблюдения только тогда становятся измерениями, когда удовлетворяют основным принципам (аксиомам) метрологии. Только в этом случае результаты наблюдений могут быть сравнимы, адекватно идентифицируемы и, следовательно, репрезентативны.

Как следует из физических основ теории измерений, чувствительность (или разрешение) метода - это его способность к выявлению сигнала определенной амплитуды. Точность - это способность прибора (метода) выявлять полезный сигнал на фоне помех. Так, например, самым чувствительным методом измерения геодеформаций является наклономерно-деформометрический. Для того чтобы в полной мере выявить полезный сигнал на уровне максимальной чувствительности приборов $-10^{-9}-10^{-10}$ в единицах относительных деформаций, необходимо их заглублять (на 20 м и более) и помещать в специально оборудованные бункеры (камеры, штольни). Только в этом случае «точность» и «чувствительность» наблюдений будут совпадать.

Если расположить эти приборы в неглубоком (3-5 м) подвале, то уровень метеорологических и экзогенных (антропогенных) воздействий существенно снизит точность наблюдений (до $10^{-5}-10^{-6}$ единиц относительных деформаций), в то время как чувствительность датчиков останется, естественно, прежней. Иными словами, по мере заглубления высокочувствительного датчика, которое увеличивает его помехозащищенность, точность прибора приближается к его чувствительности. Заметим, что характеристики «точности» измерительных инструментов, декларируемые в проспектах фирм-изготовителей геодезического и геофизического оборудования, это, на самом деле, «чувствительность» измерительных устройств. Истинная точность этих методов (инструментов) будет объективно определяться конкретными условиями установки и режимом эксплуатации измерительного оборудования. Это тем более актуально в режиме полевой эксплуатации приборов.
Современное геодинамическое состояние недр это многофакторное явление, которое обусловлено совокупностью природных и техногенных, эндогенных (глубинных) и экзогенных (поверхностных) воздействий, изменяющихся в пространстве и во времени.

В этом случае возникает ситуация, когда более чувствительный прибор (метод), измеряющий современные геодинамические процессы, будет более эффективно регистрировать не только полезный сигнал, но и помехи.

Следует иметь в виду, что стандартное геодезическое (наземное и спутниковое) и геофизическое оборудование предназначено, в первую очередь, для стационарных, «однократных» съемок. Так, геодезическое оборудование используется, как правило, для определения пространственных характеристик (координат) местности, а геофизическое (например, гравиметры и магнитометры) - для целей геологоразведки при поиске месторождений полезных ископаемых.

Задачи мониторинга, в первую очередь, требуют наличия многократных, повторных (в идеале непрерывных) измерений. А это накладывает дополнительные требования к фильтрации переменных во времени помех различной природы. Кроме того, при изучении современных деформаций земной поверхности принципиально важной является проблема закрепления измеряемых точек (реперов) на местности и их сохранности.

Классическая (наземная) геодезия за почти два века своего развития накопила значительный опыт по разработке различных типов (конструкций) реперов, которые используются в зависимости от грунтовых, геокриологических и климатических условий местности. При этом предусмотрены «антивандальные» мероприятия, сводящиеся к максимально возможному заглублению пунктов наблюдений. Это позволяет одновременно решать и вопросы повышения точности наблюдений, и проблемы «маскировки» реперов.

Используя спутниковые системы измерений деформаций земной поверхности, например, ГНСС (ГЛОНАCC/GPS), стремятся в целях реализации антивандальных мероприятий располагать приемные антенны на крышах зданий и сооружений, что повышает степень сохранности оборудования, но существенно снижает точность наблюдений. Кроме того, важно отметить, что наземные геодезические методы, при всей трудоемкости их полевой реализации, крайне просты и наглядны в методах обработки. В противоположность этому спутниковые наблюдения легче выполнить, но очень сложно, а подчас неоднозначно анализировать, что может привести к существенным искажениям итоговых оценок уровня современного геодинамического состояния недр.

При проведении дискретных (повторных) геодезических наблюдений принципиально важный вопрос заключается в установлении оптимальной пространственно-временной детальности измерений. Как прави- 
ло, большая пространственная детальность наблюдений характерна для относительно коротких наблюдательных сетей и наоборот. При этом для наземных, например нивелирных, наблюдений, когда существует необходимость пешей передачи отметок между реперами, имеется ограниченность по длительности между повторными измерениями. Именно поэтому значительные по пространственному охвату нивелирные наблюдения имеют редкую частоту опроса и малую густоту наблюдательных пунктов.

В этой связи становится очевидна необходимость проводить наблюдения, тщательно соблюдая принцип соответствия между динамическими свойствами объекта и пространственно-временной детальностью измерений. Иными словами, нельзя редкими пространственно-временными сетями производить измерения локальных, быстропротекающих процессов. По всей вероятности, именно этими обстоятельствами обусловлены парадоксальные несоответствия в результатах измерения спутниковыми и наземными геодезическими системами наблюдений в зонах разломов таких сейсмоактивных регионов, как Камчатка, Калифорния и Копетдаг [Kuzmin, 2013].

Для учета этих обстоятельств полезно иметь в виду два соотношения неопределенностей, которые известны из теории колебаний и волн. Первое соотношение связывает погрешность измерения в определении волнового числа $\Delta \mathrm{K}(\mathrm{K}=2 \pi / \lambda)$ и неопределенность в пространственной детальности измерений (густоте наблюдательных пунктов) $\Delta X: \Delta K \cdot \Delta X=1$. Второе обусловливает взаимосвязь между погрешностью определения частоты наблюдаемого процесса $\Delta \omega$ и неопределенностью во временной дискретности наблюдений $\Delta t: \Delta \omega \cdot \Delta t=1$. Из первого соотношения следует, что чем больше расстояние между пунктами наблюдений, тем большую длину волны $\lambda$ (большую по пространственному размеру аномалию деформаций) можно выявить и наоборот. Второе соотношение показывает, что более быстрые процессы необходимо регистрировать наблюдениями с повышенной частотой опроса.

Из основ метрологии следует [Shishkin, 2010] невозможность отождествления абсолютных и относительных характеристик измерений. Вместе с тем, хорошо известно, что существующие базовые характеристики процессов, которыми оперируют в современной геодинамике, а также методы их изучения в основном являются относительными.

Так, например, анализ и интерпретация повторных нивелирных наблюдений сводится к последовательности двух взаимодополняющих процедур: построение «эволюционных» и «пульсационных» графиков изменения превышений вертикальных отметок реперов и морфолого-генетический анализ выявленных аномалий движений земной поверхности.

Известно, что результаты повторных геодезических (нивелирных) наблюдений обычно представляются в виде набора профильных графиков, которые отобра- жают зависимость $\delta \Delta \mathrm{h}=\mathrm{f}(\mathrm{L}, \delta \mathrm{t})$, где L - длина профиля, а $\delta \mathrm{t}$ - интервал между повторными наблюдениями. Мониторинговая информация, как правило, отображается в двух вариантах: эволюционном и пульсационHOM.

В первом варианте все изменения вертикальных смещений земной поверхности определяются вычитанием текущих значений превышений от значений, полученных при первом наблюдении, т.е. - 2-1, 3-1, 4-1 и т.д. В этом случае прослеживается временная динамика (эволюция) поведения земной поверхности, когда каждая эпоха характеризует (итоговые) смещения, накопленные к данному моменту времени. Во втором случае используются разности между смежными эпохами - 2-1, 3-2, 4-3 и т.д. В этом случае имеется возможность выявлять периоды возникновения (пульсаций) современных вертикальных движений и определять длительность протекания аномального процесса.

На рис. 19 представлены результаты повторных нивелирных наблюдений на Камчатском геодинамическом полигоне [Kuzmin, 1999]. Было проведено 156 циклов повторных наблюдений, затем искусственным путем отобраны 11 циклов, интервал между которыми составляет три месяца.

Совместный анализ обоих графиков ярко демонстрирует относительный характер смещений. Так, если рассматривать только эволюционный график в эпоху 7-1, то ясно видно два локальных минимума (просадки земной поверхности). Если же рассматривать только пульсационный график, то в эпоху (7-6), то есть в то же самое время, наблюдаются два максимума (поднятия земной поверхности). Отсюда следует вывод, что необходимо тщательно учитывать относительный характер измеряемых величин в современной геодинамике.

Согласно второй аксиоме метрологии результаты измерений должны быть адекватно идентифицированы. Если необходимо измерить вертикальную компоненту смещения, то вся измерительная процедура от типа сенсора до обработки результатов должна быть направлена на установление именно вертикальной компоненты полного вектора смещений. Однако возможны ситуации, когда измеренные прямым методом величины допускают неоднозначную (неадекватную) трактовку.

Так, например, широко известно, что наклон земной поверхности идентифицируется как горизонтальный градиент вертикальных смещений. Это полностью соответствует рассмотренным выше ситуациям с вертикальными перемещениями фиксированных точек земной поверхности. Но возможна и другая ситуация. Наклон поверхности может быть определен и как вертикальный градиент горизонтальных смещений. В первом случае это наклон, измеряемый пузырьковым уровнем, лежащим на земной поверхности, который регистрирует угловые перемещения по горизонтали, а во втором - это наклономер, расположенный в доста- 

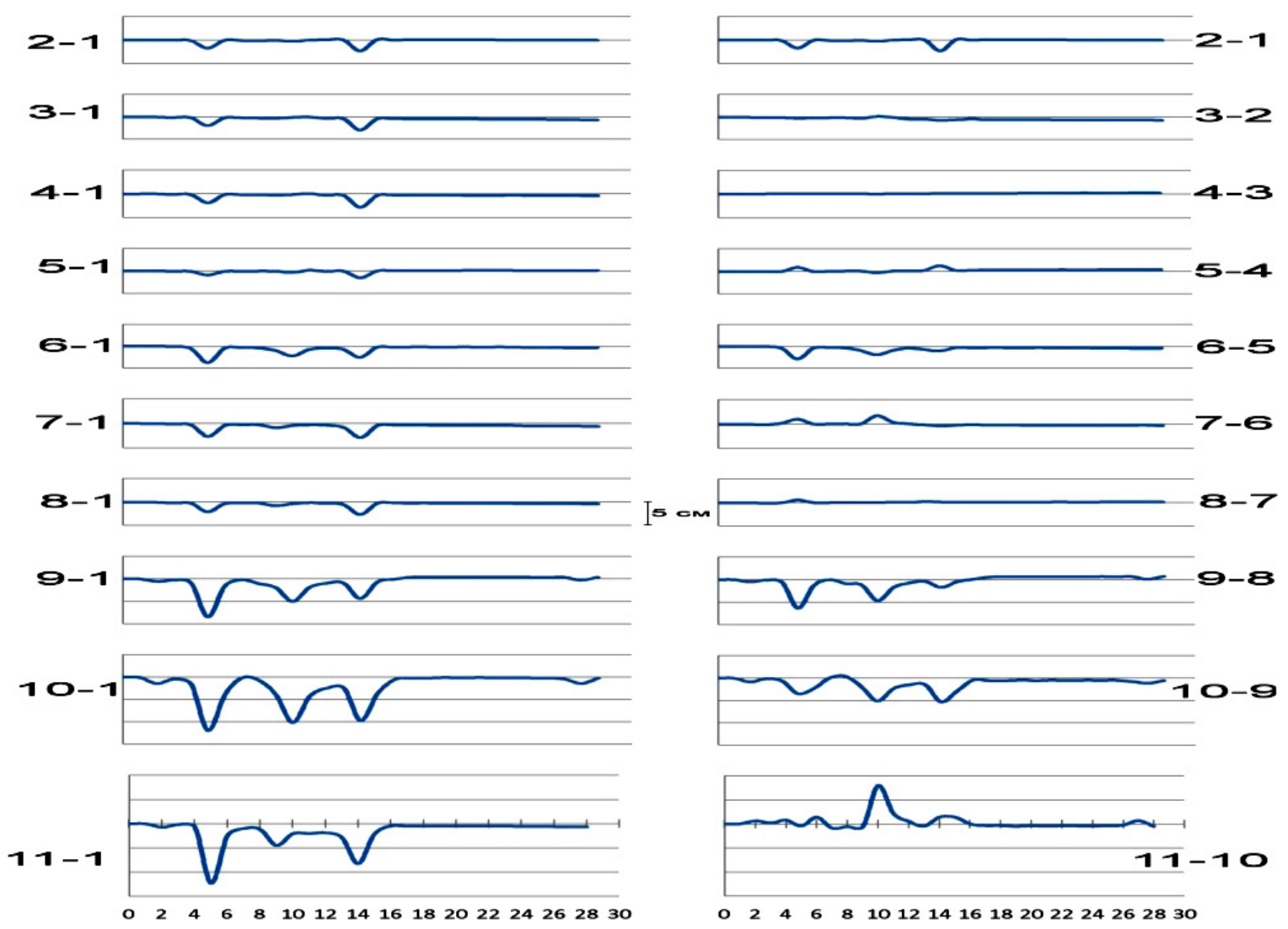

Рис. 19. «Эволюционные» (слева) и «пульсационные» (справа) графики изменений превышений вертикальных отметок реперов.

Fig. 19. “Evolutional' (left) and ‘pulsating' (right) curves showing changes of increments of vertical reference points.

точно глубокой скважине и фиксирующий уклонение от горизонтали. В первом случае наклон поверхности вызван неравномерным распределением вертикальных смещений по пространству, а во втором - неравномерным распределением горизонтальных смещений по глубине. В работе [Kuzmin, 1982] выявлен эффект влияния горизонтальных деформаций на результаты изучения «вертикальных» смещений земной поверхности маятниковыми наклономерами. Оказалось, что изза различной степени деформируемости осадочных горных пород и железобетонного пола приборы фиксировали наклоны, обусловленные вертикальным градиентом горизонтальных смещений, что приводило к неадекватной идентификации результатов.

Другим примером неадекватной идентификации результатов измерений в современной геодинамике является воздействие одноосного девиаторного напряжения во времени, которое может приводить к вариациям силы тяжести. Известно [Rabotnov, 1979], что девиаторные напряжения приводят к деформациям в плоскости и никогда не приводят к деформациям объема. Однако, если записать изменение девиаторного напряжения $\delta \Delta \sigma_{\mathrm{xx}}$ во времени, например при одноосном напряженном состоянии, то:

$$
\delta \Delta \sigma_{\mathrm{xx}}=\delta \sigma_{\mathrm{xx}}-\delta \mathrm{P},
$$

где $\delta \mathrm{P}$ - изменение литостатического давления во времени, $\delta \sigma_{\mathrm{xx}}-$ изменение во времени горизонтального (вдоль оси х) напряжения. Так как литостатическое давление в течение времени практически не изменяется,

$$
\delta \Delta \sigma_{\mathrm{xx}}=\delta \sigma_{\mathrm{xx}}
$$

Тогда, используя типовые формулы теории упругости, можно показать:

$$
\delta \Delta \sigma_{\mathrm{xx}}=\delta \sigma_{\mathrm{xx}}=\frac{\delta \cdot \Pi \cdot E}{(1-2 v)}=\frac{\delta \rho \cdot E}{\rho(1-2 v)},
$$

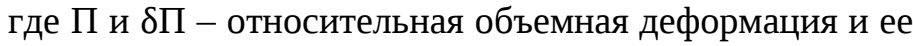
изменение во времени; E, $v$ - модуль Юнга и коэффициент Пуассона, соответственно; $\rho$ и $\delta \rho-$ плотность пород и ее вариация во времени.

Таким образом, получается парадоксальный вывод. Девиаторное напряжение, действуя одноосно, приводит к изменению объема, а значит, и к вариациям гравитационного поля во времени, что и наблюдается в дейст- 
A

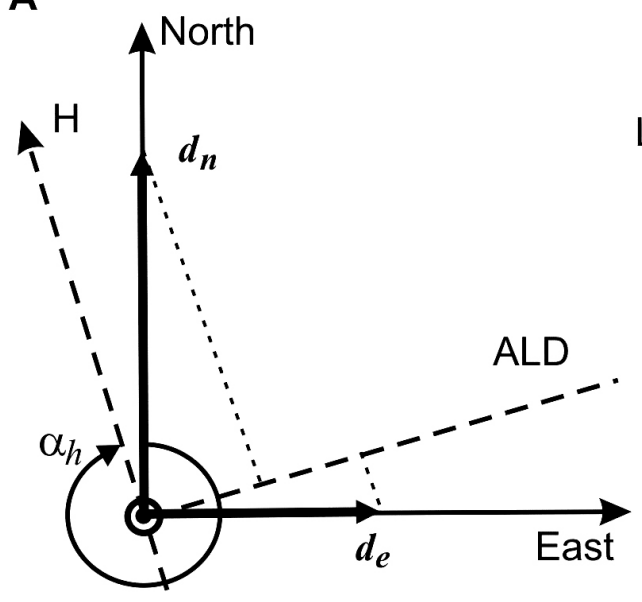

B

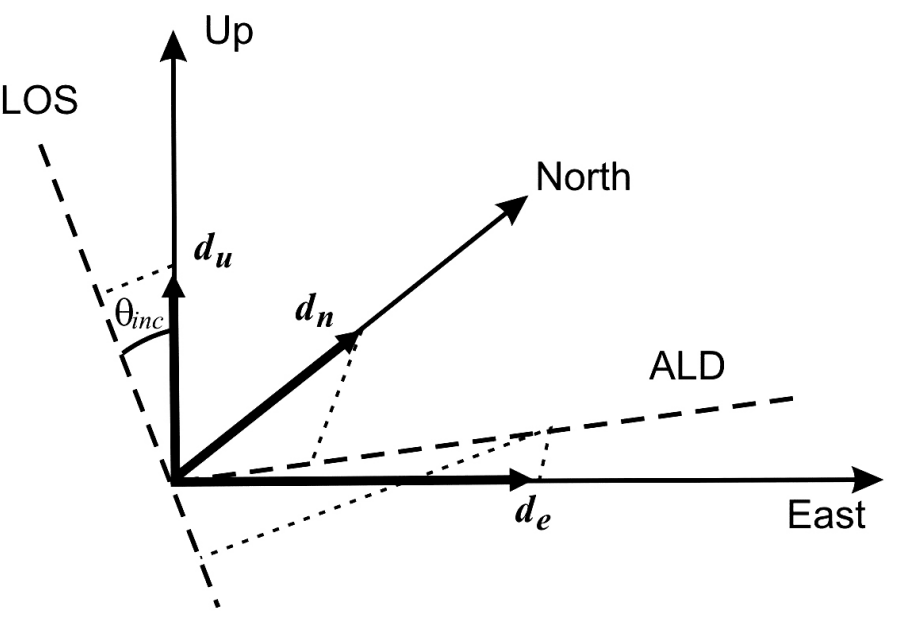

Рис. 20. Распределение компонент вектора смещений в направлении вверх, на север и на восток ( $\left.d_{u p}, d_{n}, d_{e}\right)$.

$A$ - плоская картина (вид сверху), $\alpha_{h}$ - азимут орбиты спутника, который отсчитывается от направления на север по часовой стрелке, азимут направления видения $\beta=\alpha_{h}-3 \pi / 2$. $B$ - трехмерная картина. $\theta=\theta_{\text {inc }}$ - угол видения.

Fig. 20. The pattern of displacement vector components in the upward, northward and eastward directions $\left(d_{u p}, d_{n}, d_{e}\right)$.

$A$ - plane view (from the top); $\alpha_{h}$ - satellite orbit azimuth calculated from the northward direction (clockwise); sight direction azimuth $-\beta=\alpha_{h}-3 \pi / 2$. B-3D view. $\theta=\theta_{\text {inc }}-$ sight angle.

вительности. Следовательно, необходима тщательная идентификация измеряемых деформаций.

Другим убедительным примером является идентификация измеренных смещений земной поверхности методом РСА-интерферометрии. К настоящему времени выполнены исследования деформации земной поверхности этим методом на целом ряде нефтяных и газовых месторождений. В этих работах справедливо подчеркивается, что главными достоинствами метода являются возможность площадного охвата всей территории месторождения и относительно (по сравнению с традиционными методами) небольшие затраты на выполнение работ.

Известно, что данные РСА интерферометрии позволяют определять смещения в направлении на спутник LOS (от англ. line-of-sight - направление видения спутника) относительно выбранного в качестве точки отсчета радарного изображения. Поэтому определение полного вектора смещений в форме трех составляющих: например, вверх (up), на север (n) и на восток (е) в рамках только РСА интерферометрии (без дополнительных данных) принципиально невозможно. Иными словами, имеет место ситуация, когда при одном известном значении (величины LOS-смещения) необходимо определить три неизвестные компоненты полного вектора смещений поверхности. В математике такие методы неизвестны.
Как известно [Hanssen, 2001], вектор смещений (или вектор средней скорости смещений) имеет три компоненты $\left(d_{u p}, d_{n}, d_{e}\right)$ в направлениях (положительных) соответственно вверх (up), на север (n) и на восток (е). Тогда смещение в направлении LOS равно:

$$
\begin{aligned}
& d_{L O S}=-\lambda \cdot \Delta \varphi / 4 \pi= \\
& =d_{u p} \cos \theta-\sin \theta \cdot\left[d_{n} \cos \beta+d_{e} \sin \beta\right],
\end{aligned}
$$

где $d_{\text {LOS }}$ - смещение в направлении на спутник, $\lambda-$ длина электромагнитной волны, излучаемой спутником, $\Delta \varphi-$ фазовый сдвиг, $\theta=\theta_{i n c}-$ угол видения, $\beta=\alpha_{h}-3 \pi / 2$ - азимут направления видения, $\alpha_{h}-$ азимут орбиты спутника, который отсчитывается от направления на север по часовой стрелке (рис. 20).

Анализ уравнения (4) показывает, что даже в отсутствие горизонтальных смещений, когда $d_{n}=d_{e}=0$, $d_{\text {LOS }}$ - смещение в направлении на спутник - не будет равно вертикальному смещению $d_{u p}$. Для перехода к практическим примерам необходимо рассмотреть детализацию уравнения (36) применительно к данным, полученным с конкретных спутников.

Так, например, для нисходящего трека спутника ENVISAT имеем: $\theta=23^{\circ}, \alpha_{h}=194.4^{\circ}$, следовательно, $\beta=284.4^{\circ}$. Для восходящего трека спутника ENVISAT: $\theta=23^{\circ}, \alpha_{h}=345.6^{\circ}$, следовательно, $\beta=75.6^{\circ}$. 


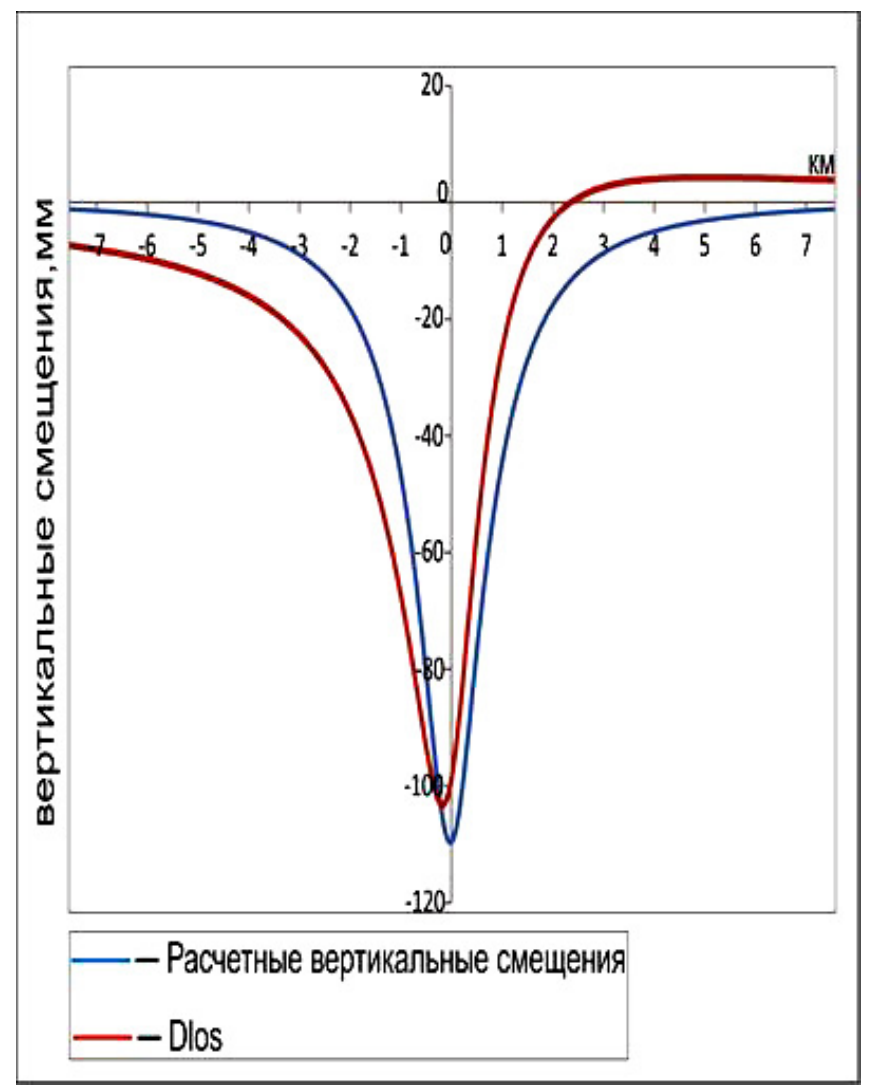

Рис. 21. Сопоставление распределения расчетных вертикальных смещений и смещений в направлении на спутник $\left(d_{L O S}\right)$ по профилю, пересекающему разломную зону.

Fig. 21. Comparison between the estimated vertical displacement patterns and displacements in the direction to the satellite ( $\left.d_{L O S}\right)$ along the profile across the fault zone.

Отсюда, вычисляя значения радианной меры углов с точностью до одной десятой, можно найти:

$$
d_{L O S}=0.9 \cdot d_{u p}-0.01 \cdot d_{n} \pm 0.4 d_{e} .
$$

Из формулы (5) следует, что вертикальная компонента существенно преобладает над смещениями на север, но вклад смещений на восток довольно значителен. При этом знак плюс соответствует нисходящему треку, а минус - восходящему, соответственно.

Таким образом, в общем случае пренебрегать вкладом горизонтальных смещений и считать, что регистрируется в основном вертикальная компонента, нельзя. Это с очевидностью следует из формулы (36).

На рис. 21 представлены модельные результаты сопоставления распределения вертикальных смещений земной поверхности и вкрест простирания разломной зоны (раздвиг), которая простирается в меридиональном направлении, для случая использования материалов ENVISAT. Видно, что и в этом случае амплитуда расчетных вертикальных смещений больше. Кроме того, отмечается смещение максимумов, а кривые затухания вертикальных и горизонтальных смещений попеременно превалируют друг над другом. При этом отчетливо видно, что в правой части графика по данным PCA интерферометрии наблюдается небольшое поднятие поверхности (начиная со второго километра), которое остается значимым и в зоне, где вертикальные смещения устремляются к нулю. Подробный анализ показывает, что кривая пересекает нулевую ординату между вторым и третьим километром профиля, а вертикальные смещения достигают нуля в области восьмого километра. Смещение «нулевых» точек, таким образом, составляет порядка пяти километров. В то же время левая часть графика показывает, что в районе седьмого километра вертикальные смещения близки к нулю, а данные «вертикальных» смещений фиксируют уверенное оседание поверхности порядка $1 \mathrm{~cm}$.

Из рис. 21 следует, что разлом в форме вертикального раздвига будет отображен в данных радарной интерферометрии как взброс или сброс в зависимости от характера взаимного расположения лежачего и висячего крыла разлома. Естественно, что подобная ситуация приведет к абсолютно неверной оценке напряженнодеформированного состояния разломной зоны, которая проводится в рамках решения обратной задачи современной геодинамики разломов [Kuzmin, 1999].

\section{7. ЗАКЛЮЧЕНИЕ}

Приведенные выше эмпирические материалы и их анализ показывают, что наиболее фундаментальными и актуальными факторами, характеризующими современную геодинамику недр, в настоящее время являются:

1) существенное отклонение от унаследованной схемы формирования пространственно-временной структуры современных геодинамических процессов («парадоксы» больших и малых скоростей деформаций);

2) принципиальные трудности адекватной тектонофизической интерпретации современных деформаций земной поверхности в зонах разломов с позиций блоковой кинематики;

3) наличие суперинтенсивных деформаций в зонах разломов платформенных (слабосейсмичных) регионов;

4) исключительно низкая среднегодовая скорость регионального напряженно-деформированного состояния (до (1-4) $10^{-8}$ в год) в сейсмоактивных регионах;

5) индуцирование современной деформационной активности разломных зон малыми воздействиями и существование пространственно-временной миграции процессов;

6) проблема комплексной (совместной) интерпретации результатов геодеформационных измерений, 
полученных методами, обладающими различной пространственно-временной детальностью, и в первую очередь наземными и спутниковыми геодезическими наблюдениями.

Действительно, полная унаследованность современных движений от прошлых геологических эпох достигается только в рамках реализации «жесткой» схемы нагружения. В этом случае современная деформационная активность разломов может объясняться движением крупных геоструктурных элементов и/или блоков по разломным зонам как ослабленным участкам среды.

С другой стороны, результаты многолетних инструментальных геодезических наблюдений, полученные в режиме повышенной пространственно-временной детальности, указывают на практическое отсутствие сдвиговых (в механическом смысле), унаследованных перемещений по разломам, а это свидетельствует в пользу квазистатического («мягкого») режима нагружения. Иными словами, существует «разломноблоковая» дилемма при тектонофизической интерпре- тации результатов наблюдений в современной геодинамике: либо активным элементом, создающим современные аномальные деформации, является блок, а разлом выступает в качестве «пассивного» элемента, либо зона разлома сама является источником аномальных движений, а блоки являются пассивными элементами - вмещающей средой.

Проведенный выше анализ показывает, что многие проблемы снимаются, если считать, что современное аномальное геодинамическое состояние недр формируется за счет параметрического возбуждения (индуцирования) деформационных процессов в зонах разломов малыми природно-техногенными воздействиями, в обстановке квазистатического режима нагружения. Это способствует возникновению автоволновых деформационных структур, обеспечивающих пространственно-временной спектр движений, наблюдаемых измерительными системами с повышенной густотой пунктов и частотой опроса.

Работа выполнена при частичной финансовой поддержке РФФИ (грант 12-05-01127-а).

\section{8. ЛИТЕРАТУРА / REFERENCES}

Antonov V.A., Kondratiev B.P., 2008. On the impossibility of the existence of elastic-viscoelastic waves propagating along the lithospheric fault. Fizika Zemli (6), 86-91 (in Russian) [Антонов В.А., Кондратьев Б.П. О невозможности существования упруго-вязкоупругих волн, распространяющихся вдоль литосферного разлома // Физика Земли. 2008. № 6. С. 86-91].

Birger B.I., 2012. Transient creep of the lithosphere and its role in geodynamics. Izvestiya, Physics of the Solid Earth 48 (6), 496-503. http://dx.doi.org/10.1134/S1069351312060018.

Bulanzhe Yu.D., Magnitsky V.A., 1974. Recent crustal movements. The state of the problem. Izvestia AN SSSR. Fizika Zemli (10), 19-54 (in Russian) [Буланже Ю.Д., Магницкий В.А. Современные движения земной коры. Состояние проблемы // Известия АН СССР. Физика Земли. 1974. № 10. С. 19-54].

Burov E.B., 2007. Plate rheology and mechanics. In: G. Schubert (Ed.), Treatise of geophysics, 6. Crust and lithospere dynamics. Elsevier, Amsterdam, p. 100-161.

Bykov V.G., 2004. Unsteady sliding in crustal faults as an auto-wave process. In: Interrelations between tectonics, seismicity, magmatism and volcanic eruptions in volcanic arcs. Proceedings of the international meeting on processes in subduction zones of Japan, Kuril-Kamchatka and Aleutian island arcs, Petropavlovsk-Kamchatsy, 21-27 August 2004. Institute of Volcanology and Seismology, Far East Branch of RAS. P. 200-202 (in Russian) [Быков В.Г. Неустойчивое скольжение в разломах земной коры как автоволновой процесс // Взаимосвязь между тектоникой, сейсмичностью, магмообразованием и извержениями вулканов в вулканических дугах: Матер. Межд. совещания по процессам в зонах субдукции Японской, Курило-Камчатской и Алеутской островных дуг, Петропавловск-Камчатский, 21-27 августа 2004 г. Петропавловск-Камчатский: ИВиС ДВО РАН, 2004. С. 200-202].

Bykov V.G., 2005a. Strain waves in the Earth: theory, field data, and models. Russian Geology and Geophysics 46 (11), 1176-1190.

Bykov V.G., 2005b. A crustal fault zone as an auto-wave system. In: Recent geodynamics and hazardous natural processes in Central Asia. Issue 3: Proceedings of the All-Russia Meeting on Recent Geodynamics and Seismicity of Central Asia: Fundamental and Application Aspects, Irkutsk, 20-23 September 2005. IEC SB RAS, Irkutsk. P. 271-273 (in Russian) [Быков В.Г. Разломная зона земной коры как автоволновая система // Современная геодинамика и опасные природные процессы в Центральной Азии: Материалы Всероссийского совещания «Современная геодинамика и сейсмичность Центральной Азии: фундаментальный и прикладной аспекты», г. Иркутск, 20-23 сентября 2005 г. Вып. 3. Иркутск: Институт земной коры СО РАН, 2005. С. 271-273].

Bykov V.G., 2008. Stick-slip and strain waves in the physics of earthquake rupture: experiments and models. Acta Geophysica 56 (2), 270-285. http://dx.doi.org/10.2478/s11600-008-0002-5.

Chen Q., Freymueller G.T., 2002. Geodetic evidence for a near-fault compliant zone along San Andreas Fault in the San Francisco Bay area. Bulletin of the Seismological Society of America 92 (2), 656-671. http://dx.doi.org/10.1785/ 0120010110.

Churikov V.A., Kuzmin Yu.O., 1998. Relation between deformation and seismicity in the active fault zone of Kamchatka, Russia. Geophysical Journal International 133 (3), 607-614. http://dx.doi.org/10.1046/j.1365-246X.1998.0.0511.x. 
De Mets C., Gordon R., Argus D.F., Stein S., 1994. Effects of recent revisions to the geomagnetic reversal time scale on estimates of current plate motions. Geophysical Research Letters 21 (20), 2191-2194. http://dx.doi.org/10.1029/ 94GL02118.

Dobrovol'sky I.P., 2009. Mathematical Theory of Preparation and Prediction of Earthquakes. FIZMATLIT, Moscow, 240 p. (in Russian) [Добровольский И.П. Математическая теория подготовки и прогноза землетрясений. М.: ФИЗМАТЛИТ, 2009. 240 с.].

Elsasser W.H., 1969. Convection and stress propagation in the upper mantle. In: S.K. Runcorn (Ed.), The application of modern physics to the Earth and planetary interiors. Wiley, New York, p. 223-246.

Frenkel Ya.I., 1948. Statistical Physics. Publishing House of the USSR Acad. Sci., Moscow -Leningrad, 760 p. (in Russian) [Френкель Я.И. Статистическая физика. М.-Л.: Изд-во АН СССР, 1948. 760 с.]

Grigoriev A.S., Volovich I.M., Mikhailova A.V. et al., 1987. Studies of the state of stresses, kinematics and development of discontinuities in the sedimentary cover under active faults in base rocks (plane deformation studied by a combination of mathematical simulation and physical modelling). In: Stress Fields and Deformations in the Earth's Crust. Nauka, Moscow, p. 5-30 (in Russian) [Григорьев А.С., Волович И.М., Михайлова А.В. и др. Исследование напряженного состояния, кинематики и развития нарушений сплошности осадочного чехла над активными разломами фундаментами (при сочетании математического и физического моделирования в условиях плоской деформации) // Поля напряжений и деформаций в земной коре. М.: Наука, 1987. С. 5-30].

Hanssen R.F., 2001. Radar Interferometry: Data Interpretation and Error Analysis. Academic Publishers, 308 p.

Izyumov S.F., Kuzmin Yu.O., 2010. Recent geodynamics of transition zone from mountain structure to platform: case of the Kopetdag region. In: Proceedings of the $9^{\text {th }}$ International Conference on Properties, Structure, Dynamics and Minerageny of the East European Platform. Nauchnaya Kniga, Voronezh, Volume 1, 308-313 (in Russian) [Изюмов С.Ф., Кузьмин Ю.О. Современная геодинамика зоны перехода от горного сооружения к платформе: на примере Копетдагского региона // Труды ХІ Международной конференции «Свойства, структура, динамика и минерагения ВосточноЕвропейской платформы». Воронеж: Научная книга, 2010. Т. 1. С. 308-313].

Karato S., 2008. Deformation of Earth Materials. Cambridge University Press, New York, 463 p.

Kasahara K., 1985. Earthquake Mechanics. Mir, Moscow, 264 p. (in Russian) [Касахара К. Механика землетрясений. М.: Мир, 1985. 264 с.].

Kissin I.G., 2009. Fluids in the Earth’s Crust. Geophysical and Tectonic Aspects. Nauka, Moscow, 328 p. (in Russian) [Kucсин И.Г. Флюиды в земной коре. Геофизические и тектонические аспекты. М.: Наука, 2009. 328 с.].

Kolmogorov A.N., Petrovskii I.G., Piskunov N.S., 1937. Investigation of the diffusion equation combined with the growth of the amount of matter, and its application to a certain biological problem. Bulleten Moskovskogo gosudarstvennogo universiteta, Seriya Mekhanika i Matematika 1 (6), 1-26 (in Russian) [Колмогоров А.Н., Петровский И.Г., Пискунов Н.С. Исследование уравнения диффузии, соединенной с возрастанием количества вещества, и его применение к одной биологической проблеме // Бюллетень МГУ, Серия Механика и математика. 1937. Т. 1. Вып. 6. С. 1-26].

Kuzmin Yu.O., 1982. About deformographic effect with reference to inclination measurements. Izvestia AN SSSR. Fizika Zemli (9), 67-71 (in Russian) [Кузьмин Ю.О. О деформографическом эффекте по наклономерным данным // Физика Земли. 1982. № 9. С. 67-71].

Kuzmin Yu.O., 1989. Recent geodynamics of fault zones of sedimentary basins and earthquake preparation processes. In: Prediction of earthquakes, Issue 11. Donish, Moscow - Dushanbe, 52-60 (in Russian) [Кузьмин Ю.О. Современная геодинамика разломных зон осадочных бассейнов и процессы подготовки землетрясений // Прогноз землетрясений, № 11, Москва - Душанбе: Дониш, 1989. С. 52-60].

Kuzmin Yu.O., 1996. Recent super intensive deformations of the ground surface in platform fault zones. In: Geological studies and subsurface use, Issue 4. Geoinformmark, Moscow, p. 43-53 (in Russian) [Кузьмин Ю.О. Современные суперинтенсивные деформации земной поверхности в зонах платформенных разломов // Геологическое изучение и использование недр. Вып. № 4. М.: Геоинформмарк, 1996. С. 43-53].

Kuzmin Yu.O., 1998. The mechanism of formation of anomalous deformation processes during preparation and occurrence of the Ashkhabad earthquake in 1948. Vestnik OGGGGN RAN 2 (4), 135-152 (in Russian) [Кузьмин Ю.О. Механизм формирования аномальных деформационных процессов в период подготовки и реализации Ашхабадского землетрясения 1948 года // Вестник ОГГГГН РАН. 1998. № 2 (4). С. 135-152].

Kuzmin Yu.O., 1999. Recent Geodynamics and Assessment of Geodynamic Risks in Subsurface Use. Economic News Agency, Moscow, 220 p. (in Russian) [Кузьмин Ю.О. Современная геодинамика и оценка геодинамического риска при недропользовании. М.: Агентство экономических новостей, 1999. 220 с.].

Kuzmin Yu.O., 2002. Recent Anomalous Geodynamics of Aseismic Fault Zones. Vestnik, Earth Sciences Division of RAS 1 (20), 1-27 (in Russian) [Кузьмин Ю.О. Современная аномальная геодинамика асейсмичных разломных зон // Вестник отделения наук о Земле РАН. 2002. № 1 (20). С. 1-27].

Kuzmin Yu.O., 2004. Recent Geodynamics of Fault Zones. Izvestiya, Physics of the Solid Earth 40 (10), 868-882.

Kuzmin Yu.O., 2005. Hazardous faults and prediction of emergencies. In: Proceedings of the $4^{\text {th }}$ Research and Practice Conference, Moscow, 19-20 October 2004. MTPE-invest, Moscow, p. 153-164 (in Russian) [Кузьмин Ю.О. Опасные разломы и прогнозирование чрезвычайных ситуаций // Проблемы прогнозирования чрезвычайных ситуаций: Материалы IV научно-практической конференции (Москва, 19-20 октября 2004 г.). М.: «МТПЕ-инвест», 2005. С. 153164]. 
Kuzmin Yu.O., 2009. Tectonophysics and recent geodynamics. Izvestiya, Physics of the Solid Earth 45 (11), $973-986$. http://dx.doi.org/10.1134/S1069351309110056.

Kuzmin Yu.O., 2013. Recent geodynamics of the faults and paradoxes of the rates of deformation. Izvestiya, Physics of the Solid Earth 49 (5), 626-642. http://dx.doi.org/10.1134/S1069351313050029.

Kuzmin Yu.O., Churikov V.A., 1999. Anomalous strain generation mechanism before the March 2, 1992, Kamchatka earthquake. Volcanology and Seismology 20, 641-656.

Kuzmin Yu.O., Zhukov V.S., 2004. Recent Geodynamics and Variations of Physical Properties of Rocks. Moscow State Mining Univ., Moscow, 204 p. (in Russian) [Кузьмин Ю.О., Жуков В.С. Современная геодинамика и вариации физических свойств горных пород. М.: МГГУ, 2004. 280 с.].

Kuz'min Yu.O., 2012. Deformation autowaves in fault zones. Izvestiya, Physics of the Solid Earth 48 (1), 1-16. http://dx.doi. org/10.1134/S1069351312010089.

Levin V.E., Magus'kin M.A., Bakhtiarov V.F., Pavlov V.M., Titkov N.N., 2006. Multisystem geodetic monitoring of recent crustal movements in Kamchatka and Komandor Islands. Vulkanologiya i Seismologiya (3), 54-67 (in Russian) [Лeвин B.E., Магуськин М.А., Бахтиаров В.Ф., Павлов В.М., Титков Н.Н. Мультисистемный геодезический мониторинг современных движений земной коры на Камчатке и Командорских островах // Вулканология и сейсмология. 2006. № 3. С. 54-67].

Magnitsky V.A., Kalashnikova I.V., 1978. About the inherited character of recent crustal movements. Izvestiya AN SSSR, Fizika Zemli (10), 13-20 (in Russian) [Магницкий В.А., Калашникова И.В. Об унаследованном характере современных движений земной коры // Физика Земли. 1978. № 10. С.13-20].

Magnitsky V.A., Kalashnikova I.V., Karakin A.V., 1974. On the horizontal and vertical movements of the lithosphere. Fizika Zemli (9), 3-10 (in Russian) [Магницкий В.А., Калашникова И.В., Каракин А.В. О горизонтальных и вертикальных перемещениях литосферы // Физика Земли. 1974. № 9. С. 3-10].

Malamud A.S., Nikolaevsky V.N., 1989. Earthquake Cycles and Tectonic Waves. Donish, Dushanbe, 144 p. (in Russian) [Maламуд А.С., Николаевский В.Н. Циклы землетрясений и тектонические волны. Душанбе: Дониш, 1989. 144 с.].

Mitlin V.S., Nikolaevsky V.N., 1990. Nonlinear diffusion of tectonic stresses. Doklady AN SSSR 315 (5), $1093-1096$ (in Russian) [Митлин B.C., Николаевский В.Н. Нелинейная диффузия тектонических напряжений // Доклады АН СССР. 1990. T. 315. № 5. С. 1093-1096].

Mukhamediev Sh.A., Grachev A.F., Yunga S.L., 2008. Nonstationary dynamic control of seismic activity of platform regions by mid-ocean ridges. Izvestiya, Physics of the Solid Earth 44 (1), 9-17. http://dx.doi.org/10.1134/S1069351308010023.

Nikolaevsky V.N., 1983. Mechanics of Geomaterials and Earthquakes. In: Results and Science of Technics in VINITI. Mechanics of Solid Deformed Body, V. 15, p. 140-230 (in Russian) [Николаевский В.Н. Механика геоматериалов и землетрясения // Итоги науки и техники ВИНИТИ. Механика твердого деформированного тела. 1983. Т. 15. C. 140-230].

Nikolaevsky V.N., 1995. Mathematical simulation of isolated deformation and seismic waves. Doklady AN 341 (3), $403-405$ (in Russian) [Николаевский В.Н. Математическое моделирование уединенных деформационных и сейсмических волн // Доклады АН. 1995. Т. 341. № 3. С. 403-405].

Nikolaevsky V.N., 2008. Elasto-viscous models of tectonic and seismic wave sin the lithosphere. Fizika Zemli 44 (6), $92-96$ (in Russian) [Николаевский В.Н. Упруго-вязкие модели тектонических и сейсмических волн в литосфере // Физика Земли. 2008. Т. 44. № 6. С. 92-96].

Rabotnov Yu.N., 1977. Elements of Inherited Mechanics of Solid Bodies. Nauka, Moscow, 384 p. (in Russian) [Paбomнов Ю.Н. Элементы наследственной механики твердых тел. М.: Наука, 1977. 384 с.].

Seminsky K.Zh., 2003. The Internal Structure of Continental Rift Zones. Tectonophysical Aspect. Geo Branch, Publishing House of SB RAS, Novosibirsk, 243 p. (in Russian) [Семинский К.Ж. Внутренняя структура континентальных разломных зон. Тектонофизический аспект. Новосибирск: Издательство СО РАН, филиал «Гео», 2003.243 с.].

Sherman S.I., 1977. Physical Regularities of Crustal Fracturing. Nauka, Novosibirsk, 102 p. (in Russian) [Шерман С.И. Физические закономерности развития разломов земной коры. Новосибирск: Наука, 1977. 102 с.].

Sherman S.I., 2012. Destruction of the lithosphere: fault-block divisibility and its tectonophysical regularities. Geodynamics \& Tectonophysics 3 (4), 315-344. http://dx.doi.org/10.5800/GT-2012-3-4-0077.

Sherman S.I., 2013. Deformation waves as a trigger mechanism of seismic activity in seismic zones of the continental lithosphere. Geodynamics \& Tectonophysics 4 (2), 83-117. http://dx.doi.org/10.5800/GT-2013-4-2-0093.

Sherman S.I., Bornyakov S.A., Buddo V.Yu., 1983. Areas of Dynamic Influence of Faults (Modelling Results). Nauka, Siberian Branch of the Academy of Sciences of the USSR, Novosibirsk, 110 p. (in Russian) [Шерман С.И., Борняков С.А., Буддо В.Ю. Области динамического влияния разломов (результаты моделирования). Новосибирск: Наука, СО АН CCCP, 1983. 110 с.].

Sherman S.I., Gorbunova E.A., 2008. The wave nature of fault activation in Central Asia on the basis of seismic monitoring. Fizicheskaya Mezomekhanika 11 (1), 115-122 (in Russian) [Шерман С.И., Горбунова Е.А. Волновая природа активизации разломов Центральной Азии на базе сейсмического мониторинга // Физическая мезомеханика. 2008. Т. 11. № 1. С. 115-122].

Sherman S.I., Tsurkan E.A., 2006. Slow deformation waves as a source and triggering mechanism of recent activation of faults in Central Asia. In: Geodynamic evolution of the lithosphere of the Central Asian mobile belt (from Continent to 
Ocean). Proceedings of the scientific meeting. IEC SB RAS, Irkutsk, p. 219-223 (in Russian) [Шерман С.И., Цуркан E.A. Медленные деформационные волны как источник и триггерный механизм современной активизации разломов Центральной Азии // Геодинамическая эволюция литосферы Центрально-Азиатского подвижного пояса (от континента к океану): Материалы научного совещания. Иркутск: ИЗК СО РАН, 2006. С. 219-223].

Shishkin I.F., 2010. Theoretical Metrology. Part 1. General Theory of Measurements. Textbook for Universities. Edition 4, rev. and add. Piter, St. Petersburg, 192 p. (in Russian) [Шишкин И.Ф. Теоретическая метрология. Часть 1. Общая теория измерений. Учебник для вузов. 4-е изд., перераб. и доп. СПб.: Питер, 2010. 192 с.].

Sidorov V.A., Kuzmin Yu.O., 1989. Recent Crustal Movements in Sedimentary Basins. Nauka, Moscow, 189 p. (in Russian) [Сидоров В.А., Кузьмин Ю.О. Современные движения земной коры осадочных бассейнов. М.: Наука, 1989. 189 c.].

Titkov N.N., Bakhtiarov V.F., Lander A.V., Poletaev V.A., 2010. Estimates of deformations and displacement according to observations of Kamchatka GPS network. In: Problems of recent geodynamics and seismicity of the Far East and Eastern Siberia: Proceedings of the Regional Scientific Symposium. Institute of Tectonics and Geophysics FEB RAS, Khabarovsk, p. 104-107 (in Russian) [Титков Н.Н., Бахтиаров В.Ф., Ландер А.В., Полетаев В.А. Оценки деформаций и перемещений по данным наблюдений Камчатской GPS сети // Проблемы сейсмичности и современной геодинамики Дальнего Востока и Восточной Сибири: Материалы регионального научного симпозиума. Хабаровск: ИТиГ ДВО РАН, 2010. С. 104-107].

Trubitsyn V.P., 2012. Rheology of the mantle and tectonics of the oceanic lithospheric plates. Izvestiya, Physics of the Solid Earth 48 (6), 467-485. http://dx.doi.org/10.1134/S1069351312060079.

Turcotte D., Schubert G., 1979. Geodynamics. Nauka, Moscow, 560 p. (in Russian) [Теркот Д., Шуберт Дж. Геодинамика. М.: Наука, 1979. 560 с.].

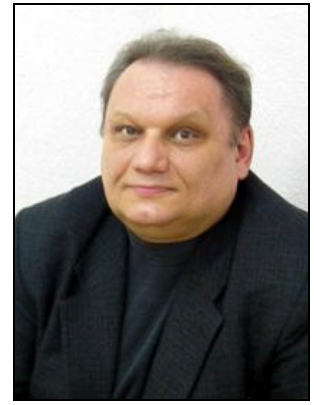

Кузьмин Юрий Олегович, докт. физ.-мат. наук, профессор, зав. лабораторией современной геодинамики Институт физики Земли им. О.Ю. Шмидта РАН

123995, ГСП-5, Москва Д-242, ул. Большая Грузинская, 10, Россия

Тел.: (495)2549135; e-mail: kuzpnex@gmail.com

Kuzmin, Yuri O., Doctor of Physics and Mathematics, Professor, Head of Laboratory of Recent Geodynamics The Schmidt Institute of Physics of the Earth RAS

10 Bol'shaya Gruzinskaya street, Moscow D-242 123995,GSP-5, Russia

Tel.: (495)2549135; e-mail: kuzpnex@gmail.com 